\title{
A Review of Three-Dimensional Tin Halide Perovskites as Solar Cell Materials
}

\author{
M. Dawson ${ }^{a, b}$, C. Ribeiro ${ }^{b *}$ (i), M. R. Morelli ${ }^{a}$ \\ ${ }^{a}$ Universidade Federal de São Carlos (UFSCar), Programa de Pós-Graduação em Ciência e \\ Engenharia de Materiais, Rod. Washington Luis, km 235, 13565-905, São Carlos, SP, Brasil. \\ ${ }^{b}$ Embrapa Instrumentação, Rua XV de Novembro, 1452, Centro, 13560-970, São Carlos, SP, Brasil.
}

Received: September 02, 2021; Revised: December 01, 2021; Accepted: January 13, 2022

Thin film solar cell materials such as 3D metal halide perovskites are cheaper alternatives to silicon. Presently, the conversion efficiency of 3D lead halide perovskites is $25.5 \%$ (2021), which represents an increase of more than $550 \%$ since their discovery in 2009 (3.8\%). Despite this remarkable progress, concerns about the toxicity of lead have sparked the quest for possible substitutes, in particular, 3D tin halide perovskites. This review covers the general properties of tin halide perovskites, synthesis and stability. It also identifies possible gaps and application beyond solar cells.

Keywords: Organic-inorganic perovskite, tin halide perovskite, lead-free perovskite, solar cell material and ceramics.

\section{Introduction}

The downsides of silicon solar cell technology such as the reduction of silicon dioxide, purification of silicon and wafer production, have motivated research on solutionprocessable solar cell technologies ${ }^{1,2}$. The advantages of solution processing include low temperature synthesis, mass production and flexibility in reagent choice. Emerging solution-processable solar cells include dye-sensitized solar cells, quantum dot solar cells, organic solar cells and perovskite solar cells ${ }^{3}$.

Among the absorbers utilized in these solar cells, threedimensional metal halide perovskites have attracted research attention due to their satisfactory carrier mobility, high absorption coefficients and direct bandgaps ${ }^{4,5}$. Examples of common 3D organic-inorganic metal halide perovskites include $\mathrm{CH}_{3} \mathrm{NH}_{3} \mathrm{PbI}_{3}$ (Methylammonium (MA) lead iodide), $\mathrm{CH}_{5} \mathrm{~N}_{2} \mathrm{PbI}_{3}$ (Formamidinium (FA) lead iodide), $\mathrm{CH}_{3} \mathrm{NH}_{3} \mathrm{SnI}_{3}$ (Methylammonium (MA) tin iodide) and $\mathrm{CH}_{5} \mathrm{~N}_{2} \mathrm{SnI}_{3}$ (Formamidinium (FA) tin iodide). For all-inorganic $3 \mathrm{D}$ tin perovskites, $\mathrm{CsSnI}_{3}$ and $\mathrm{RbSnI}_{3}$ can be cited.

In 2009, Kojima et al. ${ }^{6}$ improved the conversion efficiency of dye-sensitized solar cells (3.8\%) using lead perovskites, $\mathrm{MAPbBr}_{3}$ and $\mathrm{MAPbI}_{3}$ instead of conventional photoactive dyes. The electrolytes utilized were $\mathrm{LiBr}$ and $\mathrm{Br}_{2}$, and $\mathrm{LiI}$ and $\mathrm{I}_{2}$ in acetonitrile and methoxyacetonitrile, respectively. The major problems of this set up are the organic solvents, which can easily bleach the perovskites, and the reaction of the electrolytes with the perovskites. In a similar attempt, Im et al. ${ }^{7}$ utilized $\mathrm{MAPbI}_{3}$ quantum dots (2-3 nm) which significantly improved the conversion efficiency to $6.5 \%$. However, perovskite dissolution related to electrolyte solution was reported. To solve this problem, Kim et al. ${ }^{8}$ employed a solid state hole transport material, spiro-OMeTAD $\left(\mathrm{C}_{81} \mathrm{H}_{68} \mathrm{~N}_{4} \mathrm{O}_{8}\right)$, as a replacement for liquid

*e-mail: caue.ribeiro@embrapa.br electrolytes, rendering an efficiency of $9.7 \%$. This change in design revolutionized perovskite solar cells.

In a relatively short span of time (12 years), lead perovskite solar cells have attained efficiencies close to well-established technologies such as silicon and have surpassed dye-sensitized solar cells. The theoretical power conversion efficiency (PCE) of lead perovskites is about $31 \% 0^{9,10}$ and the highest efficiency attained so far is $25.2 \%$ (2021) $)^{11}$ compared to $26.1 \%$ for single crystal silicon cells ${ }^{12}$.

The expressive evolution of lead perovskites is accompanied by environmental and health concerns. Questions regarding the release of lead into the environment during the lifetime of the solar cell or after its disposal are open. Some researchers argue that encapsulation and safe recycling can mitigate the risk of contamination ${ }^{13}$. While these methods can be feasible, regulations and/or standards on the management of lead in perovskite solar cells have not yet been established.

In this light, possible substitutes of lead such as Sn, $\mathrm{Ge}, \mathrm{Bi}, \mathrm{Sb}$ have been proposed ${ }^{14-17}$. So far, $\mathrm{Sn}$ is considered a better alternative due to its satisfactory cation size and chemical similarity with $\mathrm{Pb}$. Furthermore, the successful application of tin perovskites in all-solid-state solar cell has been reported since 2014 with initial efficiencies of $5.73 \%$ and $6.40 \%{ }^{18,19}$. Thus, they can be considered the most studied and promising lead-free perovskite. In fact, Figure 1 shows that research interest in tin perovskites has increased continuously from 2014 to 2019. This growth peaked in 2019 and 2020, which further decreased in 2021, possibly due to the Covid-19 pandemic. However, the number of articles projected for early 2022, indicates a resurgence.

Currently, the highest reported efficiency of tin perovskite solar cells is $14.63 \%{ }^{20}$ compared to $25.2 \%{ }^{11}$ of lead perovskites. This gap in efficiency is mainly rooted in the easy oxidation of $\mathrm{Sn}(\mathrm{II})$ to $\mathrm{Sn}$ (IV), low open circuit voltage, poor film quality and irreproducibility. Many attempts have been made to increase the conversion efficiency of tin 


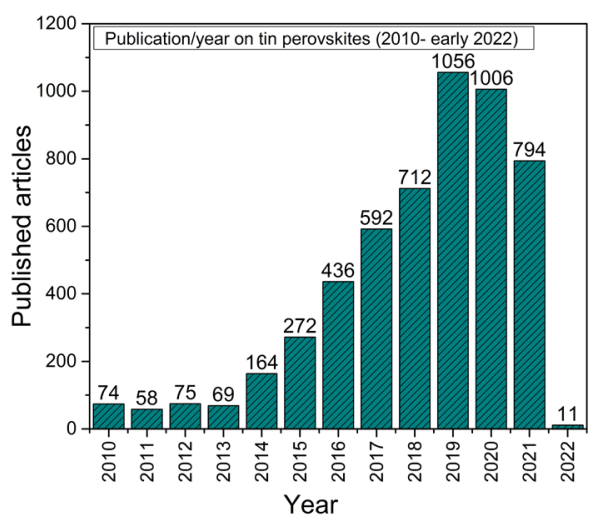

Figure 1. Number of publications per year on tin perovskite extracted from the following keywords $\left(\mathrm{CH}_{3} \mathrm{NH}_{3} \mathrm{SnI}_{3} *\right.$ or tin halide perovskite* or tin perovskite* or organic-inorganic tin* or $\mathrm{CsSnI}_{3}^{*}$ ) in the web of science database.

perovskites through solvent engineering, bandgap tuning, composition engineering, synthesis routes, doping, device modification among others.

Figure 2 shows the evolution of organic-inorganic tin perovskite efficiencies from 2014 to date. An increase of more than $120 \%$ has been achieved, a promising development for an emergent solar absorber.

The trend of Cs-based/all-inorganic tin perovskites is presented in Figure 3. A remarkable increase of more than $400 \%$ can be observed, highlighting research efforts in this area. In general, the statistics of the inorganic and organicinorganic perovskites reinforce the consistent pursuit of going lead-free.

The stability of tin perovskites against moisture, oxygen and UV radiation is unsatisfactory. Given the operating conditions of solar cells, tackling instability is very relevant to advancing the field of tin perovskites. The oxidation of these materials can be controlled but not completely eliminated because of the thermodynamics involved. To a certain degree, some levels of $\mathrm{Sn}(\mathrm{IV})$ are always present, suggesting partial stability. Unfortunately, there is no standard protocol for testing the stability of perovskites, hence comparison of results is challenging.

This review presents existing evidence and/or extent of research about various concepts and challenges of tin halide perovskites aimed at identifying research gaps and future projections.

\section{Structure}

A perovskite is $\mathrm{CaTiO}_{3}$ or any material that shares similar stoichiometry and crystal structure. Organic-inorganic metal halide structures as well as inorganic metal halides are classified as perovskites because they have the $\mathrm{ABX}_{3}$ stoichiometry. Due to cation size and charge impositions, the A position can accommodate monovalent organic or inorganic cations $\left(\mathrm{Cs}^{+}, \mathrm{CH}_{3} \mathrm{NH}_{3}^{+}, \mathrm{CH}_{5} \mathrm{~N}_{2}^{+}\right)$. The B position can be occupied by divalent metal cations such as $\mathrm{Sn}^{2+}, \mathrm{Pb}^{2+}$ and $\mathrm{Ge}^{2+}$. Lastly, the $\mathrm{X}$ position can be occupied by halides $\left(\mathrm{I}^{-}, \mathrm{Br}, \mathrm{Cl}^{-}\right)$, and pseudohalides or complex anions $\left((\mathrm{HCOO})^{-},(\mathrm{CN})^{-},(\mathrm{SCN})^{-}\right.$

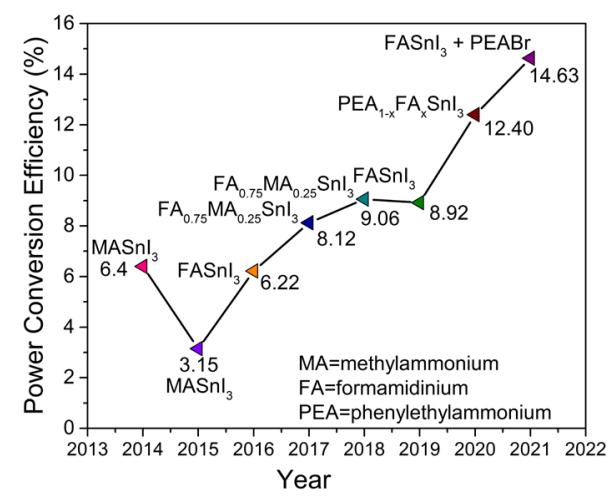

Figure 2. The evolution of the conversion efficiency of pure organicinorganic tin perovskites from 2014 to 2021.

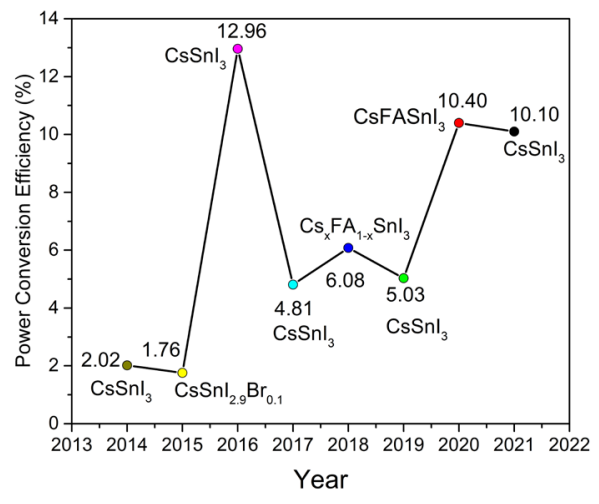

Figure 3. The evolution of the conversion efficiency of Cs-based tin perovskites from 2014 to 2021.

and $\left.\left(\mathrm{BH}_{4}\right)^{-}\right)$. In order to maintain neutrality of the structure, the sum of the oxidation states of the $\mathrm{A}$ and $\mathrm{B}$ cations must be +3 , thus requiring a 3 - charge, which is provided by three monovalent anions. Stoichiometry outside this restriction forms other dimensions of perovskites or non-perovskite structures. The chemical and structural versatility of perovskites open up many opportunities for research and applications.

Kieslich et al. ${ }^{21}$ reported 2352 possible options of perovskites based on the permutation of 13 variant protonated amines, 8 anions and 21 divalent metal ions. When restrained with geometry (tolerance factor), there are 140 recognized compounds and 600 unknown compounds ${ }^{21}$. Organic-inorganic metal perovskites are a small fraction of these known compounds. For tin perovskites alone, one can have an enormous number of perovskites consisting of tin combined with A site cations (13 protonated amines and possible inorganic cations besides $\mathrm{Cs}$ and $\mathrm{Rb}$ ) and 8 anions. The number of possibilities further increases when doping is considered.

Simulations of these permutations and the exploration of underexplored or hypothetical perovskites can serve 
as a basis for developing feasible synthesis methods and alternative applications. Figure 4 presents some A, B and X candidates for metal halide perovskite formation.

An ideal perovskite structure is cubic but can assume lower symmetries, such as tetragonal and orthorhombic forms ${ }^{22}$. Figure 5 presents the cubic, tetragonal and orthorhombic structures of tin halide perovskite.

In the cubic structure, the A cation $\left(\mathrm{CH}_{3} \mathrm{NH}_{3}^{+}, \mathrm{Cs}^{+}, \mathrm{CH}_{5} \mathrm{~N}_{2}{ }^{+}\right.$ and so forth) is located in a cuboctahedral hole and connects with the inorganic cage of the perovskite through hydrogen and dipole interactions $\mathrm{s}^{23-25}$. The strength of these bonds has strong implications on phase stability and transformations. The cube's corners are occupied by the $\mathrm{B}$ metal cations $\left(\mathrm{Pb}^{2+}\right.$, $\mathrm{Sn}^{2+}, \mathrm{Ge}^{2+}$ among others) coordinated with six X ions ( $\mathrm{I}^{-}$, $\mathrm{Br}^{-}, \mathrm{Cl}^{-}$et cetera) forming a $\mathrm{BX}_{6}$ octahedron. The octahedra share corners to form a $3 \mathrm{D}$ dimensional network.

Just like any ceramic, the size and coordination number of constituent ions determine structural arrangement. A high degree of distortion or tilting of the octahedra disrupts the perovskite structure and for this reason, the selection of cations based on size and charge is indispensable. For perovskites, the Goldschmidt tolerance factor $(t)$ and octahedral factor $(\mu)$ predict adequate cation and anion candidates for chemical and structural stability ${ }^{26}$.

Equations 1 and 2 present the Goldschmidt tolerance factor $(t)^{27}$ and octahedral factor $(\mu)^{26}$, respectively. It can be seen that both equations depend heavily on ionic radius:

$$
\mathrm{t}=\frac{\mathrm{r}_{\mathrm{A}}+\mathrm{r}_{\mathrm{X}}}{\sqrt{2}\left(\mathrm{r}_{\mathrm{B}}+\mathrm{r}_{\mathrm{X}}\right)}
$$

where $t, r_{A}, r_{B}$ and $r_{X}$ are the tolerance factor, and radius of the $\mathrm{A}$ cation, $\mathrm{B}$ cation and $\mathrm{X}$ halide, respectively,

$$
\mu=\frac{\mathrm{r}_{\mathrm{B}}}{\mathrm{r}_{\mathrm{X}}}
$$

where $\mu, r_{B}$ and $r_{X}$ is the octahedral factor and radius of the $\mathrm{B}$ and $\mathrm{X}$ ions, respectively.

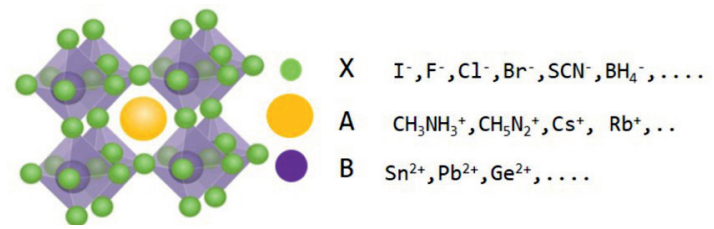

Figure 4. Possible cations and anions that form the perovskite composition.

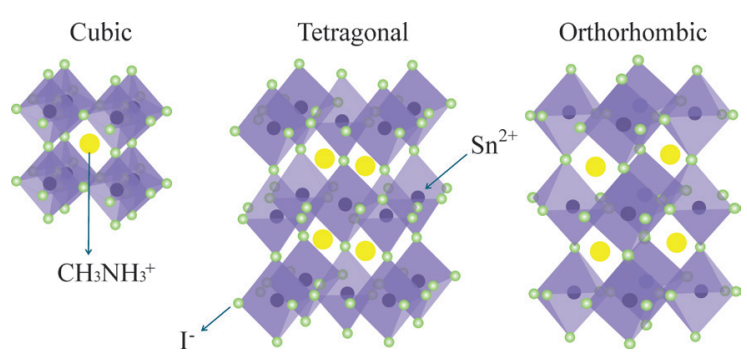

Figure 5. Cubic, tetragonal and orthorhombic structures of 3D tin halide perovskite indicating the positions of the A organic cation (methylammonium $\mathrm{CH}_{3} \mathrm{NH}_{3}^{+}$), B metal $\left(\mathrm{Sn}^{2+}\right)$ and $\mathrm{X}$ halide $\left(\mathrm{I}^{-}\right)$.
Stability depends on the octahedra framework, which is accounted for by the octahedral factor $(\mu)$. The parameter determines the $\mathrm{B}$ metal cation that can fit into the cavity formed by the $\mathrm{X}$ anions without disrupting the perovskite structure. The ratio of $\mathrm{B}$ cation to $\mathrm{X}$ anion must be greater than or equal to 0.414 to ensure the stability of the octahedra units.

Most 3D metal halide perovskites fall within the Goldschmidt's tolerance factor range of $0.8 \leq \mathrm{t} \leq 1^{28}$. A tolerance factor of 1 represents an ideal cubic perovskite structure while values between 0.8 and 1 represent deviations such as tetragonal and orthorhombic structures. Values outside the stability range are typical of non-perovskites and perovskites with 2D or 1D geometries ${ }^{29}$. Considering the ionic radius of methylammonium cation $=1.80 \AA$, iodide ion $=2.2 \AA$ and $\mathrm{Sn}(\mathrm{II})$ cation $=1.18 \AA^{30}$, the tolerance factor of tin perovskites is approximately 0.84 .

Tin perovskites present polymorphs according to temperature, rotation and/or distortion of the $\mathrm{BX}_{6}$ octahedra, and translation of cations $(\mathrm{B} \text { and } \mathrm{A})^{31}$. The three conventional polymorphs of tin perovskite are cubic with a $P m \overline{3} m$ space group ${ }^{32}$, tetragonal phase with a $P 4 \mathrm{~mm}^{33,34}$ or $I 4 / \mathrm{mcm}^{5,32,35}$ space group, and orthorhombic with a Pnma space group ${ }^{32}$.

Based on theoretical calculations and experiments, an additional hexagonal phase with a $P 6_{3} m c$ space group has been presented ${ }^{36-38}$. This phase presents a hybrid of facesharing and corner-sharing octahedra. Face-sharing alters the interaction between the octahedra and A cations, which distorts the perovskite structure with consequent changes in optoelectronic properties. Figure 6 shows the main polymorphs of tin halide perovskites with decreasing temperature and rotation of neighboring octahedra along the $\mathrm{c}$ axis.

Above $295 \mathrm{~K}\left(\sim 22^{\circ} \mathrm{C}\right)$, the cubic phase is stabilized ${ }^{35}$ and is characterized by the $P m \overline{3} m$ space group. The $\mathrm{SnI}_{6}$ octahedra do not undergo any rotation but the A cation freely rotates in the cubic cage (Figure 6).

With decrease in temperature, specifically at $275 \mathrm{~K}$ $\left(\sim 2{ }^{\circ} \mathrm{C}\right)$, the cubic phase transforms to the tetragonal phase with a $I 4 / \mathrm{mcm}$ space group ${ }^{5,32,35}$. Some authors have reported the $P 4 \mathrm{~mm}$ space group ${ }^{33,34}$. The $\mathrm{SnI}_{6}$ octahedra in the adjacent planes tilt around the $\mathrm{c}$ axis in opposite directions, favoring the tetragonal phase (Figure 6) ${ }^{31,35}$. In this configuration, the motion of the A cation is partially limited.

The temperature range in which the hexagonal phase is stable has not yet been established. However, it is believed to fall between the cubic and tetragonal phase stability range ${ }^{36}$.

At lower temperatures, in the range of $108-114 \mathrm{~K}$ $\left(-165^{\circ} \mathrm{C}\right.$ to $\left.-159^{\circ} \mathrm{C}\right)$, the orthorhombic phase is stable ${ }^{35,39}$. The $\mathrm{SnI}_{6}$ octahedra in the adjacent planes tilt around the $\mathrm{c}$ axis in a similar direction (Figure 6). In this configuration, the A cation has no rotational freedom. Likewise, holes become localized, which increases the lifetime of charge carriers $^{39}$. First principal investigations point to ultra-low conductivity in this phase ${ }^{40}$. The phase can find application in low temperature electronics due to its high conductivity and low recombination.

The lattice parameters of $\mathrm{CH}_{3} \mathrm{NH}_{3} \mathrm{SnI}_{3}$ are shown in Table 1.

All-inorganic $\mathrm{CsSnI}_{3}$ perovskites have three major polymorphs identified as black: cubic phase with a $P m \overline{3} m$ 

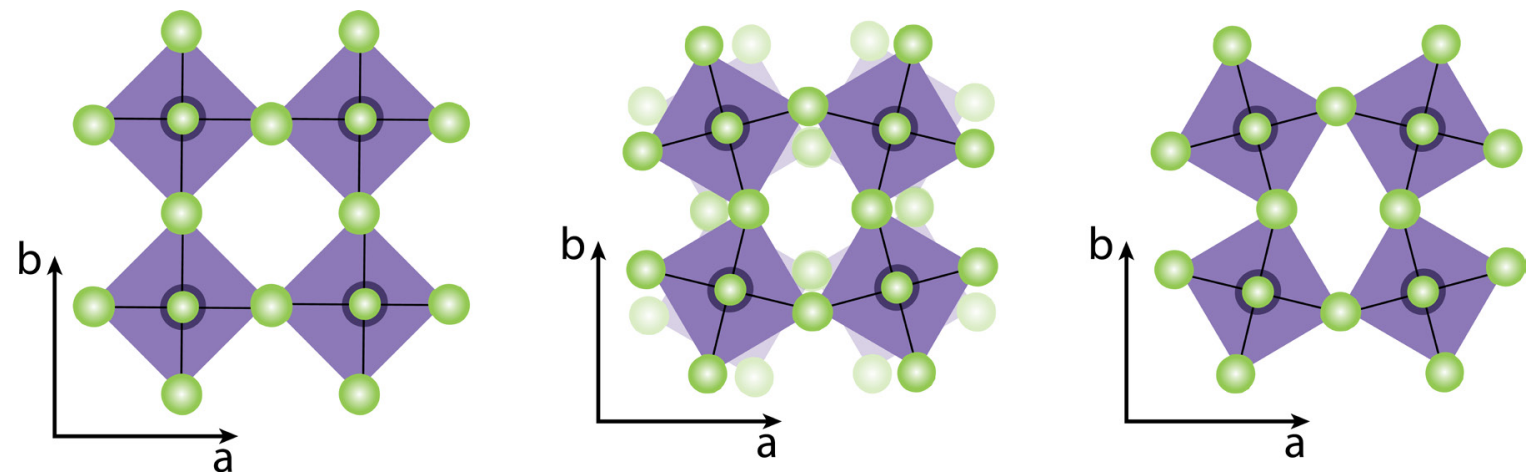

Figure 6. Rotation of adjacent octahedral layers along the $\mathrm{c}$ axis according to crystal phase. From left to right: cubic, tetragonal and orthorhombic phases.

Table 1. Lattice parameters of cubic, tetragonal and orthorhombic $\mathrm{CH}_{3} \mathrm{NH}_{3} \mathrm{SnI}_{3}$.

\begin{tabular}{cccc}
\hline Structure & $\begin{array}{c}\text { Parameter } \\
(\mathrm{a}, \AA)\end{array}$ & $\begin{array}{c}\text { Parameter } \\
(\mathrm{b}, \AA)\end{array}$ & $\begin{array}{c}\text { Parameter } \\
(\mathrm{c}, \AA)\end{array}$ \\
\hline Cubic & $6.24^{35}, 6.36^{36}$ & $6.24,6.36$ & $6.24,6.36$ \\
\hline Tetragonal & $8.73^{35}, 8.83^{36}$ & $8.73,8.83$ & $12.50,12.93$ \\
\hline Orthorhombic & $8.48^{36}$ & 9.15 & 12.67 \\
\hline Hexagonal & $8.86^{36}$ & 8.86 & 7.91 \\
\hline
\end{tabular}

space group, tetragonal phase with a $P 4 / \mathrm{mbm}$ space group and orthorhombic phase with a Pnma space group ${ }^{41}$.

The cubic phase is a high temperature stable phase at $500 \mathrm{~K}$ $\left(226.85^{\circ} \mathrm{C}\right)$, which transforms to the tetragonal phase upon cooling to $380 \mathrm{~K}\left(106.85^{\circ} \mathrm{C}\right)$. Further cooling beyond $300 \mathrm{~K}$ $\left(26.85^{\circ} \mathrm{C}\right)$, stabilizes the orthorhombic phase ${ }^{41}$. There is an additional yellow orthorhombic phase at room temperature.

Similar to organic-inorganic perovskites, the transformation from cubic to tetragonal phase involves titling of the Sn octahedra in the ab plane. For the orthorhombic phase, this tilting takes place in the axial and equatorial directions. Compared to organic-inorganic perovskites, the transformation temperatures of $\mathrm{CsSnI}_{3}$ are significantly higher, which bring attention to the limitation of organic A cations in terms of thermal stability and moisture absorption.

The black orthorhombic phase has a high hole conductivity associated with self-doping. For this reason, it has been successfully utilized in solid state solar cells as a hole transport material ${ }^{42,43}$. As a solar absorber, the black phase has a suitable bandgap $(1.3 \mathrm{eV})$ and high photoluminescence but its high hole carrier density is a problem and must be controlled ${ }^{41}$. The tin cation in $\mathrm{CsSnI}_{3}$ is no different, it oxidizes to $\mathrm{Sn}^{4+}$ upon exposure to oxygen, moisture or polar solvents at room temperature. These conditions promote the transformation of the black orthorhombic phase to the yellow phase and lastly to $\mathrm{Cs}_{2} \mathrm{SnI}_{6}$. The octahedral chains are reconstructed into edge-sharing one dimensional double chains.

Both the yellow and $\mathrm{Cs}_{2} \mathrm{SnI}_{6}$ phases are undesirable because of reduction in optical and electrical properties. In compensation, $\mathrm{Cs}_{2} \mathrm{SnI}_{6}$ is stable because of its $\mathrm{Sn}^{4+}$ charge. A study found that $\mathrm{Cs}_{2} \mathrm{SnI}_{6}$ can be utilized in solar cells due to its bandgap $(1.48 \mathrm{eV})$ and high optical absorption coefficient $\left(10^{5} \mathrm{~cm}^{-1}\right)^{44}$. An initial photovoltaic application resulted in
$1 \%$ conversion efficiency and $0.51 \mathrm{~V}$ open circuit voltage, which can be improved ${ }^{44}$.

In the case of organic-inorganic tin perovskites, the organic part of the perovskite and some tin cations can be lost, thus the oxidized perovskite does not serve a useful purpose. Perhaps the synthesis of one-dimensional double compounds that mimic oxidized perovskites can present surprising properties since oxidation is removed from the picture. Heterostructures can be formed between stable one dimensional "oxidized" compounds and 3D compounds to improve carrier mobility and band alignment for specific processes. For tin perovskites in general, the main challenge is to maintain them in a desired phase during the operation of a solar cell.

The lattice parameters of $\mathrm{CsSnI}_{3}$ are shown in Table 2 .

\section{Optical Properties}

$\mathrm{MASnI}_{3}$ is widely known to be a direct bandgap semiconductor, where the valence band maximum and conduction band minimum match in reciprocal space ${ }^{45}$. Typical bandgap values of $\mathrm{MASnI}_{3}$ and $\mathrm{CsSnI}_{3}$ are in the range of 1.1 to $1.4 \mathrm{eV}^{18,29,46-49}$, enabling absorption in the visible and infra-red regions. On the contrary, simulations show that $\mathrm{MASnI}_{3}$ in the hexagonal phase has an indirect bandgap, that is, the conduction band minimum and the valence band maximum are not aligned in reciprocal space. The predicted bandgap of $2.3 \mathrm{eV}$ is feasible for the absorption of higher energy photons, for example, $\mathrm{UV}^{36}$.

The valence band of MASnI 3 is composed of $\mathrm{Sn}(5 \mathrm{~s})$ and I (5p) anti-bonding orbitals, whereas the conduction band is formed of $\mathrm{Sn}(5 \mathrm{p})$ states $^{35}$. In this regard, the $\mathrm{SnI}_{6}$ octahedron (B and $\mathrm{X}$ ions) defines the optical bandgap either through the variation of Sn-I bond length and/or angle ${ }^{50}$. The A site cations can indirectly contribute to bandgap tuning through octahedral tilting ${ }^{51}$ and lattice distortion ${ }^{50}$. Contrary to popular trend, the $\mathrm{p}$ states of $\mathrm{N}$ and $\mathrm{C}$ atoms in organic cations can contribute to the valence band maximum ${ }^{52,53}$.

A change in A site cation whereby a larger cation takes the place of methylammonium $(1.8 \AA)^{54}$ often results in an increase of bandgap. A majority of formamidinium-based tin perovskites have a bandgap of $1.4 \mathrm{eV}^{47,55}$ due to the fairly large size of formamidinium $(1.9-2.2 \AA)^{54}$. The substitution of methylammonium for dimethylammonium $(x=0,0.10$, 
Table 2. Lattice parameters of cubic, tetragonal and orthorhombic $\mathrm{CsSnI}_{3}$.

\begin{tabular}{cccc}
\hline Structure & Parameter $(\mathrm{a}, \AA)$ & Parameter $(\mathrm{b}, \AA)$ & Parameter $(\mathrm{c}, \AA)$ \\
\hline Cubic & $6.21^{41}$ & 6.21 & 6.21 \\
\hline Tetragonal & $8.72^{41}$ & 8.72 & 6.19 \\
\hline Orthorhombic & $8.69^{41}$ & 12.38 & 8.64 \\
\hline Orthorhombic (yellow) & $10.35^{41}$ & 4.76 & 17.68 \\
\hline
\end{tabular}

$0.15,0.30,0.40$ and 1) in $\mathrm{MASnBr}_{3}$ caused a significant expansion of the lattice to the extent that the pure cubic structure transformed into orthorhombic with $100 \%$ dimethylammonium ${ }^{56}$. As expected, the bandgap increased from $2.05 \mathrm{eV}(\mathrm{x}=0)$ to $2.9 \mathrm{eV}$ for $(\mathrm{x}=100)$. A similar behavior was observed in mixed cation perovskites, $\mathrm{FA}_{\mathrm{x}} \mathrm{MA}_{1-\mathrm{x}} \mathrm{SnI}_{3}$, where the bandgap of $\mathrm{MASnI}_{3}$ increased from $1.26 \mathrm{eV}$ to $1.36 \mathrm{eV}(100 \% \mathrm{FA})$ with increasing formamidinium content ${ }^{57}$.

A first-principle study showed the prospects of aziridinium cation $(2.27 \AA)^{58}$ for 3D tin perovskites ${ }^{59}$. The predicted bandgap of $1.06 \mathrm{eV}$ was surprisingly lower than $\mathrm{MASnI}_{3}$, but no further explanation was given.

In relation to ethylenediammonium, doping of $\mathrm{MASnI}_{3}$ perovskites with $15 \%$ increased the bandgap from $1.25 \mathrm{eV}^{3}$ to $1.40 \mathrm{eV}^{60}$. For FASnI ${ }_{3}$, the incorporation of $25 \%$ ethylenediammonium caused the bandgap to increase from $1.4 \mathrm{eV}$ to $1.9 \mathrm{eV}^{61}$. The effect of ethylenediammonium on the perovskite structure (also known as hollow perovskite) and consequently, optical properties is fascinating. In perovskites where ethylenediammonium is combined with either methylammonium or formamidinium, Schottky defects are formed in order for the perovskite structure to simultaneously accommodate ethylenediammonium and maintain neutrality ${ }^{60,61}$. These defects are empty regions (hollow) within the perovskite structure induced by the removal of neutral units of $\mathrm{SnI}_{2}{ }^{61}$. Thus, the widths of the valence and conduction bands are narrowed, corresponding to an increase in bandgap with increase in missing $\mathrm{SnI}_{2}$ units ${ }^{60,61}$.

Among $\mathrm{FA}_{1-\mathrm{x}} \mathrm{MA}_{\mathrm{x}} \mathrm{SnBr}_{3}(\mathrm{X}=0,0.05,0.2,0.3,0.6$, 0.8 and 1) perovskites, it was found that the bandgap of $\mathrm{FASnBr}_{3}$ decreased from $2.4 \mathrm{eV}$ to $1.9 \mathrm{eV}$ with increase in methylammonium $(\mathrm{x}=0.82)$ but increased slightly for pure $\operatorname{MASnBr}_{3}(2 \mathrm{eV})^{52}$. The variation in bandgap was attributed to the reduction in lattice distortion and partial contribution of the $2 \mathrm{p}$ states ( $\mathrm{N}$ and $\mathrm{C}$ atoms) of formamidinium to the valence band maximum and density of states, compared to the $2 \mathrm{p}$ states (only $\mathrm{N}$ ) of methylammonium ${ }^{52}$.

Doping of the A cation site of $\mathrm{FASnI}_{3}$ with a smaller cation, such as $\mathrm{Cs}^{+}$, causes lattice contraction, hence increases and reduces the valence band energy and bandgap, respectively ${ }^{62}$.

The 3D structure is no longer stable when an A cation is too large to fit in the cuboctahedral hole. In principle, lowdimensional (2D) perovskites are favored with consequent changes in bandgap. Cations such as phenylethylammonium, butylammonium, hexylammonium, and octylammonium can form 2D layered tin iodide perovskites ${ }^{63}$. These perovskites present dual excitonic emission, which is advantageous for optoelectronic applications where charge injection/extraction can occur in the Sn-I layers as well as edges ${ }^{63}$.

Lanzetta et al.$^{64}$ observed an increase in bandgap from 3D $\mathrm{MASnI}_{3}(1.26 \mathrm{eV})$ to $2 \mathrm{D}(\mathrm{PEA})_{2} \mathrm{SnI}_{4}(1.97 \mathrm{eV})$, where PEA represents phenethylammonium cation. Cao et al. ${ }^{65}$ reported that in Ruddlesden-Popper $\left(\mathrm{CH}_{3}\left(\mathrm{CH}_{2}\right)_{3} \mathrm{NH}_{3}\right)_{2}\left(\mathrm{CH}_{3} \mathrm{NH}_{3}\right)$ ${ }_{n-1} \mathrm{Sn}_{\mathrm{n}} \mathrm{I}_{3 \mathrm{n}+1}$ perovskites, the bandgap decreases with increase in $n$ values: from $1.83(n=1)$ to $1.42 \mathrm{eV}(\mathrm{n}=4)$ corresponding to $2 \mathrm{D}$ structures and $\mathrm{n}=\infty$ equivalent to $3 \mathrm{D} \mathrm{MASnI}_{3}(1.2 \mathrm{eV})^{65}$.

As mentioned earlier, the $\mathrm{B}$ cation states are present in both the valence and conduction bands; hence modification on this site has a correlation with optoelectronic properties. Lattice modifications that increase the overlap of the B-X bonds can increase the valence band energy with a consequent decrease in bandgap ${ }^{50}$. In this case, lattice contraction can reduce the bandgap of tin perovskites while tilting of the octahedra has an opposite effect ${ }^{50}$. On the other hand, a study observed bandgap increase with lattice contraction ${ }^{19}$.

Doping $\mathrm{Sn}$ with metal cations is one means of tuning the bandgap of tin perovskites. Dimesso et al. ${ }^{33}$ showed that the bandgap of $\mathrm{MASn}_{(1-\mathrm{x})} \mathrm{Mg}_{\mathrm{x}} \mathrm{I}_{3}$ decreased $(\mathrm{X}=0,1.18 \mathrm{eV})$ with increasing $\mathrm{Mg}$ contents $(\mathrm{X}=0.025,1.13 \mathrm{eV})$ up to $0.050(\mathrm{X}=0.050,1.13 \mathrm{eV})$. Beyond this $\mathrm{Mg}$ value $(\mathrm{X}=0.100$, $1.19 \mathrm{eV} ; \mathrm{X}=0.300,1.25 \mathrm{eV})$, the bandgap increased compared to the pristine sample. In the same study, the bandgaps of $\mathrm{MASn}_{(1-\mathrm{x})} \mathrm{Ca}_{\mathrm{x}} \mathrm{I}_{3}$ and $\mathrm{MASn}_{(1-\mathrm{x})} \mathrm{Sr}_{\mathrm{x}} \mathrm{I}_{3}$ perovskites were higher or lower than pristine $\mathrm{MASnI}_{3}(1.18 \mathrm{eV})$ depending on dopant content ${ }^{33}$. The authors highlight defects, vacancies, impurities and polarity of dopants as responsible for the changes in bandgap.

Yuan et al. ${ }^{66}$ reported a decrease in the bandgap of GASn $\mathrm{Co}_{\mathrm{x}} \mathrm{I}_{2-2 \mathrm{x}} \mathrm{Cl}_{1+2 \mathrm{x}}(\mathrm{x}=0.025$ to $0.15 \%)$ from $1.55 \mathrm{eV}$ to $1.51 \mathrm{eV}$ with increase in cobalt content $(\mathrm{GA}=$ Guanidinium). In this study, the reduction was associated with the replacement of $\mathrm{Sn}$ (II) with a smaller cation, $\mathrm{Co}(\mathrm{II})$. The bandgap of mixed Ge-Sn perovskite, $\mathrm{FA}_{0.75} \mathrm{MA}_{0.25} \mathrm{Sn}_{1-\mathrm{x}} \mathrm{Ge}_{\mathrm{x}} \mathrm{I}_{3}$, was found to increase from $1.40 \mathrm{eV}$ to $1.53 \mathrm{eV}$ with increasing Ge content of $x=0$ to $0.20^{67}$. The changes in bandgap were associated with the upshift of the valence and conduction bands mediated by Ge. Hasegawa et al. ${ }^{68}$ showed that Bi doping is capable of reducing the bandgap of $\mathrm{MASnI}_{3}$. This behavior was attributed to $\mathrm{Bi}(\mathrm{III})$ empty $6 \mathrm{p}$ orbitals being lower in energy than the $\mathrm{Sn}$ (II) empty 5 p orbitals, thus shifting the minimum of the conduction band downwards. The partial replacement of Sn with Mn can result in bandgap increase due to lower coupling of the Sn-I bonds ${ }^{69}$. Indium (X=0.0051\%, 0. 002\% and $0.057 \%$ ) did alter the bandgap of $\mathrm{MASnI}_{3}$, although in theory the conduction band minimum should be lowered by indium due to its lower potential compared to $\mathrm{Sn} 5 \mathrm{p}^{70}$. The aforementioned study presumed that the doping level of indium was too small to observe bandgap changes.

The $\mathrm{X}$ anions participate in bandgap tuning through modifications of the valence band maximum. The replacement of iodide ions with chloride and bromide ions causes a significant shift in bandgap values. In general, the bandgap of $\mathrm{MASnI}_{3}$ increases with choice of halide in the order of $\mathrm{I}<\mathrm{Br}<\mathrm{Cl}$ due to increase in electronegativity ${ }^{71}$. The bandgap 
of $\mathrm{MASnI}_{3}$ can be significantly altered from $1.3 \mathrm{eV}$ to $2.5 \mathrm{eV}$ $(\mathrm{x}=4)$ with $\mathrm{Br}$ doping in the form of $\mathrm{MASnI}_{3-\mathrm{x}} \mathrm{Br}_{\mathrm{x}}(\mathrm{x}=0-4)^{19}$. It was found that doping provoked an upward shift in the conduction band energy with negligible change in the valence band energy. The effect of chlorine on bandgap modification is highlighted in the work of Kumar et al. ${ }^{72}$, where they show that methylammonium tin chloride perovskite presents a bandgap of $3.7 \mathrm{eV}$, rendering the perovskite unfeasible for visible light applications. Methylammonium tin chloride perovskites prepared with different solvents had bandgaps of $2.63 \mathrm{eV}$ and $2.82 \mathrm{eV}$, being higher than conventional methylammonium tin iodide ${ }^{73}$. A range of $2.3 \mathrm{eV}$ to $2.70 \mathrm{eV}$ was reported by Moyez and Roy ${ }^{74}$.

A recent development in $\mathrm{X}$ site doping is the application of pseudohalides. A study shows that pseudohalides, for example thiocyanate, can partially or completely replace traditional halides and further strengthen the $3 \mathrm{D}$ tin perovskite structure $^{75}$. The bandgap of FASnI $3(1.4 \mathrm{eV})$ decreased to $1.36 \mathrm{eV}\left(\mathrm{FASnI}_{2}(\mathrm{SCN})\right)$ and $1.38 \mathrm{eV}\left(\mathrm{FASnI}(\mathrm{SCN})_{2}\right)$ with thiocyanate doping. In virtue of the facile hybridization of $\mathrm{S}$ and $\mathrm{N}$ p orbitals with I 5p orbitals, negligible changes in the valence band width were observed. On the other hand, a decrease in Sn-I hybridization strength was correlated with the downward shift of the conduction band minimum.

The excitation of perovskites can produce electron-hole pairs, excitons, held together by electrostatic Coulomb force. Tin perovskites due to their dielectric nature are more likely to produce Wannier-Mott excitons compared to Frenkel excitons ${ }^{76}$. The exciton energy of metal halide perovskites was estimated to be a few millielectronvolts at room temperature indicating the facile production of photogenerated carriers ${ }^{77}$. Other studies reported upper limits of $12 \pm 4 \mathrm{meV}^{78}$ and $16 \mathrm{meV}^{79}$ at room temperature. These values are lower than the mean thermal energy at the operation temperature of photovoltaic devices, hence free charge carrier instead of excitons are photogenerated ${ }^{79}$. Spinorbit coupling (SOC-GW) calculations report the average effective masses of electrons and holes for $\mathrm{CH}_{3} \mathrm{NH}_{3} \mathrm{SnI}_{3}$ to be 0.13 and 0.28 , respectively ${ }^{5}$. The lighter effective mass of holes compared to electrons, promotes high hole mobility and unbalanced charge carrier transport ${ }^{5,80}$.

\section{Design of Perovskite Solar Cells}

There are two main designs of tin perovskite solar cells: the regular (n-i-p) and inverted ( $\mathrm{p}-\mathrm{i}-\mathrm{n})$ designs. The abbreviation $n-i-p$ represents $n$ semiconductor, intrinsic semiconductor and $\mathrm{p}$ semiconductor, respectively. Similarly, $\mathrm{p}-\mathrm{i}-\mathrm{n}$ stands for $\mathrm{p}$ semiconductor, intrinsic semiconductor and $\mathrm{n}$ semiconductor, respectively. In a regular (n-i-p) configuration, a conducting transparent glass (FTO) functions as a substrate as well as a transparent electrode.

The first layer is an $n$ type semiconductor film, usually $\mathrm{TiO}_{2}$. It serves as an electron transport layer, allowing the movement of electrons and blocking the passage of holes. A compact titanium dioxide film is deposited followed by a second titanium dioxide film, which is mesoporous in nature. Besides being an electron transport material, the compact layer prevents direct contact between the two selective contacts while the mesoscopic layer serves as a base for the nucleation and growth of the perovskite layer, facilitating charge transport and electron collection ${ }^{81,82}$.

Various thicknesses of the compact $\mathrm{TiO}_{2}$ layer have been reported for tin perovskites: $30 \mathrm{~nm}^{19,83}$ and $100 \mathrm{~nm}^{18,84}$. For mesoporous $\mathrm{TiO}_{2}, 350 \mathrm{~nm}^{47,48}, 400 \mathrm{~nm}^{18,47}$ and $500 \mathrm{~nm}^{47}$ thick mesoporous $\mathrm{TiO}_{2}$ layers can be cited. The effect of $\mathrm{TiO}_{2}$ thickness $(350,450$ and $500 \mathrm{~nm})$ on the conversion efficiency of $\mathrm{FASnI}_{3}$ was investigated by Koh et $\mathrm{al}^{47}$. They reported that the $\mathrm{FASnI}_{3}$ film was completely formed within a $500 \mathrm{~nm}$ mesoporous $\mathrm{TiO}_{2}$ structure, leaving minimal capping layer for bulk recombination and concurrently, improving charge mobility and transfer. The conversion efficiency was increased from $1.7 \%$ to $2.10 \%$.

To foster the rapid injection of electrons, the conduction band energy level of the electron transport material should be lower in energy than that of $\mathrm{MASnI}_{3}$ perovskite $(-4.17 \mathrm{eV})$. Examples of alternative electron transport materials include $\mathrm{ZnO}, \mathrm{SnO}_{2}, \mathrm{Nb}_{2} \mathrm{O}_{5}$ among others.

A solar cell with an n-i-p design is designated mesoscopic or planar depending on the morphology of its electron transport layer (for example, $\mathrm{TiO}_{2}$ ). Figure 7 presents the regular (n-i-p) design of perovskite cells. For mesoscopic designs, the electron transport layer is composed of compact and mesoporous $\mathrm{TiO}_{2}$ layers, according to Figure 7A. For planar designs, the $\mathrm{TiO}_{2}$ layer is completely compact as shown in Figure 7B.

The hole transportmaterial can be $\mathrm{C}_{81} \mathrm{H}_{68} \mathrm{~N}_{4} \mathrm{O}_{8}$ (Spiro-OMeTAD), or a $\mathrm{p}$ semiconductor. The function of this layer is to transport holes and block electrons. The hole transport material should have energy levels compatible with the perovskite for the effective extraction of holes, which leads to high open circuit voltage and lower recombination at the interface.

Spiro-OMeTAD utilized in regular mesoporous devices is usually doped with lithium and cobalt to increase transport properties. These elements were found to increase the degradation of tin perovskites. Lithium bis(trifluoromethanesulfonyl) imide (Li-TFSI), the main lithium salt, was replaced with hydrogen bis(trifluoromethanesulfonyl)imide (H-TFSI), which improved stability ${ }^{18}$. Another additive utilized in the Spiro-OMeTAD solution is tertbutylpyridine ${ }^{18}$. Although been successfully utilized, some authors have chosen 2,6-lutidine and 4-isopropyl-4'-methyldiphenyliodonium tetrakis(pentafluorophenyl)borate over tertbutylpyridine due to concerns with dissolution of perovskite films ${ }^{19,48}$.

Alternative dopant-free hole transport materials such as tetrakis-triphenylamine (TPE) $)^{85}$, polytriarylamine (PTAA $)^{86}$, $\mathrm{P} \mathrm{HT}^{87}, \mathrm{C}_{60}{ }^{87}, \mathrm{Cu}_{2} \mathrm{O}^{88}$, nickel oxide ${ }^{89}$, benzodithiophene ${ }^{90}$, $\mathrm{Nb}_{2} \mathrm{O}_{5}{ }^{91}$ and graphene ${ }^{92}$ have been introduced.

There is a clear preference for mesoscopic design over planar design. The short diffusion length of charge carriers among tin perovskites associated with oxidation is a major drawback for the use of planar configurations ${ }^{18}$. Another factor is charge buildup at the interface due to inadequate carrier extraction, leading to recombination. Both factors undermine conversion efficiency. In a study, $0.3 \%$ efficiency was reported for a planar $\mathrm{TiO}_{2} / \mathrm{MASnI}_{3} /$ poly(triaryl amine) (PTAA)/gold device ${ }^{86}$. In a planar $\mathrm{TiO}_{2} /$ $\mathrm{MASnBr}_{3}$ /hole transport material device, three hole transport materials (Poly(3-hexylthiophene) (P3HT), Spiro-OMeTAD and $\mathrm{C}_{60}$ ) were tested. The highest efficiency was P3HT 
$(0.35 \%)$, followed by $\mathrm{C}_{60}(0.221 \%)$ and Spiro-OMeTAD $(0.002 \%)^{87}$. A study achieved an efficiency of $7.40 \%$ in planar $\mathrm{FASnI}_{3}$ (hallow) perovskite solar cell by adopting $\mathrm{SnO}_{2} / \mathrm{C}_{60}$ pyrrolidine tris-acid combination as an electron transport material ${ }^{93} \cdot \mathrm{C}_{60}$ pyrrolidine tris-acid was sandwiched between $\mathrm{SnO}_{2}$ and the perovskite, the conduction band of $\mathrm{C}_{60}$ pyrrolidine tris-acid facilitated electron transfer from the perovskite to $\mathrm{SnO}_{2}$.

Liao et al. ${ }^{49}$ inverted the sequence of the device layers to $\mathrm{p}-\mathrm{i}-\mathrm{n}$, where the perovskite (intrinsic) is deposited on a dopant-free hole transport material (PEDOT:PSS), which eliminates the risk of bleaching the perovskite. Figure 8 shows the inverted (p-i-n) design.

For the inverted design, indium tin oxide (ITO) glass is used as a substrate. A hole transport material is deposited, followed by the perovskite, electron transport material and then, a metal cathode usually $\mathrm{Ag}, \mathrm{Al}$ or $\mathrm{Ca}$. Poly(3,4-ethylenedioxythiophene (PEDOT:PSS) ${ }^{94}$ and nickel oxide $^{89}$ are examples of some traditional hole transport materials compatible with the p-i-n design. Regarding electron transport materials, $[6,6]$-Phenyl $\mathrm{C}_{61}$ butyric acid methyl ester $(\mathrm{PCBM})^{95}$ and $\mathrm{C}_{60}{ }^{49}$ can be cited. The dismissal

\section{(a) n-i-p mesoscopic}

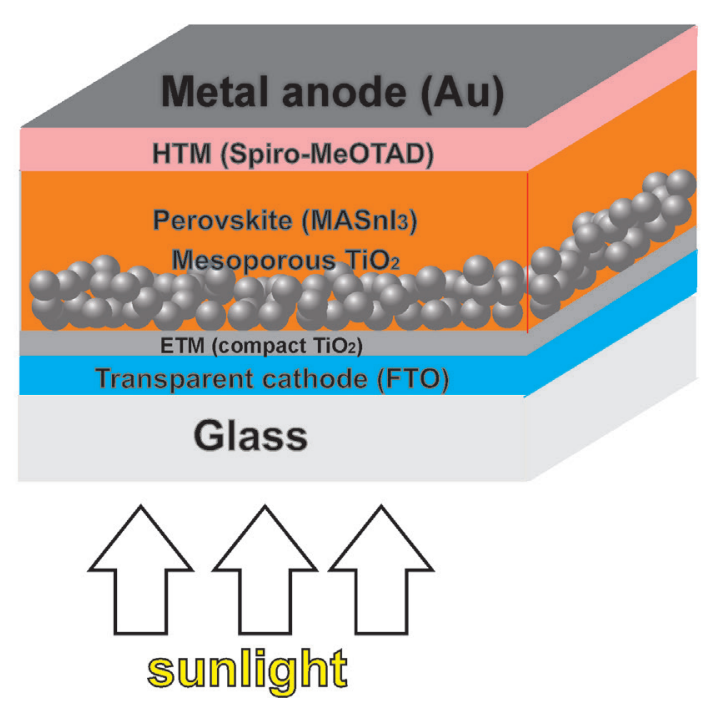

\section{(b) n-i-p planar}

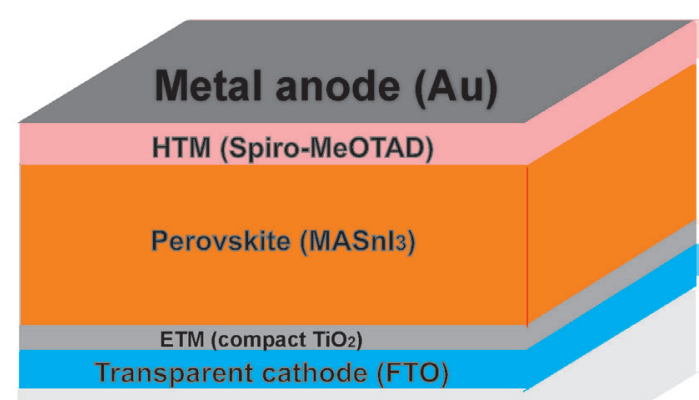

Glass

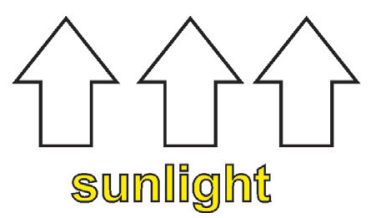

Figure 7. Design of perovskite solar cell A) n-i-p mesoscopic and B) n-i-p planar.

\section{(a) p-i-n planar}

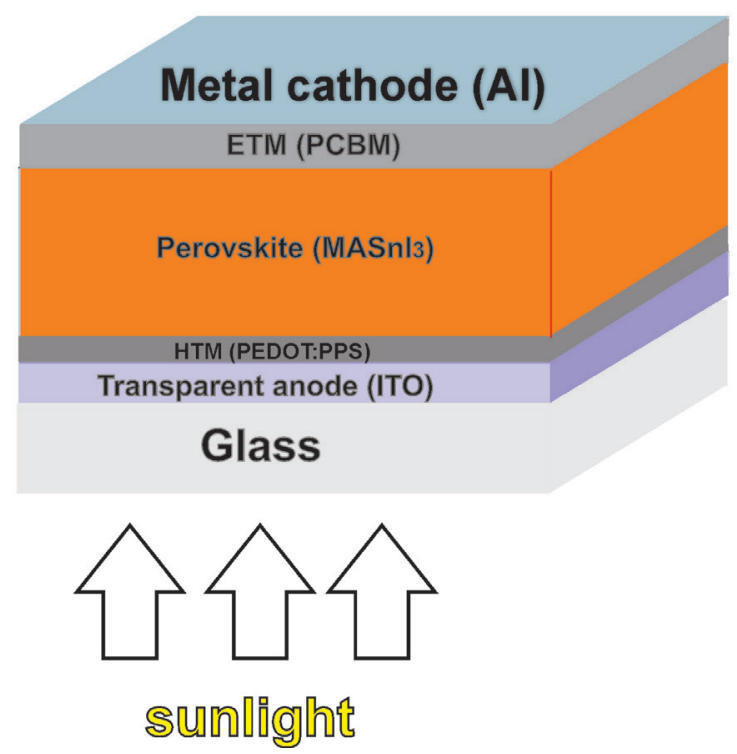

(b) p-i-n mesoscopic

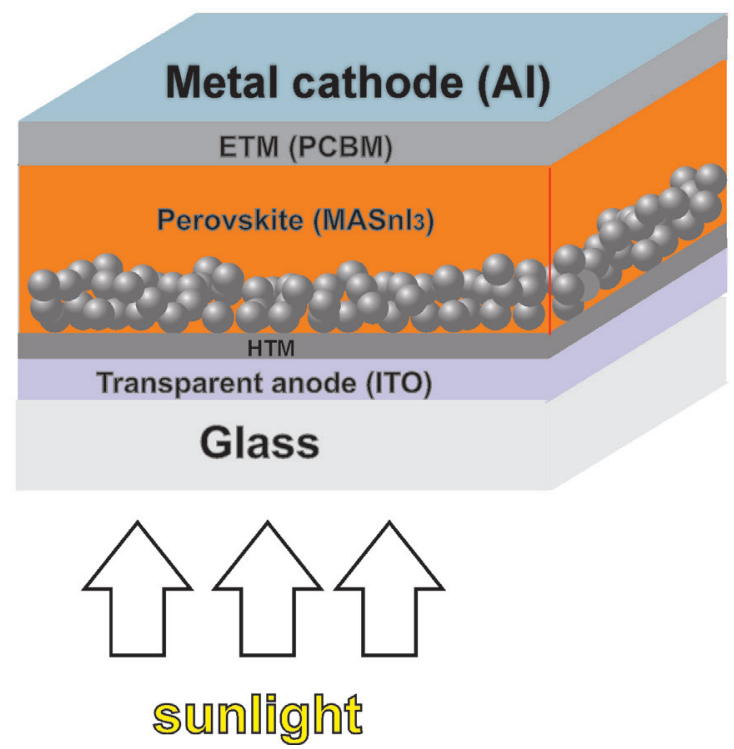

Figure 8. Design of perovskite solar cell A) p-i-n planar and B) p-i-n mesoscopic. 
of mesoporous $\mathrm{TiO}_{2}$ as an electron transport layer in this design increases the tendency of using low temperature methods compatible with large scale production ${ }^{49}$.

Irrespective of design, low open circuit voltage and recombination at the interface are challenging problems for tin perovskite devices ${ }^{91,96,97}$. The selection of hole and transport materials with adequate band alignment with the perovskite material is crucial for carrier extraction efficiency and low recombination, which reflect in high efficiency. The conduction band offset between the electron transport and the perovskite must be minimum to facilitate electron transfer ${ }^{91,96}$. At the same time, the energy difference between the conduction band minimum of the electron transport material and the valence band maximum must be sufficiently large to prevent recombination of holes from the perovskite with electrons transferred through the transport layer ${ }^{91,96}$.

In a $\mathrm{TiO}_{2} / \mathrm{FASnI}_{3} / \mathrm{PTAA}$ device, the introduction of $\mathrm{ZnS}$ between $\mathrm{TiO}_{2}$ and $\mathrm{FASnI}_{3}$ was sufficient to reduce the conduction band offset, aiding in the flow of electrons. Simultaneously, $\mathrm{ZnS}$ acts as a blocking layer against recombination of electrons of $\mathrm{TiO}_{2}$ with holes from the perovskite ${ }^{96}$. An open circuit voltage of $0.38 \mathrm{~V}$ and efficiency of $5.27 \%$ were reported. Yokoyama et al..$^{91}$ employed $\mathrm{Nb}_{2} \mathrm{O}_{5}$ as an electron transport material for tin perovskites due to its lower conduction offset compared to $\mathrm{TiO}_{2}$ and $\mathrm{SnO}_{2}$. The authors reported an efficiency of $5.1 \%$ and a Voc of $0.42 \mathrm{~V}$.

The valence band offset between tin perovskites and conventional hole transport materials such as Spiro-OMeTAD and PEDOT:PSS can be high, which affects hole transfer and open circuit voltage ${ }^{97}$. The facile oxidation of tin perovskites can cause the valence band maximum values to deviate from the norm, hence increasing the valence band offset ${ }^{97}$. The hole extraction properties and work function of PEDOT:PSS can be modified with a LiF layer, aimed at attaining high open circuit voltage ${ }^{98}$.

The presence of poly(tetraphenylethene 3,3'-(((2,2-diphenylethene-1,1-diyl)bis(4,1-phenylene)) bis(oxy))-bis(N,N-dimethylpropan-1-amine)tetraphenylethene) (PTN-Br) in $\mathrm{FASnI}_{3}$ perovskites improved hole transfer by providing an intermediate energy level between the perovskite and PEDOT:PSS ${ }^{97}$. This configuration produced a champion efficiency of $7.94 \%$ and improved open circuit voltage. Poly(N,N'-bis-4-butylphenyl-N,N'-bisphenyl)benzidine (Poly TPD) with a valence band maximum close to $\mathrm{MASnI}_{3}$ was sandwiched with PEDOT:PSS, which contributed to a high open circuit voltage of $0.49 \mathrm{~V}$ and efficiency of $1.7 \%{ }^{99}$. A study reported an open circuit voltage of $0.94 \mathrm{~V}$ attributed to a lower energy offset between indene- $\mathrm{C}_{60}$ bisadduct and tin perovskite compared to $\mathrm{PCBM}^{100}$.

\section{Operation of Perovskite Solar Cell}

The operation of perovskite solar cells is simplified in three steps: photogeneration of charge carriers, charge transport/ separation and charge extraction. The low bandgap of tin perovskites (1.1-1.3 eV) allows absorption of the visible and infra-red portions of the solar spectrum. The excitation of tin perovskites leads to the liberation of charge carriers.

Once the carriers are generated, they must be separated. The driving force for the selective carrier transport of holes (from perovskite to hole transport material) and electrons (from perovskite to electron transport material) is the alignment of energy bands of the transport materials with the perovskite. Perovskite solar cells work on a n-i-p or $p-i-n$ junction configuration for the separation of charges. For the sake of brevity, only the charge separation mechanism for an n-i-p solar cell composed mainly of an electron transport material $\left(\mathrm{TiO}_{2}\right)$, an intrinsic semiconductor (tin perovskite) and a hole transport material (Spiro-OMeTAD) is shown (Figure 9) ${ }^{101,102}$.

Electrons from the perovskite material can be injected into the electron transport material if there is suitable band alignment. This means that the conduction band energy of the perovskite should be slightly higher than that of the electron transport material for energetically favorable and efficient electron transport. In a similar way, holes created in a valence band with lower energy (perovskite) can be transferred to a material with a higher energy valence band (hole transport material).

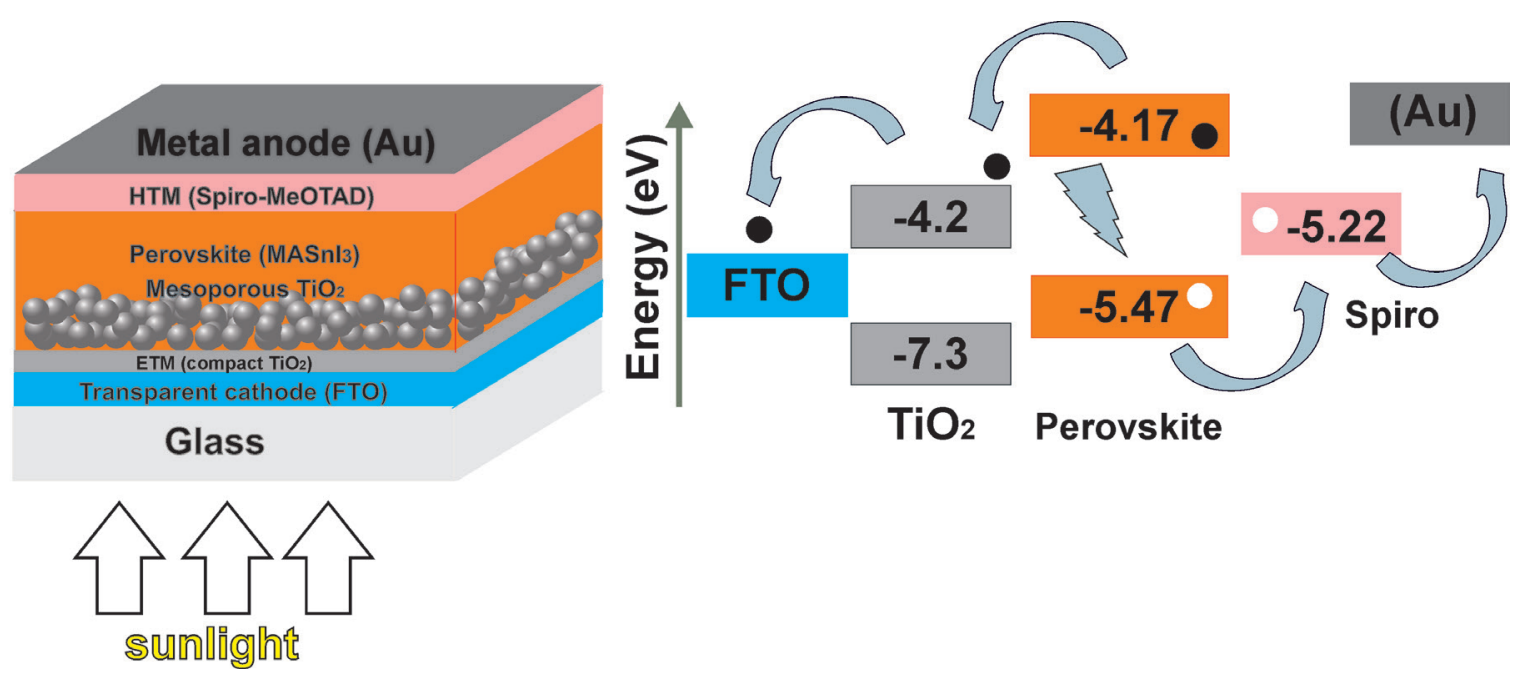

Figure 9. The mechanism of electron and hole injection at the perovskite-electron transport material interface $\left(\mathrm{TiO}_{2}\right)$ and perovskite-hole transport material interface (spiro-OMeTAD), respectively. Value of perovskite was extracted from Bakr et al. ${ }^{101}$. 
The aforementioned transport scenarios are idealized; in fact, holes and electrons can recombine even before they are transferred at the interface. Radiative recombination occurs in the form of band to band transitions while non-radiative recombination occurs via impurity centers and crystal defects $^{103,104}$. Another form of recombination is between the interface layers of the solar cell. For instance, pinholes in the perovskite film can promote recombination. Electrons in the $\mathrm{TiO}_{2}$ layer can recombine with holes in the perovskite when it is energetically favorable.

Besides carrier annihilation through recombination, the dynamics of the carriers determine the efficiency of charge separation and collection. From the point at which they are generated, the carriers must travel a determined pathway (carrier diffusion length) for a specific time (carrier lifetime) in order to be separated and collected. It is desired that the carrier diffusion length is higher than the width of the perovskite absorber so that carriers generated within this area can be collected before they recombine ${ }^{105}$. In this case, collection efficiency is higher and recombination rate is lowered. On the other hand, shorter diffusion length implies that recombination occurs before charge transfer. The pace at which the carriers drift through the semiconductor to the collection interface is controlled by their mobility and effective mass. Scattering due to impurities and lattice defects reduce the mobility of electrons and holes. The diffusion length of carriers in tin perovskites can be as long as $550 \mathrm{~nm}$, which increases charge separation efficiency ${ }^{86}$. However, the holes in tin perovskites tend to have lighter effective masses compared to electrons, resulting in high hole mobility and unbalanced charge carrier transport ${ }^{80}$.

The next stage of the photovoltaic process involves the collection of electrons and holes by the cathode and anode, respectively. The final stage of the solar cell is characterized by the conversion of the collected charges into current.

\section{Synthesis of Tin Perovskites}

The functioning of perovskite solar cells depends on film properties such as substrate coverage, thickness, morphology, structural phase and optical characteristics. These properties can be controlled by choice of synthesis method, precursor concentration, solvent, humidity, temperature/time conditions et cetera.

To synthesize MASnI ${ }_{3}$ perovskite films, a mole ratio of 1:1 of $\mathrm{Sn}$ (II) iodide precursor to methylammonium iodide is normally utilized. When faced with the need to use other tin halide precursors besides $\mathrm{SnI}_{2}$ to synthesize $\mathrm{MASnI}_{3}$ such as $\mathrm{SnCl}_{2}$, a ratio of $1: 3$ of tin(II) halide to methylammonium iodide can be employed in order to have sufficient iodide ions ${ }^{106}$. On the other hand, chlorine is not totally eliminated from the perovskite ${ }^{106,107}$. Some sources of tin(II) outside of conventional $\mathrm{Snl}_{2}, \mathrm{SnCl}_{2}$ and $\mathrm{SnBr}_{2}$ consist of $\mathrm{SnF}_{2}{ }_{2}^{108}, \mathrm{SnO}^{55}$, tin acetate ${ }^{39}$, metallic $\mathrm{Sn}^{20}$, tin octoate, tin sulfate and so forth.

Tin perovskites present a rapid crystallization behavior evidenced by their formation at room temperature. As a consequence, the control of reaction kinetics of precursors, nucleation density and crystal growth have been employed ${ }^{109-111}$.

Tin perovskite can be synthesized by two main methods: solution and vapor/vacuum processing methods. Depending on the sequence of deposition, the method can be divided into one-step and two-steps ${ }^{112}$. In the one-step method, the precursor solution (for example, containing tin precursor plus methylammonium iodide) is deposited in a single step. For the two-step method, each precursor is deposited separately.

\section{Solution Processing}

In the one-step solution process, the perovskite is synthesized using a single precursor solution containing both metal and organic halides. For $\mathrm{MASnX}_{3}$ tin halide $\left(\mathrm{SnX}_{2}\right)$ and organic halide (AX) precursors (mole ratio of 1:1) are dissolved in an appropriate solvent. For $\mathrm{CsSnX}_{3}$, cesium halide $(\mathrm{CsX})$ and tin halide $\left(\mathrm{SnX}_{2}\right)$ precursors (mole ratio of 1:1) are dissolved in an appropriate solvent. The pioneers of tin perovskites used N,N-dimethylformamide (DMF), a polar aprotic solvent, whose boiling point and vapor pressure is $153{ }^{\circ} \mathrm{C}$ and $0.49 \mathrm{kPa}\left(25^{\circ} \mathrm{C}\right)$, respectively ${ }^{18,19}$. Other polar aprotic solvents can also be utilized such as Dimethyl sulfoxide (DMSO), g-butyrolactone (GBL) and N-Methyl-2-pyrrolidone (NMP). The resultant solution with the precursors is deposited and subsequently annealed for phase formation as shown in Figure 10A.

The deposition methods can be spin coating, drop casting $^{113}$ and doctor blade ${ }^{114}$, roll-to-roll ${ }^{115}$, among others. Films produced by the one-step method present nonuniform morphology and properties due to fast reaction. Many methods have been proposed to control the kinetics of film formation. Solvent engineering plays a major role in controlling the crystallization of tin perovskites through the selection of solvents and the manipulation of their properties for specific interests. Solvents such as DMSO compared to DMF strongly coordinates with tin salts, forming adducts that slow down crystallization ${ }^{110}$. Tin iodide dissolved in $\mathrm{DMSO}$, forms $\mathrm{SnI}_{2} \cdot 3 \mathrm{DMSO}$ adduct which controls the rate of crystallization, ensuring highly uniform and pinhole-free perovskite films ${ }^{110}$. The utilization of NMP also results in a controlled crystallization compared to $\mathrm{DMF}^{110}$. The reaction between $\mathrm{Sn}$ metal and $\mathrm{I}_{2}$ in DMSO can be utilized to form quality $\mathrm{SnI}_{2} \cdot 3 \mathrm{DMSO}$ adduct for tin perovskite synthesis ${ }^{20}$.

To gain a balance between the properties of the solvents, a cosolvent is introduced. For instance, the combination of DMF and DMSO has been tested in tin perovskites ${ }^{49,109}$. The health risks associated with DMF and DMSO have motivated options such as methanol and 1,4-dioxane mixture ${ }^{116}$. Dioxane has the ability to coordinate with $\mathrm{Sn}(\mathrm{II})$ ions, slowing the crystallization process.

When the combination of solvents is employed, antisolvents are crucial for good morphology and coverage. Anti-solvents are solvents that do not dissolve the perovskite but dissolve the perovskite precursors. Some examples are diethyl ether, toluene, chlorobenzene, benzene et cetera. The anti-solvent is applied on the perovskite during spin coating as shown in Figure 10B. The function of the antisolvent is to lower solubility and foster supersaturation, fast nucleation and growth ${ }^{117,118}$. Furthermore, it extracts the precursor solvent, usually DMF.

A pyrazine $/ \mathrm{SnF}_{2}$ anti-solvent was adopted for a $\mathrm{DMF}$ plus DMSO mixture ${ }^{109}$. The film produced by this method was smooth and dense compared to that without a pyrazine/ $\mathrm{SnF}_{2}$ anti-solvent. A study tested various anti-solvents (chlorobenzene, toluene, and diethyl ether) among tin 


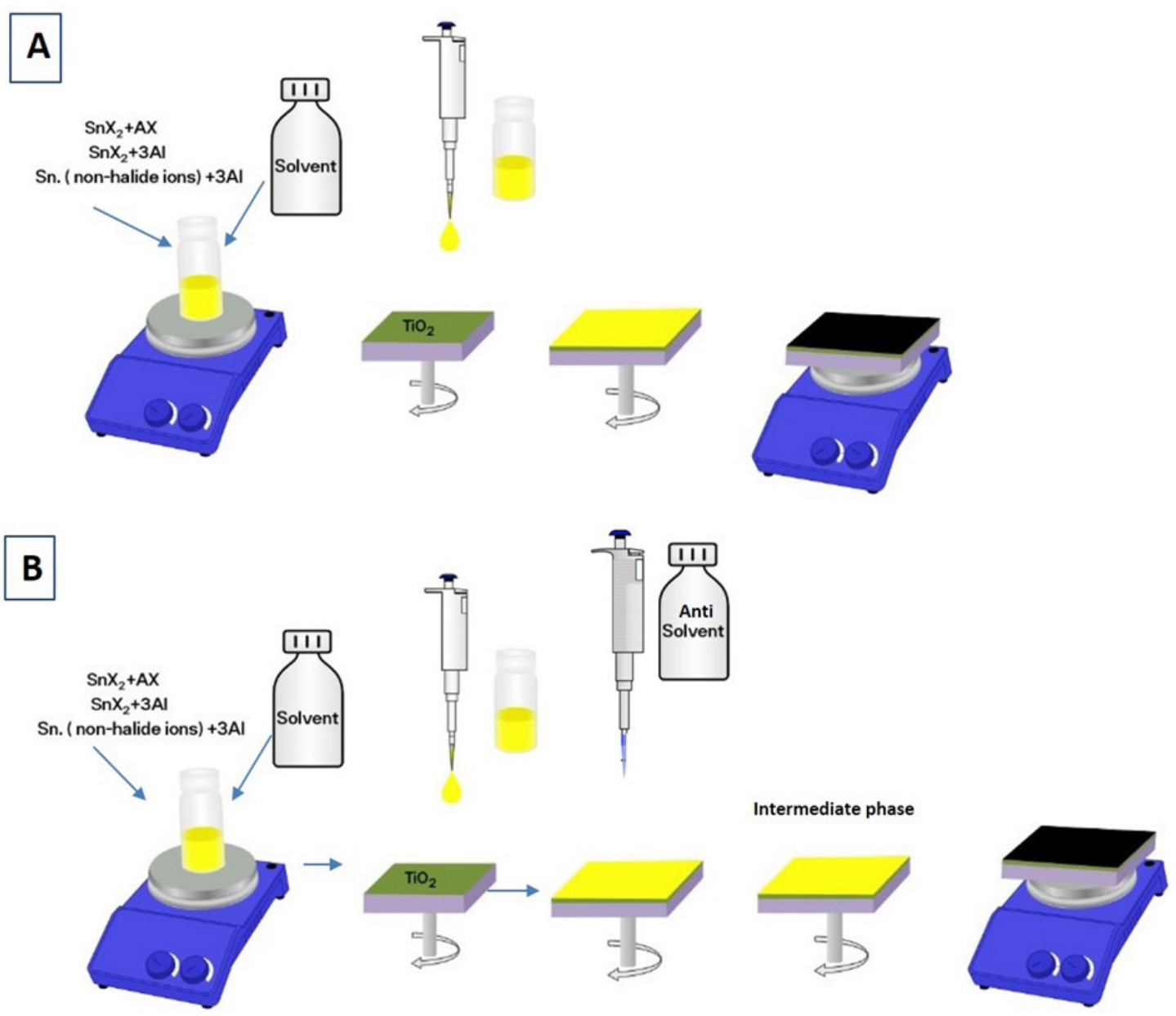

Figure 10. A) Conventional one-step method and B) one-step with anti-solvent dripping.

perovskites prepared with DMF and DMSO solvents containing $\mathrm{SnF}_{2}^{49}$, where diethyl ether coupled with $\mathrm{SnF}_{2}$ additive at an optimum level produced the most uniform and pinhole-free perovskites. Figure 11 presents the $\mathrm{FASnI}_{3}$ perovskite films with various levels of $\mathrm{SnF}_{2}$.

According to Xiao et al. ${ }^{119}$ precipitates of $\mathrm{SnF}_{2}$ formed during spin coating can serve as nucleation sites for the homogenous growth of MASnIBr${ }_{2}$.

Anti-solvents applied to a one-solvent solution have also been reported. Fujihara et al. ${ }^{120}$ prepared tin perovskites using a precursor solution with DMSO. In order to obtain a uniform morphology, they dipped the perovskite film in a solution composed of two anti-solvents (toluene and hexane, controlled temperature) which have different miscibilities with DMSO. The process enabled the extraction of DMSO to be controlled and consequently, the production of uniform and dense films.

Hot anti-solvent dripping was found to improve film coverage through increased nucleation sites ${ }^{121}$. Anti-solvent dripping in conjunction with rapid solvent evaporation promoted higher nucleation density necessary for dense films ${ }^{122}$.

Additives are employed in the one-step process to control and direct crystallization. Isomeric fluorinated ligands control crystallization based on hydrogen bonding between ammonium cation (ligand) and Sn-I octahedra (4-fluorophenethylammonium iodide, 3-fluoro-phenethylammonium iodide, and 2-fluoro-phenethylammonium iodide) ${ }^{123}$. Hydrogen bonding between polyvinyl acetate (PVA) and FASnI $\mathrm{Fas}_{3}$ found to retard crystallization and promote homogeneous and pinhole-free perovskite films ${ }^{124}$. Polyethylene glycol regulated the crystallization of $\mathrm{FASnI}_{3}$ films through its $\mathrm{C}-\mathrm{O}-\mathrm{C}$ (ether bond) bonds with hydrogen groups in formamidinium and coordination with $\mathrm{Sn}^{125}$. It links the perovskite grains during annealing, ensuring uniform coverage and no pinholes ${ }^{125}$. The carbonyl bonds in poly(ethylene-co-vinyl acetate) (EVA) form complexes with $\mathrm{Sn}$ (II) to decrease the crystallization rate of $\mathrm{FASnI}_{3}{ }^{126}$. In addition, the organic ligands are protective against water and oxygen.

The surface energy of $\mathrm{FASnI}_{3}$ perovskite was controlled in the presence of pentafluorophen-oxyethylammonium iodide (FOEI), creating highly oriented and smooth films ${ }^{127}$. The efficiency of the pristine perovskite increased from $6.93 \%$ to $8.13 \%$ (phenylethylammonium iodide) and $10.81 \%$ (pentafluorophen-oxyethylammonium iodide) accordingly ${ }^{127}$. The orientation of tin perovskite $\left(\mathrm{FASnI}_{3}\right)$ films along the (100) plane can be controlled by n-propylammonium iodide additive during film synthesis ${ }^{128}$. It enables charge transport and high efficiency (11.22\%). Butylammonium iodide 


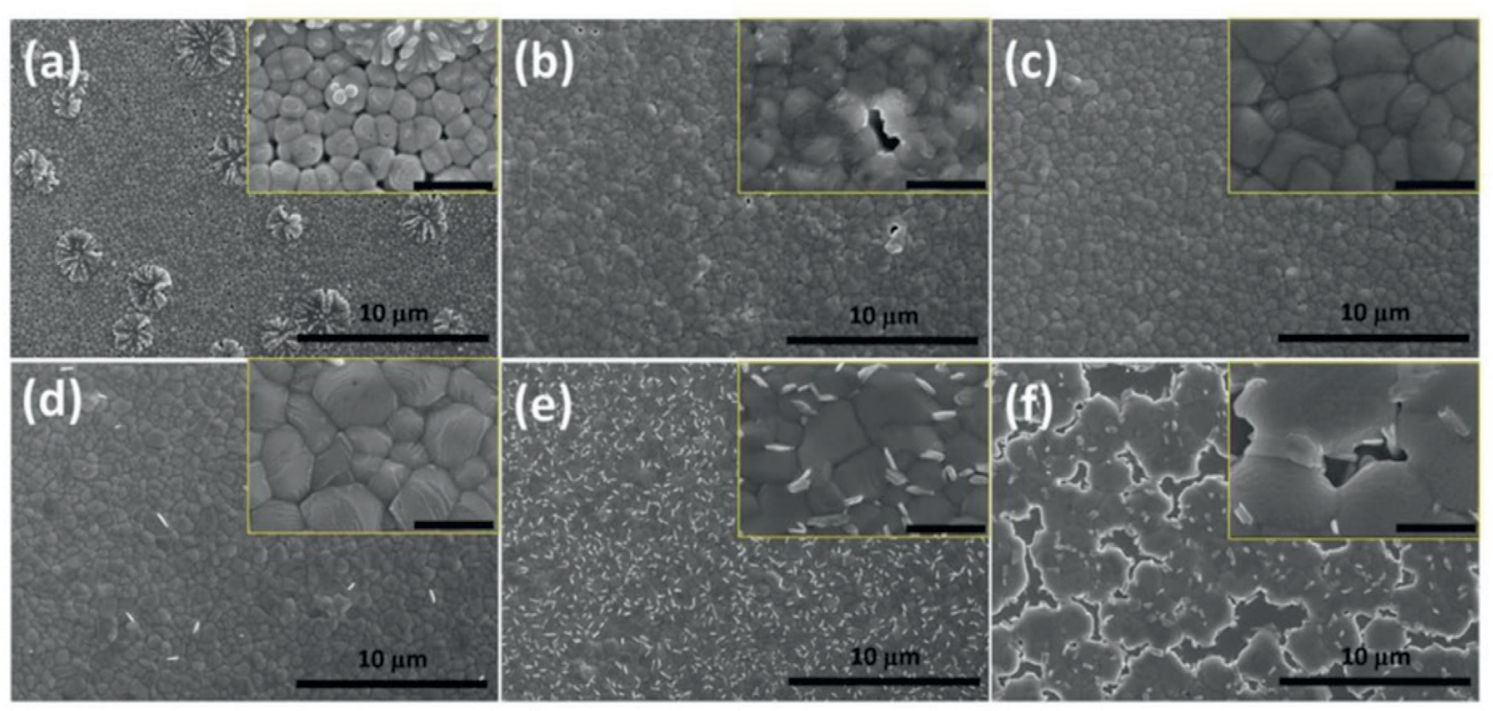

Figure 11. SEM micrographs of FASnI ${ }_{3}$ with different levels of $\mathrm{SnF}_{2}$ : (a) $0 \mathrm{~mol} \%$, (b) $5 \mathrm{~mol} \%$, (c) $10 \mathrm{~mol} \%$, (d) $15 \mathrm{~mol} \%$, (e) $20 \mathrm{~mol} \%$, (f) $30 \mathrm{~mol} \%$. Scale bar $10 \mu \mathrm{m}$. Insert (scale bar $1 \mu \mathrm{m}$ ): SEM micrographs at high magnification. Copyright (2016) Wiley. Used with permission from Liao et al. ${ }^{49}$.

in $\mathrm{FASnI}_{3}$ was found to enhance film crystallization and orientation due to hybrid 2D/3D structures. However, the problem of pinholes was apparent because of rapid crystal growth. Thus, the addition of ethylenediammonium diiodide, a bigger cation, slowed down the process and passivated the pinholes ${ }^{129}$.

$\mathrm{MASnI}_{3}$ containing ethylenediammonium (15\%) presented smaller grains and higher density compared to the pristine sample, which are attributed to the additional organic cation in the perovskite structure ${ }^{60}$. In $\mathrm{FASnI}_{3}$, ethylenediammonium increased film texture and lowered pinholes ${ }^{61}$.

Post annealing with edamine Lewis base was found to improve film morphology, reduce recombination and consequently increase device efficiency through passivation of uncoordinated tin(II) species ${ }^{130}$. Similar properties can be obtained using ethylenediamine, furthermore it forms superficial 2D films, improving film formation and conversion efficiency ${ }^{131}$.

Single crystals of perovskites can be grown in ambient conditions, using the top-seeded solution growth method. In this method, formamidinium acetate and methylammonium iodide can be reacted with $\mathrm{SnO}$ in a mixed solution of $\mathrm{HI}-\mathrm{H}_{3} \mathrm{PO}_{2}$ to obtain spontaneous seed crystals in air ${ }^{55}$. The single crystals were grown over a month. $\mathrm{H}_{3} \mathrm{PO}_{2}$ acted as a reducing environment.

Perovskites can be synthesized in the form of quantum dots for application in solar cells, light emitting diodes etc. For the synthesis of $\mathrm{CsSnI}_{3}$ nanocrystals, a modified hot injection method can be utilized. $\mathrm{SnX}_{2}$ can be dissolved in tri-n-octylphosphine. The resultant solution is injected into a $\mathrm{Cs}_{2} \mathrm{CO}_{3}$ solution containing oleic acid and oleylamine at $170^{\circ} \mathrm{C}^{132}$.

Quantum dots can be prepared using a one-step method, which involves the dissolution of $\mathrm{CsX}$ and $\mathrm{SnX}_{2}$ in $\mathrm{DMF}$ : DMSO (volume ratio $=5: 1$ ) and subsequent addition of triphenylphosphite and heating at $90{ }^{\circ} \mathrm{C}$ for $10 \mathrm{~min}^{133}$.
Another option is spontaneous crystallization, although the method is for lead nanocrystals, it can find application in $\mathrm{Sn}$ perovskites. In this method, MA-oleate precursor is injected into a toluene solution containing a $\mathrm{SnI}_{2}$-ligand complex for spontaneous crystallization $^{134}$.

Burschka et al. ${ }^{135}$ proposed the two-step method for the controlled synthesis of lead perovskites, which can be adapted for tin perovskites. In the two-step solution process, a separate solution of each precursor, methylammonium iodide or tin halide, is prepared in an appropriate solvent such as dimethyl sulfoxide (DMSO), N-methyl-2pyrrolidone (NMP), and N,Ndimethylformamide (DMF) and $\gamma$-butyrolactone (GBL),

The tin precursor solution is first deposited and annealed. Then, the substrate with the tin precursor is dipped in an isopropanol solution containing methylammonium iodide to form the perovskite. Despite the success of the method among lead perovskites, the method is not frequently employed for tin perovskites due to the solubility of the tin perovskite ${ }^{110}$. Zhu et al. ${ }^{136}$ synthesized uniform FASnI $_{3}$ film by sequential deposition of a tin precursor solution (trimethylamine, $\mathrm{SnI}_{2}$ and $\mathrm{SnF}_{2}$ ) followed by formamidinium iodide solution. The formula for success was the addition of trimethylamine in the ethanol/SnI 2 precursor solution. Trimethylamine and $\mathrm{SnF}_{2}$ form complexes, which slow down the synthesis reaction with formamidinium iodide.

Shahbazi et al. ${ }^{137}$ utilized a two-step method which consisted of $\mathrm{DMSO} / \mathrm{SnI}_{2}$ and $\mathrm{SnF}_{2}$ /ethylenediammonium dihypophosphitesolution deposition. Subsequently, formamidinium iodide dissolved in hexafluoro-2-propanol, isopropanol, and chlorobenzene mixture was deposited. The kinetics of crystallization was controlled by the coordination of DMSO with tin iodide coupled with hexafluoro-2-propanol and isopropanol-induced hydrogen bonds with formamidinium iodide. In addition, the extraction of residual DMSO mediated by chlorobenzene was reported. 


\section{Vapor/Vacuum Processing}

Vapor/vacuum processes permit the synthesis of tin perovskites by sequential deposition since major problems with solvent, kinetics and reproducibility are tackled. Yokoyama et al ${ }^{48}$ devised the low-temperature vapor assisted solution process for tin perovskites where $\mathrm{SnI}_{2}$ film reacts with MAI gas to produce perovskite film with good coverage, better stability and high reproducibility compared to conventional one-step method. Jung et al. ${ }^{87}$ obtained perovskite films based on two methods: co-evaporation and sequential evaporation of $\mathrm{SnBr}_{2}$ and $\mathrm{MABr}$. The film deposited by sequential deposition presented better stability against oxidation when transferred into the glovebox due to a protective $\mathrm{MABr}$ layer. This also contributed to higher efficiencies compared to the film deposited by co-doping.

Yu et al. ${ }^{99}$ improved the morphology of tin perovskite through a hybrid thermal evaporation method. Tin iodide $\left(\mathrm{SnI}_{2}\right)$ and methylammonium iodide (MAI) were heated in crucibles and the vapors were co-deposited to form a film with good coverage and without pinholes. Weiss et al..$^{138}$ deposited $\mathrm{SnI}_{2}$ by thermal evaporation and subsequently, MAI was deposited. The resultant films were homogeneous and had higher surface coverage than solution-processed films.

Annealing under vapor pressure has been shown to be an effective method for the fabrication of uniform and dense perovskite films and the associated efficiencies were quite high compared to normal annealing. Methylammonium chloride provided a vapor pressure for the synthesis of tin perovskites in the work of Chowdhury et al. ${ }^{139}$ and an efficiency of $6.3 \%$ was reported. Liu et al. ${ }^{121}$ employed DMSO vapor and achieved efficiencies over $7 \%$. The vacuum extraction of solvents before annealing improves film morphology by preventing phase segregation, especially when solvents of different volatilization rates are involved ${ }^{140}$. Perovskite films can be treated under vacuum $\left(5 \times 10^{-4} \mathrm{~Pa}\right)$ after annealing to promote the complete removal of solvents as well as reduce defects. With this method, it is possible to attain a $10.3 \%$ efficiency ${ }^{141}$.

Through one-step flash method, MASnI ${ }_{3}$ powders were deposited as thin films on substrates without the need for solvents. The powders were heated to sublimation in the flash evaporator device and the powder was subsequently deposited. Factors such as quantity of powder, pressure, source temperature and heating time can be modified for film synthesis ${ }^{46}$.

Physical vapor deposition (PVD) was employed for the synthesis of tin perovskites and advantages such as high reproducibility and lower formation of pinholes were obtained $^{142}$. A variation of physical vapor deposition known as laser pulsed deposition was employed to deposit mixed cation tin perovskites ${ }^{143}$. The optimum deposition conditions were room temperature and 100 to $130 \mathrm{~mJ}$. The stoichiometry of the targets was higher than conventional in order to compensate for the loss of volatile organic components.

\section{Other Methods}

Fine powders of tin precursors and methylammonium ( iodide, bromide and chloride) were ground in ball mill for the mechanochemical synthesis of tin perovskites ${ }^{144,145}$. The stability of the samples in air was improved by $\mathrm{SnF}_{2}{ }_{2}^{14,145}$.

Based on the high temperature tolerance of $\mathrm{CsSnX}_{3}$ perovskites, it can be formed by solid state reactions. In this method, a mole ratio of 1:1 of cesium halide (CsX) to tin halide $\left(\mathrm{SnX}_{2}\right)$ precursors are placed in an evacuated Pyrex and heated above the melting temperature of $\mathrm{CsSnI}_{3}$ for a specified time. After, the sample is cooled to room temperature. The perovskite is dissolved in appropriate solvents for deposition ${ }^{43,146}$.

\section{Advent of Tin Perovskite}

Early reports on the synthesis of organic-inorganic tin halide perovskites date back to $1978^{147}$. Scientists became fascinated about their structures, physical properties and conductivity in the 90s and beyond. Using 127I-NQR and 119Sn Mössbauer spectroscopy, Yamada et al. ${ }^{148}$ highlighted the dependence of their electrical properties on temperature. Mitza et al. ${ }^{149}$ showed that tin perovskites can be layered with the formula, $\left(\mathrm{C}_{4} \mathrm{H}_{9} \mathrm{NH}_{3}\right)_{2}\left(\mathrm{CH}_{3} \mathrm{NH}_{3}\right)_{\mathrm{n}-1} \mathrm{Sn}_{\mathrm{n}} \mathrm{l}_{3 \mathrm{n}+1}$, as well as crystallize at near room temperature. They can transition from semiconductor to metallic behavior by tuning the dimension of the perovskite layers with increasing $\mathrm{n}$, where $(\mathrm{n}=\infty)$ forms a tridimensional frame.

Mitza et al. ${ }^{150}$ classified $\mathrm{MASnI}_{3}$ as a low carrier density p-type metal with a Hall hole density (1/RHe) of $\left(\simeq 2 \times 10^{19} \mathrm{~cm}^{-3}\right)$ and whose resistivity decreases with decrease in temperature. Takahashi et al. ${ }^{35}$ proved that $\mathrm{MASnI}_{3}$ is not a semi-metal as widely perceived but a p-doped semiconductor. Spontaneous hole doping is responsible for the so-called metallic transport.

In the midst of all these characterizations, an overlooked detail was the possible application of these materials as solar absorbers. Ogomi et al ${ }^{151}$ reported a mixed $\mathrm{Sn}-\mathrm{Pb}$ perovskite with a P3HT transport material. They observed that pure tin perovskites showed null efficiency due to the oxidation of $\mathrm{Sn}$ (II). However, the addition of $\mathrm{Pb}$ in different quantities improved efficiency. An optimum efficiency of $4.18 \%$ was obtained with $\mathrm{MASn}_{0.5} \mathrm{~Pb}_{0.5} \mathrm{I}_{3}$. Noel et al. ${ }^{18}$ synthesized the first mesoporous $\mathrm{MASnI}_{3}$ solar cell with an efficiency of $6.4 \%$.

The protocols followed were the modification of spiroOMeTAD with hydrogen bis(tri-fluoromethanesulfonyl)imide (H-TFSI) instead of oxidizing lithium bis(-trifluoromethylsulfonyl) imide salt (Li-TFSI) and encapsulation with epoxy. The authors highlighted the need to suppress the oxidation of Sn(II) so as to reduce the background density of holes and improve the diffusion length of charge carriers.

Hao et al. ${ }^{19}$ synthesized mesoporous $\mathrm{CH}_{3} \mathrm{NH}_{3} \mathrm{SnI}_{3}$ and $\mathrm{CH}_{3} \mathrm{NH}_{3} \mathrm{SnI}_{3-\mathrm{x}} \mathrm{Br}_{\mathrm{x}}$ perovskites solar cells using conventional spiro-OMeTAD as a hole transport material. An efficiency of $5.7 \%$ was achieved by tuning the bandgap through $\mathrm{Br}$ doping aimed at improving the open circuit voltage. Performance loss was mainly attributed to decrease in photocurrent density, poor film coverage and fill factor, arising from $\mathrm{p}$-type doping via $\mathrm{Sn}(\mathrm{II})$ oxidation.

\section{Sn Compensators}

Based on these initial works, effort was directed towards oxidation control. One of the major approach is the use of 
Sn(II) compensators. They are $\mathrm{Sn}(\mathrm{II})$ precursors utilized as extra sources of $\mathrm{Sn}$ (II) in the event of oxidation. They impede tin vacancy/Sn(IV) formation and/or act as reducing agents. One can cite $\mathrm{SnI}_{2}{ }^{152}, \mathrm{SnBr}_{2}{ }^{153}, \mathrm{SnCl}_{2}{ }^{153}, \mathrm{SnF}_{2}{ }^{47,109,154}$, and $\mathrm{Sn}$ metal ${ }^{155}$ as examples.

Kumar et al. ${ }^{154}$ introduced $\mathrm{SnF}_{2}$ as a possible solution to decrease carrier density linked with tin oxidation and vacancies in $\mathrm{CsSnI}_{3}$. An efficiency of $2.02 \%$ was obtained with $20 \% \mathrm{SnF}_{2}$. In the proposal, $\mathrm{SnF}_{2}$ will make up for tin vacancies created by oxidation, thereby regulating intrinsic carrier density. A recent study found that fluorine plays a major role in the complexation of Sn(IV) and provision of antioxidative properties ${ }^{156}$.

Koh et al. ${ }^{47}$ incorporated $\mathrm{SnF}_{2}$ in formamidinium tin-based perovskites and observed an improvement in stability at optimum amounts through the retarding of $\mathrm{Sn}$ (II) oxidation. A $2.10 \%$ efficiency was reported with the presence of $\mathrm{SnF}_{2}$. However, excess $\mathrm{SnF}_{2}$ promoted segregation and poor morphology, motivating Lee et al. ${ }^{109}$ to introduce pyrazine-SnF ${ }_{2}$ complex to mitigate the problem, rendering an efficiency of $4.8 \%$. The encapsulated device conserved $98 \%$ of its initial efficiency in over 100 days.

The versatility of $\mathrm{SnF}_{2}$ was highlighted when Liao et al. ${ }^{49}$ reported improvement in morphology and stability of formamidinium tin-based perovskites deposited on PEDOT:PSS. The design of the device coupled with $\mathrm{SnF}_{2}$ incorporation was responsible for the high efficiency of $6.22 \%$. The devices were stable under incessant illumination as well as in the dark. During 30 days, $85 \%$ of the initial efficiency was maintained.

Xiao et al. ${ }^{119}$ revealed that $\mathrm{SnF}_{2}$ serves as a nucleation site for the formation of uniform films. The solar device with $30 \% \mathrm{SnF}_{2}$ presented an efficiency of $3.7 \%$, being stable for 60 days in a glovebox and retaining $80 \%$ of its initial efficiency.

$\mathrm{CsSnI}_{3}$ containing excess $\mathrm{SnI}_{2}(10 \mathrm{~mol} \%)$ presented device stability when exposed to air and continuous illumination, indicating the reduction of tin vacancies ${ }^{157}$. The excess $\mathrm{SnI}_{2}$ can lodge in positions which prevent the entry of oxygen and water.

With the success of $\mathrm{SnF}_{2}$, alternative halide additives such as $\mathrm{SnI}_{2}, \mathrm{SnBr}_{2}, \mathrm{SnCl}_{2}$ and $\mathrm{Sn}$ metal, have been tested. Marshall et al. ${ }^{153}$ co-doped tin precursors with $\mathrm{SnCl}_{2}$ for the synthesis of $\mathrm{CsSnI}_{2}$ perovskites and reported improved stability compared to $\mathrm{SnBr}_{2}$ and $\mathrm{SnF}_{2}$. This was mainly attributed to the rich $\mathrm{Sn}$ environment (capping layer) formed by $\mathrm{SnCl}_{2}$ and the higher solubility of the precursor in solvents, aiding film formation.

Song et al. ${ }^{152}$ utilized extra $\mathrm{SnI}_{2}$ levels combined with a hydrazine atmosphere for the stabilization of $\mathrm{Sn}$ (II) in Csbased tin perovskites. Secondary phases derived from $\mathrm{Sn}$ (II) species during the synthesis of tin perovskites may act as tin compensators against oxidation. It was found that $\mathrm{SnO}$ and $\mathrm{Sn}(\mathrm{OH})_{2}$ formed by the insufficient supply of iodine to $\mathrm{SnI}_{2}$ and the presence of water, may be responsible for low hole density ${ }^{84}$.

\section{Reducing Agents}

It can be deduced that the synthesis of perovskites has room for a wide range of additives which directly reduce or control the oxidation of $\mathrm{Sn}(\mathrm{II})$. The additives do not only reduce oxidation but also act in controlling morphology, perhaps because they slow down the crystallization energy of tin perovskites.

Dang et al. ${ }^{55}$ synthesized $\mathrm{FASnI}_{3}$ and $\mathrm{MASnI}_{3}$ single crystals from solution using $\mathrm{H}_{3} \mathrm{PO}_{2}$ as a reducing agent to stabilize $\mathrm{Sn}(\mathrm{II}) . \mathrm{Sn}$ (II) in the $\mathrm{FASnI}_{3}$ sample remained stable for a month in ambient atmosphere. 5-ammonium valeric acid iodide (5-AVAI) has been reported as an efficient additive for the stabilization of methylammonium tin perovskites ${ }^{158}$. The produced powders maintained their oxidation properties for 46.1 hours before total decomposition. The authors associated 5-AVAI layer to stability.

A study utilized $\mathrm{Sn}$ metal as a tin reducing agent in formamidinium iodide precursor solution. The metal acted as a compensator of $\mathrm{Sn}$ (II) and reducing agent, leading to a champion efficiency of $6.75 \%{ }^{159}$. Ascorbic acid served as a reducing agent for $\mathrm{MA}_{0.5} \mathrm{FA}_{0.5} \mathrm{~Pb}_{0.5} \mathrm{Sn}_{0.5} \mathrm{I}_{3}$ perovskites. Besides being a reducing agent, it modulated crystallization through intermediate complexes ${ }^{160}$. Song et al. ${ }^{161}$ created a reducing hydrazine vapor atmosphere in a spin coating chamber during the synthesis of tin perovskite, resulting in an efficiency of $3.89 \%$.

The partial substitution of methylammonium with hydrazine ions improved the stability of $\mathrm{MASnI}_{3}$ against light-mediated oxidation of $\mathrm{Sn}(\mathrm{II})^{162}$. Li et al. ${ }^{163}$ synthesized $\mathrm{MASnI}_{3}$ by organic cation displacement mediated by hydrazinium tin iodide. Hydrazine produced during the reaction acts as a reducing agent. Kayesh et al. ${ }^{164}$ reported the reducing potential of hydrazinium chloride $\left(\mathrm{N}_{2} \mathrm{H}_{5} \mathrm{Cl}\right)$ in $\mathrm{FASnI}_{3}$ film. The concentration of $\mathrm{Sn}(\mathrm{IV})$ content was reduced by $20 \%$ and a high efficiency of $5.4 \%$ was attained.

Hydrazine dihydrochloride inhibited the oxidation of $\mathrm{Sn}$ (II) in mixed organic cation tin perovskite, causing efficiency retention of $90 \%$ in unencapsulated devices after 55 days $^{165}$. Trihydrazine dihydriodide suppressed Sn(IV) levels in FASnI films through the formation of hydrazine, which also improved morphology. A high efficiency of $8.48 \%$ was reported ${ }^{166}$

Phenylhydrazine hydrochloride ( $\mathrm{PHCl})$ was used in FASnI ${ }_{3}$ films as an additive to reduce $\mathrm{Sn}(\mathrm{IV})$ to $\mathrm{Sn}$ (II) in the precursor solution and passivate defects through its hydrazine group ${ }^{167}$. The champion cell with $5 \% \mathrm{PHCl}$ showed an efficiency of $11.4 \%$ and an open circuit voltage of $0.76 \mathrm{~V}$. Nakamura et al. ${ }^{155}$ scavenged $\mathrm{Sn}(\mathrm{IV})$ impurities in tin precursor solution using $\mathrm{Sn}(0)$ nanoparticles synthesized in situ through the reduction of $\mathrm{SnF}_{2}$ with 1,4-bis(trimethylsilyl)-2,3,5,6tetramethyl-1,4-dihydropyrazine (TM-DHP). An efficiency of as high as $11.5 \%$ was reported and enhanced stability (unencapsulated) in inert environment for 50 days.

Catechin was employed as a reducing agent to suppress $\mathrm{Sn}$ (II) formation, enabling a conversion efficiency of $6.02 \%$ compared to the sample without Catechin $(4.29 \%)^{168}$. Ethylenediammonium dihypophosphite repressed oxidation in $\mathrm{FASnI}_{3}$ devices, increasing efficiency by $2 \%$ compared to the pristine device ${ }^{137}$. The stability of the devices was guaranteed over a long period $(4000 \mathrm{~h})$. The use of ethylenediammonium additive combined with $\mathrm{Cs}$ and GA doping of FASnI 3 induces passivation, which reduces defect density and allows fine control of film quality as well as stability ${ }^{169}$. 


\section{Doping}

Mixed lead-tin perovskites are one of the pioneering subjects on metal cation doping. The benefits of lead doping include improved efficiency and stability. Ogami et al. ${ }^{151}$ found that adding only $30 \%$ of $\mathrm{PbI}_{2}$ to tin perovskite was sufficient to increase efficiency from 0 to $2 \%$. They also observed an increase in the binding energy of $\mathrm{Sn}$ with increase in $\mathrm{Pb}$, pointing to stability. In another study, the efficiency of tin perovskite increased from $0.04 \%$ to $0.11 \%$ with $50 \%$ increase in $\mathrm{Pb}^{170}$. Through thermogravimetric analysis and in-situ X-ray, Leijtens et al. ${ }^{171}$ proved that the oxidation kinetics of tin perovskite is reduced by $\mathrm{Pb}$ through the formation of $\mathrm{I}_{2}$, which is energetically demanding instead of $\mathrm{SnI}_{4}$, known to induce the loss of $\mathrm{Sn}$. A 50\%-based tin perovskite $\left(\mathrm{MASn}_{0.5} \mathrm{~Pb}_{0.5} \mathrm{I}_{3}\right)$ presented an efficiency of $13.6 \%{ }^{172}$. The success of the device was reported to be the improvement of morphology through the reduction of crystallization kinetics. The stability of $\mathrm{FA}_{0.75} \mathrm{Cs}_{0.25} \mathrm{Sn}_{0.5} \mathrm{~Pb}_{0.5} \mathrm{I}_{3}$ was associated with the modification of the valence band maximum due to the presence of $\mathrm{Sn}$ and $\mathrm{Pb}$, which reduces $\mathrm{Sn}(\mathrm{II})$ oxidation ${ }^{173}$.

Other metals have been utilized. Yuan et al.$^{66}$ proposed that cobalt can increase the binding energy of Sn3d and I3d, a possible reason for stability against oxidation. The perovskite in the form of $\mathrm{GASn}_{1-\mathrm{x}} \mathrm{Co}_{\mathrm{x}} \mathrm{I}_{2-2 \mathrm{x}} \mathrm{Cl}_{1+2 \mathrm{x}}$ presented interesting properties such as redshift in absorption, bandgap of $1.5 \mathrm{eV}$ and improved stability ${ }^{66}$. Indium decreased the metallic conductivity of tin perovskite without changing its carrier density or bandgap, thus controlling resistivity ${ }^{70}$.

Doping of tin perovskites with bismuth has been reported to shift the bottom of the conduction band downwards without increasing the level of carriers ${ }^{68}$. Tin perovskites doped with alkali-earth metals have been studied ${ }^{33}$. Sr doping was shown to stabilize $\mathrm{Sn}$ (II) oxidation state by causing minimal distortion of the $\mathrm{SnI}_{6}$ octahedra. $\mathrm{Mg}$ doping increased the thermal stability of tin perovskites through $\mathrm{Mg}$-I bonds. Germanium doping presented as $\mathrm{FA}_{0.75} \mathrm{MA}_{0.25} \mathrm{Sn}_{1-\mathrm{x}} \mathrm{Ge}_{\mathrm{x}} \mathrm{I}_{3}$ was shown to reduce the probability of $\mathrm{Sn}$ (IV) doping through surface passivation. In this process, Ge fills the defects and vacancies on the surface ${ }^{67}$. Doping tin perovskites with $\mathrm{GeI}_{2}$ offers some protection against oxidation by forming a $\mathrm{GeO}_{4}$ protective layer ${ }^{131}$. Mn doping can improve phase stability by maintaining a higher level of Sn(II) ions and lower levels of $\mathrm{SnO}_{2}$ and tin vacancies ${ }^{69}$.

\section{Stability}

When perovskites are in contact with oxygen, $\mathrm{Sn}$ (II) oxidizes to $\mathrm{Sn}(\mathrm{IV})$, which changes the neutrality of the perovskite structure. According to Takahashi et al. ${ }^{32}$ when $\mathrm{Sn}$ (II) is oxidized, $\left(\mathrm{CH}_{3} \mathrm{NH}_{3}\right)_{1-2 \mathrm{x}} \mathrm{Sn}_{1-\mathrm{x}}{ }_{1-2} \mathrm{Sn}_{\mathrm{x}}^{4} \mathrm{I}_{3}$ or $\left(\mathrm{CH}_{3} \mathrm{NH}_{3}\right)$ $\mathrm{Sn}^{2}{ }_{1-\mathrm{x}} \mathrm{Sn}^{4}{ }_{\mathrm{x} / 2} \mathrm{I}_{3}$ variants are formed, causing the loss of methylammonium cations and/or $\mathrm{Sn}$ atoms. This process is known as self-doping, where the tin vacancies elevate the concentration of holes, reducing resistivity ${ }^{32}$. Noel et al. ${ }^{18}$ reported that oxidation tempers with the charge neutrality of the perovskite structure which is accompanied with tin oxides/ hydroxides and methylammonium iodide formation. It has been stipulated that decreasing the concentration of holes to $10^{15} / \mathrm{cm}^{3}$ could increase the diffusion length of $\mathrm{MASnI}_{3}$ from $30 \mathrm{~nm}$ to more than a micron comparable to lead perovskites ${ }^{18}$.
Several studies have reported the deterioration of crystalline structure, photoluminescence, optical properties and efficiency associated with oxidation ${ }^{18,174}$.

Some studies have shown that compounds with the same chemical structure as oxidized perovskites can present interesting properties. $\mathrm{Cs}_{2} \mathrm{SnI}_{6}$ and $\mathrm{MA}_{2} \mathrm{SnI}_{6}$ perovskites intentionally prepared with $\mathrm{Sn}(\mathrm{IV})$ have been developed as air stable alternatives. $\mathrm{Cs}_{2} \mathrm{SnI}_{6}$ has a significant absorption coefficient (over $10^{5} / \mathrm{cm}$ ) and a bandgap of $1.48 \mathrm{eV}^{44}$ while $\mathrm{MA}_{2} \mathrm{SnI}_{6}$ presents a bandgap of $1.81 \mathrm{eV}$ and absorption coefficient of $7 \times 10^{4} / \mathrm{cm}^{175}$, properties that make them suitable for solar applications. Thus, oxidized perovskites can be useful if the compound still has all its chemical constituents.

Leijtens et al. ${ }^{171}$ reported a possible oxidation mechanism of tin perovskites containing an additional cation (lead) based on thermogravimetric analysis and in-situ X-ray diffraction. During oxidation, some $\mathrm{SnI}_{2}$ bonds are broken to produce $\mathrm{SnI}_{4}$ and $\mathrm{SnO}_{2}$ (Equation 3). This route was considered energetically favorable for the loss of tin through $\mathrm{SnI}_{4}$ evaporation. For oxidation in the presence of lead, the process is energy intensive since all six $\mathrm{SnI}_{2}$ bonds must be broken. In this case, different by-products are formed such as $\mathrm{I}_{2}, \mathrm{SnO}_{2}$ and $\mathrm{PbI}_{2}$, thus $\mathrm{I}_{2}$ is sacrificed (Equation 4) ${ }^{171}$.

$$
\begin{aligned}
& 2 \mathrm{CH}_{3} \mathrm{NH}_{3} \mathrm{SnI}_{3}+\mathrm{O}_{2} \rightarrow \mathrm{SnO}_{2}+2\left(\mathrm{CH}_{3} \mathrm{NH}_{3} \mathrm{I}\right)+\mathrm{SnI}_{4} \\
& 2 \mathrm{CH}_{3} \mathrm{NH}_{3} \mathrm{Sn}_{0.5} \mathrm{~Pb}_{0.5} \mathrm{I}_{3}+\mathrm{O}_{2} \rightarrow \mathrm{SnO}_{2}+2\left(\mathrm{CH}_{3} \mathrm{NH}_{3} \mathrm{I}\right)+\mathrm{PbI}_{2}+\mathrm{I}_{2}
\end{aligned}
$$

$\mathrm{SnI}_{4}$ is detrimental to tin perovskites. Its role in the degradation of perovskites $(20 \%$ phenylethylammonium and $80 \%$ formamidinium as organic cations) was further clarified and a mechanism was proposed based on X-ray diffraction, spectroscopy and ab initio simulation techniques ${ }^{176}$. Figure 12 shows the degradation mechanism of tin perovskites under ambient conditions (relative humidity $=38$; temperature $=22.9^{\circ} \mathrm{C}$ ).

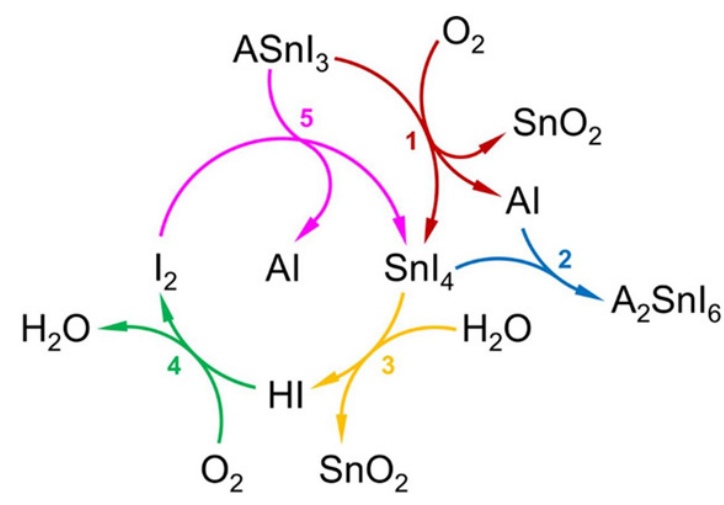

Figure 12. Cyclic degradation of tin perovskite upon air exposure. $\mathrm{A}=$ Organic cations $(20 \%$ phenylethylammonium and $80 \%$ formamidinium). Path 1: perovskite oxidation resulting in AI, $\mathrm{SnO}_{2}$ and $\mathrm{SnI}_{4}$ products; Path 2: $\mathrm{A}_{2} \mathrm{SnI}_{6}$ formation via $\mathrm{SnI}_{4}$ and AI, A =FA. Path 3: $\mathrm{SnI}_{4}$ hydrolysis with $\mathrm{SnO}_{2}$ and $\mathrm{HI}$ formation; Path 4: $\mathrm{HI}$ oxidation accompanied with $\mathrm{O}_{2}$ and $\mathrm{I}_{2}$ formation; Path 5: perovskite oxidation via $\mathrm{I}_{2}$, resulting in $\mathrm{SnI}_{4}$ and $\mathrm{AI}$ formation. Reproduced from Lanzetta et al. ${ }^{176}$. with permission from Springer Nature, copyright 2021. 
From Equation 5, the perovskite reacts with oxygen to produce $\mathrm{SnI}_{4}, \mathrm{SnO}_{2}$ and $\mathrm{AI}(\mathrm{A}=\text { organic cation })^{176}$.

$2 \mathrm{ASnI}_{3}+\mathrm{O}_{2} \rightarrow \mathrm{SnO}_{2}+2 \mathrm{AI}+\mathrm{SnI}_{4}$

Based on Equation 6, there is a reaction between $\mathrm{SnI}_{4}$ and $\mathrm{AI}(\mathrm{A}=$ organic cation $)$ to produce the $\mathrm{A}_{2} \mathrm{SnI}_{6}$, an oxidized variant $^{176}$.

$$
\mathrm{SnI}_{4}+2 \mathrm{AI} \rightarrow \mathrm{A}_{2} \mathrm{SnI}_{6}
$$

However, this process takes time, thus the coexistence of the products $\mathrm{SnI}_{4}, \mathrm{SnO}_{2}$ and $\mathrm{AI}(\mathrm{A}=$ organic cation) is more plausible ${ }^{176}$.

$\mathrm{SnI}_{4}$ can react with water to form $\mathrm{SnO}_{2}$ and $\mathrm{HI}\left(\right.$ Equation 7) ${ }^{176}$.

$\mathrm{SnI}_{4}+2 \mathrm{H}_{2} \mathrm{O} \rightarrow \mathrm{SnO}_{2}+4 \mathrm{HI}$

Then $\mathrm{HI}$ reacts with oxygen to form $\mathrm{I}_{2}$ and water (Equation 8$)^{176}$.

$$
4 \mathrm{HI}+\mathrm{O}_{2} \rightarrow 2 \mathrm{I}_{2}+2 \mathrm{H}_{2} \mathrm{O}
$$

Iodine can react with tin perovskite to form $\mathrm{SnI}_{4}$, which causes the cycle to repeat (Equation 9) ${ }^{176}$.

$2 \mathrm{ASnI}_{3}+\mathrm{I}_{2} \rightarrow \mathrm{SnI}_{4}+\mathrm{AI}$

A series of mechanisms have been proposed to capture $\mathrm{Sn}(\mathrm{IV})$ species based on anti-solvents such chlorobenzene, toluene and anisole ${ }^{177}$. First, $\mathrm{SnI}_{4}$ being non-polar can dissolve in non-polar solvents, thus be easily eliminated with annealing. Second, solvents such as DMF and DMSO with polar CO and SO bonds have a tendency to coordinate with $\mathrm{Sn}$ (IV) species $^{177}$. These complexes can be soluble in non-polar solvents such as toluene, and then removed by annealing. Third, non-polar aromatic solvents (benzene, toluene and xylene) form complexes with $\mathrm{SnI}_{4}$, where the former and latter are Lewis base and acid, respectively. The complexes can be eliminated by annealing ${ }^{177}$.

The sources of $\mathrm{Sn}$ (II) oxidation was investigated by ${ }^{118} \mathrm{Sn}-$ NMR based on the reaction between $\mathrm{Sn}$ (II) and DMSO. The content of $\mathrm{Sn}(\mathrm{IV})$ in precursors was not significant, unless exposed to air. In solution, the signal of $\mathrm{Sn}$ (IV) was absent in $\mathrm{SnI}_{2}$ or $\mathrm{FASnI}_{3}$ dissolved in DMF or DMSO. With annealing, $\mathrm{Sn}(\mathrm{IV})$ was found in DMSO solution containing $\mathrm{SnI}_{2}$ heated at $100{ }^{\circ} \mathrm{C}$ for $30 \mathrm{~min}$ compared to $80^{\circ} \mathrm{C}$, highlighting the role of temperature on its formation. Furthermore, heating of $\mathrm{FASnI}_{3}$ in DMF showed no $\mathrm{Sn}$ (IV) species compared to DMSO. Thus, DMSO can contribute to oxidation based on Equation 10:

$2 \mathrm{SnI}_{2}+2\left(\mathrm{CH}_{3}\right)_{2} \mathrm{SO} \rightarrow \mathrm{SnI}_{4}+\mathrm{SnO}_{2}+2\left(\mathrm{CH}_{3}\right) \mathrm{S}$

\section{Humidity}

Tin perovskites are susceptible to degradation mediated by water. Water contains hydrogen and oxygen, which can easily form bonds with the constituent elements of the perovskite, thereby reducing its stability. Hydrogen bonding can occur between $\mathrm{H}\left(\mathrm{H}_{2} \mathrm{O}\right)$, I (Sn octahedra) and $\mathrm{N}$ atoms (organic cation) $)^{174,178}$. These hydrogen bonds (H-I and $\mathrm{N}-\mathrm{H}$ ) act to reduce the strength of the Sn-I bonds, which in turn, facilitate the incorporation of oxygen into the lattice and depletion of organic components ${ }^{174,178,179}$. Thus, water molecules speed oxidation. Furthermore, the oxygen in water can form a bond with Sn, which contributes to the weakening of the Sn-I bonds ${ }^{174}$.

Organic cations or hybrid cations with strong hydrogen bonds, steric functions and hydrophobic effects can control the stability problems related to moisture. A hybrid 3,3-diphenylpropylammonium and formamidinium cation was employed for the production of tin perovskites ${ }^{180}$. The films presented improved water stability owing to the hydrophobic effects of 3,3-diphenylpropylammonium related to its two aromatic ring. Also, its size could block the penetration of water molecules at grain boundaries. The replacement of $20 \%$ of formamidinium with phenylethylammonium resulted in $2 \mathrm{D}$ tin perovskites with high stability against oxidation due to the encapsulating organic ligands which prevent the entrance of water and oxygen ${ }^{181}$.

Ethylene vinyl acetate (EVA), a polymer, presents encapsulating properties for combating the incorporation of water and oxygen. Under humidity of $60 \%$ and aging for $48 \mathrm{~h}$, the original efficiency in the presence of EVA was maintained at $62.4 \%{ }^{126}$.

With the aim of increasing stability against water, iodide ions have been partially replaced by pseudohalides such as thiocyanate $(\mathrm{SCN}-)^{75}$. Based on long-term ambient and accelerated stability tests and other characterizations, the incorporation of thiocyanate into $3 \mathrm{D} \mathrm{FASnI}_{(3-\mathrm{x})}(\mathrm{SCN})$ x perovskites confers hydrophobicity, moisture resistance, stronger interaction between $\mathrm{Sn}$ and $\mathrm{SCN}^{-}$and lower $\mathrm{Sn}$ (II) formation $^{75}$. The capsulated FASnI(SCN) $)_{2}$ maintained its performance for $2000 \mathrm{~h}$ in ambient conditions $(\mathrm{RH}=65 \%)$.

The large phenyl group of phenylhydrazine hydrochloride $(\mathrm{PHCl})$ can form a barrier against water and oxygen permeation $^{167}$. The unencapsulated device withstood 110 days in a glovebox with negligible reduction in efficiency. When exposed to air for 10 days, the efficiency dropped from $9.8 \%$ to $4.1 \%$. It was returned to the glovebox and irradiated, and the efficiency was recuperated. Density functional theory predicts graphene/MASnI ${ }_{3}$ heterojunction as effective for the blocking of humidity ${ }^{182}$. Bulky cations such as 4-(aminomethyl) piperidinium encapsulate perovskite grains, thus increasing stability against water, oxygen and illumination ${ }^{183}$. With this modification, an efficiency of $10.9 \%$ was reported and $77 \%$ of initial efficiency was maintained during $500 \mathrm{~h}$ illumination.

Based on density functional theory and non-adiabatic molecular dynamics simulations, the effect of water on $\mathrm{MASnI}_{3}$ was studied ${ }^{184}$. It was found that when $\mathrm{MASnI}_{3}$ is exposed to water, a monohydrate phase $\left(\mathrm{MASnI}_{3} \cdot \mathrm{H}_{2} \mathrm{O}\right)$ with increased lattice volume is stable $\mathrm{e}^{184}$.

Hydrogen from water creates bonds with both the organic (methylammonium) and inorganic (iodide ions) components of the perovskite. The hydrogen and oxygen atoms in water strongly bind with methylammonium, which affects stability because the same hydrogen bond is shared with iodide ions. The collective interactions with methylammonium, restrict the dynamic rotation of the same, with implications on recombination properties ${ }^{184}$.

Optical properties can be altered with water absorption. In the presence of water, there are modifications in the valence (decrease in energy) and conduction (subtle increase) bands. 
These changes can raise the bandgap. Also, the absorption coefficient was reported to decrease ${ }^{184}$.

\section{Photodegradation}

The components of the perovskite solar cell are prone to photodegradation. The perovskite can be damaged by radiation according to Equation $11^{185}$. The reaction was devised for lead perovskite but can be adopted for tin perovskites. The transport layer, $\mathrm{TiO}_{2}$, can oxidize iodide ions to iodine according to Equation $12^{185}$. Methylammonium ion can lose a proton producing methylamine gas (Equation $\left.13^{185}\right)$. Another possibility is the formation of $\mathrm{HI}$ according to Equation $14^{185}$.

$$
\begin{aligned}
& \mathrm{CH}_{3} \mathrm{NH}_{3} \mathrm{SnI}_{3} \stackrel{h v}{\leftrightarrow} \mathrm{CH}_{3} \mathrm{NH}_{2} \uparrow+\mathrm{SnI}_{2} \uparrow+H I \\
& 2 I^{-} \stackrel{h v}{\leftrightarrow} I_{2}+2 e^{-}
\end{aligned}
$$

$3 \mathrm{CH}_{3} \mathrm{NH}_{3}^{+} \stackrel{h v}{\leftrightarrow} 3 \mathrm{H}^{+}+3 \mathrm{CH}_{3} \mathrm{NH}_{2} \uparrow$

$I^{-}+I_{2}+3 H^{+}+2 e^{-\stackrel{h v}{\leftrightarrow}} 3 H I \uparrow$

A study investigated the behavior of different types of tin perovskites under light soaking conditions in a glovebox $(100 \pm 5 \mathrm{~mW} / \mathrm{cm})^{186}$. FASnI 3 phase presented traces of perovskite phase coupled with amorphous species at $1000 \mathrm{~h}$, indicating some stability. MASnI showed no diffraction peaks after $300 \mathrm{~h}$, suggesting total degradation through disintegration of methylammonium and photolysis. In $\mathrm{FASnBr}_{3}$ and $\mathrm{MASnBr}_{3}, \mathrm{SnBr}_{2}$ was detected, pointing to decomposition into the halide phase instead of direct photolysis. The $\mathrm{CsSnI}_{3}$ and $\mathrm{CsSnBr}_{3}$ outperformed their organic-inorganic halide perovskites in terms of light stability. Given that the only difference between the samples is the A cation, the light stability can be mainly attributed to the Cs cation although all the ions in the perovskite play a part.

\section{All-Inorganic CsSnI}

$\mathrm{CsSnI}_{3}$ has been applied as a hole transport material in solid dye sensitized solar cell due to its high hole mobility associated with self-doping ${ }^{42,43}$. In photovoltaics, self-doping increases defect density which is detrimental to efficiency, thus some strategies have been devised to reduce defect density and increase the stability of inorganic $\mathrm{CsSnI}_{3}$. Just like organic-inorganic perovskites, oxidation control is one of the means of ensuring the stability of these perovskites. In 2014, Kumar et al. ${ }^{154}$ synthesized $\mathrm{CsSnI}_{3}$ with $\mathrm{SnF}_{2}$ in order to control hole carrier density. The perovskite presented a high short circuit current density due to absorption in the infra-red region $\left(22.70 \mathrm{~mA} . \mathrm{cm}^{-2}\right)$ but the fill factor and open circuit voltage were low $(0.24 \mathrm{~V})$ leading to a mere efficiency of $2.02 \%$. It was observed from Hall measurements that $\mathrm{SnF}_{2}$ was able to lower the density of holes compared to the pristine sample.

In an attempt to improve the open circuit voltage of $\mathrm{CsSnI}_{3}, \mathrm{SnF}_{2}$ additives and $\mathrm{Br}$ doping were employed. Doping with electronegative ions such as $\mathrm{Br}$, can widen the bandgap of the perovskite ${ }^{187}$. This translates into changes in energy levels and a higher barrier for recombination. These properties combined with the presence of $\mathrm{SnF}_{2}$ induced hole reduction associated with a higher short circuit current density $\left(24.60 \mathrm{~mA} . \mathrm{cm}^{-2}\right)$, a reasonable open circuit $(0.22 \mathrm{~V})$ based on the era of the publication and an efficiency of $1.76 \%$.

The combination of excess $\mathrm{SnI}_{2}$ and reducing atmosphere has been reported to suppress hole density and conductivity through $\mathrm{Sn}$ compensation and suppressed oxidation ${ }^{152}$. The efficiency related to this approach was $4.81 \%$ with a high Jsc $\left(25.71 \mathrm{~mA} . \mathrm{cm}^{-2}\right)$ but fair Voc $(0.38 \mathrm{~V})$.

Some additives do not only reduce hole transport but also form a capping layer, this is the case of $\mathrm{SnCl}_{2}{ }^{153}$. The capping layer formed was sufficient to guarantee some form of stability which protected the perovskite and enhanced the open circuit voltage $(0.5 \mathrm{~V})$, fill factor $(68 \%)$ and efficiency $(3.56 \%)$.

A framework of amorphous triple layer halides with $\mathrm{CsFASnI}_{3}$ polycrystals was studied for stability and efficiency ${ }^{188}$. An efficiency of $10.4 \%$, Voc $(0.64 \mathrm{~V})$ and FF $(75.20 \%)$ were reported associated with better band alignment with the PCBM transport layer, reduced trap density, lower recombination and amorphous layer providing a shield against degradation conditions such as oxygen, humidity etc.

The application of $\mathrm{NiOx}$ as a hole transport material in large-grained $\mathrm{CsSnI}_{3}$ perovskites compared to Spiro-OMetad increased $\mathrm{Voc}(0.52 \mathrm{~V})$ and FF $(62.84 \%)^{146}$. The reason being that the p semiconductor's energy level is compatible for the transfer of holes.

Reducing the dimensionality of 3D inorganic perovskites to $0 \mathrm{D}$ and $1 \mathrm{D}$ perovskites has significant effects on the optoelectronic and emission properties of perovskites due to quantum effects and chemical stability associated with dimension. Quantum dots are nanocrystalline semiconductor crystals or particles in the $1 \mathrm{~nm}$ to $10 \mathrm{~nm}$ size range. In this range, quantum confinement effects are dominant, resulting in interesting properties such as size and shape-dependent optoelectronic properties (absorption and emission), fluorescence, high photoluminescence quantum yield, high surface area and tunable bandgaps. Thus, the use of quantum dots has many advantages.

$\mathrm{CsSnI}_{3}$ quantum rods were prepared by solvothermal synthesis and was applied in solar cells ${ }^{189}$. The Voc $(0.86 \mathrm{~V})$, FF $(65 \%)$, Jsc $\left(23.21 \mathrm{~mA} \cdot \mathrm{cm}^{-2}\right)$ and conversion efficiency $(12.96 \%)$ are among the highest for $\mathrm{CsSnI}_{3}$ perovskites. This was attributed to improved light absorption, lower trap density, good crystallinity and enhanced charge transfer. In 2019, $\mathrm{CsSnI}_{3}$ quantum dot solar cell presented an efficiency of $5.03 \%{ }^{133}$. Quantum dots provide intimate connection with the layers of the perovskite, thus improving charge transport. Also, the use of triphenyl phosphite antioxidant solvent during the synthesis provided a reducing which improved stability.

To improve the crystallinity and stability of $\mathrm{CsSnI}_{3}$, the same was doped with ethylenediammonium (en) additive ${ }^{60}$. The additive controls crystallization, increases bandgap and reduces trap density. The Cs cation does not fully occupy the A site, thus the incorporation of ethylenediammonium (en) can increase its stability. The efficiency due to the additive was $3.79 \%$ where a high Jsc $\left(25.07 \mathrm{~mA} . \mathrm{cm}^{-2}\right)$ was reported as well as a fair FF $(53.82 \%)$, indicating the quality of the films, good optical properties and reduced trap density. 
The chemical environment around the Sn atom can be modified with additives which have lone electrons on specific groups such as $\mathrm{NH}$ and $\mathrm{CO}$. Additives like Phthalimide and N,N'-methylenebis-(acrylamide) have this criterium, thus can coordinate with $\mathrm{Sn}^{2+}$ to reduce the loss of electrons. The reported efficiency following this method was $10.10 \%$ with a high fill factor $(72.10 \%)$, Jsc $\left(21.81 \mathrm{~mA} . \mathrm{cm}^{-2}\right)$ and $\operatorname{Voc}(0.64 \mathrm{~V})^{190}$. Clearly, the reduced trap density was responsible for the high FF and $\mathrm{Voc}^{190}$. Also, indene- $\mathrm{C}_{60}$ disadduct was utilized in the design of the perovskite for band alignment.
For N,N'-methylenebis-(acrylamide), the reported efficiency was $7.08 \%$, Voc $(0.45 \mathrm{~V})$, FF $(67 \%)$ and Jsc $\left(24.85 \mathrm{~mA} . \mathrm{cm}^{-2}\right)^{191}$. The strong coordination between the additive group electrons with $\mathrm{Sn}$, enhanced controlled crystallization with good coverage, lower defect density and consistent optical properties.

Table 3 contains information on the major papers covered in the present review: perovskite composition, cell architecture, bandgap, open circuit voltage, short circuit current density, fill factor, PCE, main approach, year of publication and reference.

Table 3. Information on perovskite composition, cell architecture, bandgap, open circuit voltage, short circuit current density fill factor, PCE, main approach, year of publication and reference.

\begin{tabular}{|c|c|c|c|c|c|c|c|c|}
\hline Perovskite & Device architecture & $\begin{array}{c}\text { Bandgap } \\
(\mathrm{eV})\end{array}$ & $\begin{array}{l}\text { Voc } \\
(\mathrm{V})\end{array}$ & $\begin{array}{c}\mathrm{Jsc}(\mathrm{mA} . \\
\left.\mathrm{cm}^{-2}\right)\end{array}$ & $\mathrm{FF}(\%)$ & $\begin{array}{l}\mathrm{PCE} \\
(\%)\end{array}$ & Main Approach & Yearef \\
\hline $\mathrm{FASnI}_{3}+\mathrm{PEABr}$ & $\begin{array}{c}\text { ITO/PEDOT:PSS/PVSK/ } \\
\text { indene- } \mathrm{C}_{60} \text { bisadduct /BCP/Ag }\end{array}$ & - & 0.91 & 20.60 & 77.10 & 14.63 & $\begin{array}{l}\text { One-step synthesis of } \mathrm{SnI}_{2} \text {. } \\
\text { DMSO complex }\end{array}$ & $2021^{20}$ \\
\hline $\mathrm{FASnI}_{3}+\mathrm{PEABr}$ & $\begin{array}{c}\text { ITO/PEDOT:PSS/PVSK/ } \\
\text { indene-C }{ }_{60} \text { bisadduct/BCP/Ag }\end{array}$ & - & 0.96 & 16.70 & 76.40 & 12.20 & $\begin{array}{c}\text { Two step synthesis of } \mathrm{SnI}_{2} \\
\text { DMSO complex and removal } \\
\text { of } \mathrm{Sn}^{4+} \text { impurity }\end{array}$ & $2021^{20}$ \\
\hline $\mathrm{FA}_{0.75} \mathrm{MA}_{0.25} \mathrm{SnI}_{3}$ & $\begin{array}{c}\text { ITO/PEDOT:PSS/PVSK/C } 60 \\
\text { BCP/Ag }\end{array}$ & 1.37 & 0.63 & 21.62 & 75.50 & 10.30 & Vacuum treatment & $2021^{141}$ \\
\hline $\mathrm{CsSnI}_{3}$ & $\begin{array}{c}\text { ITO/PEDOT:PSS/PVSK/ } \\
\text { indene- } \mathrm{C}_{60} \text { disadduct/BCP/Ag }\end{array}$ & 1.31 & 0.64 & 21.81 & 72.10 & 10.10 & $\begin{array}{c}\text { Localized electron engineering } \\
\text { via phthalimide additive and } \\
\text { indene- } \mathrm{C}_{60} \text { disadduct for band } \\
\text { alignment }\end{array}$ & $2021^{190}$ \\
\hline $\mathrm{FA}_{0.75} \mathrm{MA}_{0.25} \mathrm{SnI}_{3}$ & $\begin{array}{c}\text { ITO/PEDOT:PSS/PVSK/C } 60 / \\
\text { BCP/Ag }\end{array}$ & 1.31 & 0.58 & 21.93 & 72.81 & 9.26 & $\begin{array}{c}\text { Hydrazine dihydrochloride } \\
\text { additive }\end{array}$ & $2021^{165}$ \\
\hline $\mathrm{FASnI}_{3}$ & $\begin{array}{c}\text { ITO/PEDOT:PSS/PSVK/C } 60 / \\
\text { BCP/Ag }\end{array}$ & 1.40 & 0.53 & 21.80 & 65.80 & 7.53 & Polyethylene glycol scafford & $2021^{125}$ \\
\hline $\mathrm{CsSnI}_{3}$ & 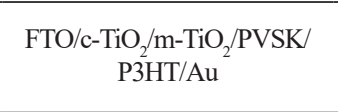 & 1.30 & 0.45 & 24.85 & 67.00 & 7.50 & $\begin{array}{c}\text { N,N'-methylenebis(acrylamide) } \\
\text { (MBAA) additive and P3HT } \\
\text { transport material }\end{array}$ & $2021^{191}$ \\
\hline $\mathrm{CsSnI}_{3}$ & 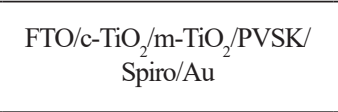 & 1.30 & 0.45 & 22.07 & 71.00 & 7.06 & $\begin{array}{c}\text { N,N'-methylenebis(acrylamide) } \\
\text { (MBAA) additive and Spiro- } \\
\text { OMeTAD }\end{array}$ & $2021^{191}$ \\
\hline $\mathrm{FA}_{0.75} \mathrm{MA}_{0.25} \mathrm{SnI}_{2} \mathrm{Br}$ & $\begin{array}{c}\text { ITO/PEDOT:PSS/PVSK/ } \\
\mathrm{PC}_{61} \mathrm{BM} / \mathrm{BPhen} / \mathrm{Ag} \\
\end{array}$ & - & 0.56 & 16.66 & 65.00 & 6.02 & Catechin antioxidant/dopant & $2021^{168}$ \\
\hline $\begin{array}{c}\mathrm{GeI}_{2} \text { doped } \\
\left(\mathrm{FA}_{0.90} \mathrm{EA}_{0.1}\right)_{0.98} \mathrm{EDA}_{0.01} \mathrm{SnI}_{3}\end{array}$ & $\begin{array}{c}\text { FTO/PEDOT:PSS/PVSK/C } 60 \\
\text { BCP/Ag/Au }\end{array}$ & 1.42 & 0.84 & 20.32 & 78.00 & 13.24 & $\begin{array}{c}\text { EDA surface } \\
\text { passivation,bandgap alignment } \\
\text { via EA doping and } \mathrm{GeO}_{4} \\
\text { protective layer }\end{array}$ & $2020^{131}$ \\
\hline $\mathrm{PEA}_{\mathrm{x}} \mathrm{FA}_{1-\mathrm{x}} \mathrm{SnI}_{3}$ & $\begin{array}{c}\text { ITO/PEDOT:PSS/PVSK/ } \\
\text { indene-C }{ }_{60} \text { disadduct/BCP/Ag }\end{array}$ & 1.39 & 0.94 & 17.40 & 75.00 & 12.40 & $\begin{array}{c}\mathrm{NH}_{4} \mathrm{SCN} \text { additive, } \\
\mathrm{PEA}(15 \%) / \mathrm{FA} \text { combination } \\
\text { and indene- } \mathrm{C}_{60} \text { disadduct } \\
\text { electron transport material }\end{array}$ & $2020^{100}$ \\
\hline $\mathrm{FA}_{0.75} \mathrm{MA}_{0.25} \mathrm{SnI}_{3}$ & $\begin{array}{c}\text { ITO/PEDOT: PSS/PVSK/C } 60 / \\
\text { BCP/Ag }\end{array}$ & 1.36 & 0.76 & 22.00 & 69.00 & 11.50 & $\begin{array}{c}\text { Sn nanoparticle in precursor } \\
\text { solution, surface treatment } \\
\text { with EDA and } \mathrm{PC}_{61} \mathrm{BM}\end{array}$ & $2020^{155}$ \\
\hline $\mathrm{FASnI}_{3}$ & $\begin{array}{c}\text { ITO/PEDOT:PSS/PVSK/C } 60 \\
\text { BCP/Ag }\end{array}$ & 1.40 & 0.76 & 23.50 & 64.00 & 11.40 & $\begin{array}{c}\text { Phenylhydrazine } \\
\text { hydrochloride additive, } \mathrm{SnF}_{2} \\
\text { additive }\end{array}$ & $2020^{167}$ \\
\hline
\end{tabular}

PEA=phenylethylamonium, ITO=indium tin oxide, PEDOT:PSS=poly(3,4-ethylenedioxythiophene):polystyrene sulfonate, PVSK=perovskite, $\mathrm{C}_{60}=$ puckminsterfullerene, $\mathrm{BCP}=$ bathocuproine, $\mathrm{c}-\mathrm{TiO}_{2}=$ compact $\mathrm{TiO}_{2}, \mathrm{~m}-\mathrm{TiO}_{2}=$ mesoporous $\mathrm{TiO}_{2} \mathrm{P} 3 \mathrm{HT}=$ poly $\left(3\right.$-hexylthiophene, $\mathrm{PC} \mathrm{C}_{61} \mathrm{BM}=[6,6]-\mathrm{Phenyl}$ $\mathrm{C}_{61}{ }_{61}$ butyric acid methyl ester, $\mathrm{BPhen}=$ bathophenanthroline, $\mathrm{EA}=$ ethylammonium, $\mathrm{EDA}=$ ethylenediamine, $\mathrm{PCBM}=[6,6]-\mathrm{Phenyl} \mathrm{C}_{61}$ butyric acid methyl ester, $\mathrm{PC}_{60} \mathrm{BM}=[6,6]-$ Phenyl $\mathrm{C}_{61}$ butyric acid methyl ester, PTAA=poly(triaryl amine), $\{$ en $\}=$ ethylenediammonium, BDT-4D=tetra-4,4'-dimethoxy triphenylamine-substituted benzodithiophene, $\mathrm{m}-\mathrm{MTDATA}=4,4^{\prime}, 4^{\prime \prime}$-tris $(\mathrm{N}, \mathrm{N}$-phenyl-3-methylamino) triphenylamine, $\mathrm{PTN}-\mathrm{Br}=$ poly[tetraphenylethene 3,3'-(((2,2-diphenylethene-1,1-diyl)bis(4,1-phenylene))bis(oxy))-bis(N,N-dimethylpropan-1-amine)tetraphenylethene, FTO=Fluorine doped tin oxide, PEI= Polyethylenimine, TPE $=$ tetrakis-triphenylamine, $\mathrm{CPTA}=\mathrm{C}_{60}$ Pyrrolidine tris-acid, TPD=Poly $(\mathrm{N}, \mathrm{N}$ '-bis-4-butylphenyl-N,N'-bisphenyl)benzidine, TBAI= Tetrabutylammonium iodide, TPFB=tetrakis(pentafluorophenyl)borate, $\mathrm{tBP}=$ tertbutylpyridine and $\mathrm{TFSI}=$ bis(trifluoromethanesulfonyl)imide. 
Table 3. Continued...

\begin{tabular}{|c|c|c|c|c|c|c|c|c|}
\hline Perovskite & Device architecture & $\begin{array}{c}\text { Bandgap } \\
(\mathrm{eV})\end{array}$ & $\begin{array}{l}\text { Voc } \\
\text { (V) }\end{array}$ & $\begin{array}{c}\text { Jsc (mA. } \\
\left.\mathrm{cm}^{-2}\right)\end{array}$ & $\mathrm{FF}(\%)$ & $\begin{array}{l}\text { PCE } \\
(\%)\end{array}$ & Main Approach & Year ${ }^{\text {ref }}$ \\
\hline $\mathrm{FASnI}_{3}$ & $\begin{array}{c}\text { ITO/PEDOT:PSS/PSVK } / \mathrm{C}_{60} / \\
\text { BCP/Ag }\end{array}$ & - & 0.70 & 19.59 & 73.30 & 11.22 & $\begin{array}{l}n \text {-propylammonium iodide } \\
\text { film }\end{array}$ & $2020^{128}$ \\
\hline $\mathrm{FASnI}_{3}$ & $\begin{array}{c}\mathrm{FTO} / \mathrm{Cu}-\mathrm{NiO}_{x} / \mathrm{PVSK} / \mathrm{PCBM} / \\
\mathrm{BCP} / \mathrm{Ag}\end{array}$ & 1.43 & 0.69 & 21.15 & 74.00 & 10.90 & $\begin{array}{l}\text { 4-(aminomethyl)piperidinium } \\
\text { (4AMP) additive }\end{array}$ & $2020^{183}$ \\
\hline $\mathrm{FASnI}_{3}$ & $\begin{array}{c}\text { ITO/PEDOT:PSS/PSVK } / \mathrm{C}_{60} \\
\text { BCP/Ag }\end{array}$ & - & 0.67 & 21.59 & 75.00 & 10.81 & $\begin{array}{c}\text { Pentafluorophen- } \\
\text { oxyethylammonium iodide } \\
\text { additive }\end{array}$ & $2020^{127}$ \\
\hline $\mathrm{CsFASnI}_{3}$ & $\begin{array}{c}\text { FTO/PEDOT:PSS/PSVK/ } \\
\text { PCBM/BCP/Ag }\end{array}$ & 1.39 & 0.64 & 21.60 & 75.20 & 10.40 & $\begin{array}{l}\text { Triple (I, } \mathrm{Cl} \text { and } \mathrm{I} \text { ) halide } \\
\text { amorphous system and } \\
\text { CsFASnI }_{3} \text { polycrystals }\end{array}$ & $2020^{188}$ \\
\hline $\mathrm{FASnI}_{3}$ & $\begin{array}{c}\text { ITO/PEDOT:PSS/PSVK } / \mathrm{C}_{60} / \\
\text { BCP/Ag }\end{array}$ & 1.41 & 0.69 & 21.53 & 68.46 & 10.17 & $\begin{array}{l}\text { 2-fluoro-phenethylammonium } \\
\text { iodide }\end{array}$ & $2020^{123}$ \\
\hline $\mathrm{GeI}_{2}$ doped $\mathrm{FA}_{0.98} \mathrm{EDA}_{0.01} \mathrm{SnI}_{3}$ & $\begin{array}{c}\text { FTO/PEDOT:PSS/PVSK/C } 60 / \\
\text { BCP/Ag/Au }\end{array}$ & 1.39 & 0.54 & 23.15 & 72.00 & 9.03 & $\begin{array}{l}\mathrm{GeI}_{2} \text { doping }\left(\mathrm{GeO}_{4} \text { protective }\right. \\
\text { layer }) \text { and } \mathrm{EDA} \text { doping }\end{array}$ & $2020^{131}$ \\
\hline $\mathrm{FASnI}_{3}$ & $\begin{array}{c}\text { ITO/PEDOT:PSS/PSVK/C } 60 \\
\text { BCP/Ag }\end{array}$ & - & 0.60 & 19.75 & 69.10 & 8.13 & $\begin{array}{l}\text { Phenylethylammonium } \\
\text { iodide additive }\end{array}$ & $2020^{127}$ \\
\hline $\mathrm{MASnI}_{3}$ & $\begin{array}{l}\text { ITO/PEDOT:PSS/MASnI// } \\
\quad \mathrm{PC}_{61} \mathrm{BM} / \mathrm{BCP} / \mathrm{Ag}\end{array}$ & - & 0.57 & 20.68 & 66.00 & 7.78 & $\begin{array}{c}\text { Perovskite synthesis by ion } \\
\text { exchange reaction between } \\
\mathrm{SnF}_{2} \text { and } \mathrm{CH}_{3} \mathrm{NH}_{3} \mathrm{I} \text { Reaction } \\
\text { time }\end{array}$ & $2020^{108}$ \\
\hline $\mathrm{FASnI}_{3}$ & $\begin{array}{c}\text { ITO/PEDOT:PSS/PSVK } / \mathrm{C}_{60} / \\
\text { BCP/Ag }\end{array}$ & - & 0.52 & 22.80 & 64.69 & 7.72 & $\begin{array}{c}\text { Poly(ethylene-co-vinyl acetate } \\
\text { additive }\end{array}$ & $2020^{126}$ \\
\hline $\mathrm{FASnI}_{3}$ & $\begin{array}{c}\text { ITO/PEDOT:PSS/PSVK } / \mathrm{C}_{60} / \\
\text { BCP/Ag }\end{array}$ & - & 0.54 & 19.41 & 66.40 & 6.93 & Anti-solvent dripping & $2020^{127}$ \\
\hline $\mathrm{FASnI}_{3}$ & $\begin{array}{c}\text { ITO/PEDOT: PSS/PVSK/C } 60 / \\
\text { BCP/Ag }\end{array}$ & - & 0.53 & 17.37 & 73.47 & 6.80 & $\begin{array}{c}\text { Ethylenediammonium } \\
\text { dihypophosphite additive } \\
\text { and co-solvent (hexafluoro- } \\
\text { 2-propanol (HFP), } \\
\text { isopropyl alcohol (IPA), and } \\
\text { chlorobenzene) }\end{array}$ & $2020^{137}$ \\
\hline $\mathrm{DPPA}_{0.02} \mathrm{FA}_{0.98} \mathrm{SnI}_{3}$ & $\begin{array}{c}\text { ITO/PEDOT:PSS/PVSK/C } 60^{\prime} \\
\text { BCP/Ag }\end{array}$ & - & 0.48 & 21.73 & 65.34 & 6.75 & $\begin{array}{l}\text { 3,3-diphenylpropylammonium } \\
\text { (DPPA) doping }\end{array}$ & $2020^{180}$ \\
\hline $\begin{array}{c}(\mathrm{CsGA})_{0.15} \mathrm{FA}_{0.70} \mathrm{SnI}_{3} \text { with } \\
1.5 \% \mathrm{EDAI}_{2}\end{array}$ & $\begin{array}{c}\text { ITO/PEDOT:PSS/PVSK/ } \\
\mathrm{PC}_{60} \mathrm{BM} / \mathrm{BCP} / \mathrm{Ag}\end{array}$ & - & 0.36 & 21.16 & 75.00 & 5.69 & $\begin{array}{l}\text { Cs, GA, FA combination and } \\
\mathrm{EDAI}_{2} \text { additive }\end{array}$ & $2020^{169}$ \\
\hline $\mathrm{FASnI}_{3}$ & $\mathrm{ITO} / \mathrm{Nb}_{2} \mathrm{O}_{5} / \mathrm{PVSK} / \mathrm{PTAA} / \mathrm{Au}$ & - & 0.42 & 22.80 & 52.00 & 5.10 & $\mathrm{Nb}_{2} \mathrm{O}_{5}$ transport electron layer & $2020^{91}$ \\
\hline $\begin{array}{c}\mathrm{PEA}_{0.1} \mathrm{FA}_{0.9} \mathrm{SnI}(\mathrm{SCN})_{2}+5 \% \\
\mathrm{EDAI}_{2}\end{array}$ & $\begin{array}{c}\mathrm{ITO} / \mathrm{c}-\mathrm{TiO}_{2} / \mathrm{m}-\mathrm{TiO}_{2} / \mathrm{Al}_{2} \mathrm{O}_{3} / \\
\mathrm{NiO} / \mathrm{PVSK} / \text { Carbon }\end{array}$ & - & 0.33 & 20.17 & 57.40 & 3.70 & $\begin{array}{c}\text { PEAI }(10 \%) \text { doping, } \text { EDAI }_{2} \\
(5 \%) \text { additive and Thiocynate } \\
\left(\mathrm{SCN}^{-}\right) \text {doping }\end{array}$ & $2020^{75}$ \\
\hline $\mathrm{FASnI}(\mathrm{SCN})_{2}$ & $\begin{array}{c}\mathrm{ITO} / \mathrm{c}-\mathrm{TiO} / \mathrm{m}-\mathrm{TiO}_{2} / \mathrm{Al}_{2} \mathrm{O}_{3} / \\
\text { PVSK/Carbon }\end{array}$ & 1.38 & 0.27 & 16.04 & 54.9 & 2.40 & Thiocynate (SCN-) doping & $2020^{75}$ \\
\hline $\mathrm{Cs}_{0.05}\left(\mathrm{FA}_{0.83} \mathrm{MA}_{0.17}\right)_{0.95} \mathrm{~Pb}_{05} \mathrm{Sn}_{053} \mathrm{I}$ & $\begin{array}{c}\text { ITO/PEDOT:PSS/PVSK/ } \\
\mathrm{PC}_{60} \mathrm{BM} / \mathrm{Al} \text { doped } \mathrm{Zn} / \mathrm{BCP} / \mathrm{Ag}\end{array}$ & 1.27 & 0.62 & 27.59 & 61.00 & 11.60 & $\begin{array}{c}\text { Toluene antisolvent and } \\
\text { thermal treatment }\end{array}$ & $2019^{177}$ \\
\hline $\mathrm{FASnI}_{3}$ & $\begin{array}{c}\text { ITO/PEDOT:PSS/PSVK/C } 60 \\
\text { BCP/Ag }\end{array}$ & 1.37 & 0.63 & 20.37 & 69.30 & 8.92 & Poly(vinyl alcohol) additive & $2019^{124}$ \\
\hline $\mathrm{FA}_{0.98} \mathrm{EDA}_{0.01} \mathrm{SnI}_{3}$ & $\begin{array}{c}\text { FTO/PEDOT:PSS/PVSK/C } 6{ }_{60} \\
\text { BCP/Ag/Au }\end{array}$ & 1.38 & 0.49 & 24.08 & 75.00 & 8.90 & 1,2-diaminoethane passivation & $2019^{130}$ \\
\hline $\mathrm{GA}_{\mathrm{x}} \mathrm{FA}_{1-\mathrm{x}-2 \mathrm{y}} \mathrm{SnI}_{3-\mathrm{y}} \mathrm{EDAI}_{2}$ & $\begin{array}{c}\text { ITO/PEDOT:PSS/PVSK/C } 60 \\
\text { BCP/Ag }\end{array}$ & 1.50 & 0.56 & 20.80 & 72.60 & 8.50 & $\begin{array}{l}\text { GA/FA combination and } \\
\text { EDAI }_{2} \text { additive }\end{array}$ & $2019^{192}$ \\
\hline $\mathrm{FASnI}_{3}$ & $\begin{array}{c}\text { ITO/PEDOT:PSS/PVSK/ } \\
\text { PCBM/BCP/Ag }\end{array}$ & - & 0.54 & 22.12 & 71.00 & 8.48 & $\begin{array}{c}\text { Trihydrazine } \\
\text { dihydriodide additive }\end{array}$ & $2019^{166}$ \\
\hline
\end{tabular}

PEA=phenylethylamonium, ITO=indium tin oxide, PEDOT:PSS=poly (3,4-ethylenedioxythiophene):polystyrene sulfonate, PVSK=perovskite, $\mathrm{C}_{60}=$ puckminsterfullerene, $\mathrm{BCP}=$ bathocuproine, $\mathrm{c}-\mathrm{TiO}_{2}=$ compact $\mathrm{TiO}_{2}, \mathrm{~m}-\mathrm{TiO}_{2}=$ mesoporous $\mathrm{TiO}_{2}, \mathrm{P} 3 \mathrm{HT}=$ poly $\left(3\right.$-hexylthiophene, $\mathrm{PC} 6 \mathrm{C}_{6} \mathrm{BM}=[6,6]-\mathrm{Phenyl}$ $\mathrm{C}_{61}$ butyric acid methyl ester, $\mathrm{BPhen}=$ bathophenanthroline, $\mathrm{EA}=$ ethylammonium, $\mathrm{EDA}=$ ethylenediamine, $\mathrm{PCBM}=[6,6]-\mathrm{Phenyl} \mathrm{C}_{61}$ butyric acid methyl ester, $\mathrm{PC}_{60} \mathrm{BM}=[6,6]$-Phenyl $\mathrm{C}_{61}$ butyric acid methyl ester, PTAA=poly(triaryl amine), \{en $\}=$ ethylenediammonium, BDT-4D=tetra-4,4'-dimethoxy triphenylamine-substituted benzodithiophene, m-MTDATA =4, 4', 4"-tris(N,N-phenyl-3-methylamino) triphenylamine, $\mathrm{PTN}$ - $\mathrm{Br}=$ poly[tetraphenylethene 3,3'-(((2,2-diphenylethene-1,1-diyl)bis(4,1-phenylene))bis(oxy))-bis(N,N-dimethylpropan-1-amine)tetraphenylethene, FTO=Fluorine doped tin oxide, $\mathrm{PEI}=$ Polyethylenimine, $\mathrm{TPE}=$ tetrakis-triphenylamine, $\mathrm{CPTA}=\mathrm{C}_{60}$ Pyrrolidine tris-acid, TPD=Poly $(\mathrm{N}, \mathrm{N}$ '-bis-4-butylphenyl-N,N'-bisphenyl)benzidine, $\mathrm{TBAI}=$ Tetrabutylammonium iodide, TPFB=tetrakis(pentafluorophenyl)borate, $\mathrm{tBP}=$ tertbutylpyridine and $\mathrm{TFSI}=\mathrm{bis}$ (trifluoromethanesulfonyl)imide. 
Table 3. Continued..

\begin{tabular}{|c|c|c|c|c|c|c|c|c|}
\hline Perovskite & Device architecture & $\begin{array}{c}\text { Bandgap } \\
(\mathrm{eV})\end{array}$ & $\begin{array}{l}\text { Voc } \\
\text { (V) }\end{array}$ & $\begin{array}{c}\mathrm{Jsc}(\mathrm{mA} . \\
\left.\mathrm{cm}^{-2}\right)\end{array}$ & $\mathrm{FF}(\%)$ & $\begin{array}{l}\text { PCE } \\
(\%)\end{array}$ & Main Approach & Yearef \\
\hline$\{\mathrm{en}\} \mathrm{FASnI}_{3}$ & $\begin{array}{c}\mathrm{FTO} / \mathrm{c}-\mathrm{TiO}_{2} / \mathrm{m}^{-\mathrm{TiO}_{2}} / \mathrm{PVSK} / \\
\mathrm{BDT}-4 \mathrm{D} / \mathrm{Au}\end{array}$ & - & 0.50 & 22.41 & 68.21 & 7.59 & $\begin{array}{l}\text { Tetra- 4,4'-dimethoxy } \\
\text { triphenylamine-substituted } \\
\text { benzodithiophene hole } \\
\text { transport material }\end{array}$ & $2019^{90}$ \\
\hline$\{\mathrm{en}\} \mathrm{FASnI}_{3}$ & $\begin{array}{c}\mathrm{FTO} / \mathrm{SnO}_{2}-\mathrm{CPTA} / \mathrm{PVSK} / \\
\text { PTAA } / \mathrm{Au}\end{array}$ & - & 0.69 & 16.45 & 65.00 & 7.40 & $\begin{array}{c}\mathrm{SnO}_{2}-\mathrm{C}_{60} \text { pyrrolidine tris-acid } \\
\text { electron transport layer }\end{array}$ & $2019^{93}$ \\
\hline $\mathrm{FASnI}_{3}$ & $\begin{array}{c}\text { ITO/PEDOT:PSS/PVSK/PTN- } \\
{\mathrm{Br} / \mathrm{C}_{60} / \mathrm{BCP} / \mathrm{Ag}}\end{array}$ & 1.35 & 0.57 & 20.66 & 67.40 & 7.38 & $\begin{array}{c}\text { PTN-Br/perovskite } \\
\text { heterojunction, Band } \\
\text { alignment and passivation }\end{array}$ & $2019^{97}$ \\
\hline $\mathrm{MASnI}_{3}$ & $\begin{array}{c}\mathrm{FTO} / \mathrm{c}-\mathrm{TiO}_{2} / \mathrm{m}_{-}-\mathrm{TiO}_{2} / \mathrm{MASnI}_{3} / \\
\mathrm{PTAA} / \mathrm{Au}\end{array}$ & - & 0.49 & 22.91 & 64.00 & 7.12 & $\begin{array}{l}\mathrm{NH}_{2} \mathrm{NH}_{3} \mathrm{SnI}_{3} \text { derived } \\
\text { perovskite and two step } \\
\text { method }\end{array}$ & $2019^{163}$ \\
\hline $\mathrm{FASnI}_{3}$ & $\begin{array}{c}\text { ITO/PEDOT: } \mathrm{PSS} / \mathrm{PVSK} / \mathrm{C}_{60} / \\
\text { BCP/PEI/Ag }\end{array}$ & - & 0.53 & 19.59 & 61.00 & 6.33 & $\begin{array}{l}\text { Post-deposition vapor } \\
\text { annealing with } \mathrm{MACl}_{2}\end{array}$ & $2019^{139}$ \\
\hline $\mathrm{CsSnI}_{3}$ & $\begin{array}{c}\text { ITO/PEDOT:PSS/PVSK/ } \\
\text { PCBM/Ag }\end{array}$ & - & - & - & - & 5.03 & $\begin{array}{l}\text { Quantum dots and triphenyl } \\
\text { phosphite antioxidant solvent }\end{array}$ & $2019^{133}$ \\
\hline $\mathrm{FA}_{0.75} \mathrm{MA}_{0.25} \mathrm{SnI}_{3}$ & $\mathrm{FTO} / \mathrm{c}-\mathrm{TiO}_{2} / \mathrm{PVSK} / \mathrm{PTAA} / \mathrm{Au}$ & 1.33 & 0.26 & 17.40 & 42.00 & 1.85 & Gas pump treatment & $2019^{122}$ \\
\hline $\mathrm{FA}_{0.75} \mathrm{MA}_{0.25} \mathrm{SnI}_{3}$ & $\begin{array}{c}\text { ITO/PEDOT:PSS/PSVK/C } 6{ }^{\prime} \\
\mathrm{BCP} / \mathrm{Al}\end{array}$ & 1.31 & 0.55 & 24.30 & 67.30 & 9.06 & $\begin{array}{l}\text { Chlorobenzene antisolvent } \\
\text { dripping plus } \mathrm{SnF}_{2}\end{array}$ & $2018^{111}$ \\
\hline $\mathrm{FASnI}_{3}$ & $\begin{array}{c}\text { ITO/PEDOT:PSS/PSVK/C } 60 \text { / } \\
\text { BCP/Ag }\end{array}$ & 1.43 & 0.58 & 21.30 & 71.80 & 8.90 & $\begin{array}{l}\text { Ethylenediammonium } \\
\text { diiodide additive }\end{array}$ & $2018^{129}$ \\
\hline $\mathrm{FA}_{0.75} \mathrm{MA}_{0.25} \mathrm{SnI}_{3}$ & $\begin{array}{c}\text { ITO/PEDOT:PSS/ PSVK/C } 6{ }_{60}^{\prime} \\
\mathrm{BCP} / \mathrm{Al}\end{array}$ & 1.31 & 0.52 & 22.70 & 62.70 & 7.52 & $\begin{array}{l}\text { Toluene antisolvent dripping } \\
\text { plus } \mathrm{SnF}_{2}\end{array}$ & $2018^{111}$ \\
\hline$(\mathrm{PEA}, \mathrm{FA}) \mathrm{SnI}_{3}$ & $\begin{array}{c}\text { ITO/LiF/PEDOT:PSS/PVSK/ } \\
\mathrm{C}_{60} / \mathrm{BCP} / \mathrm{Ag} \\
\end{array}$ & 1.37 & 0.47 & 20.07 & 74.00 & 6.98 & $\begin{array}{c}\mathrm{LiF} \text { layer and 2D-3D } \\
\text { heterojunction }\end{array}$ & $2018^{98}$ \\
\hline $\mathrm{FASnI}_{3}$ & $\begin{array}{c}\text { ITO/PEDOT:PSS/PVSK/C } 60 \\
\text { BCP/Ag }\end{array}$ & - & 0.58 & 17.50 & 66.30 & 6.75 & $\begin{array}{l}\text { Purification of tin precursor } \\
\text { using } \mathrm{Sn} \text { metal and } \mathrm{SnF}_{2} \\
\text { additive }\end{array}$ & $2018^{159}$ \\
\hline $\mathrm{FA}_{0.75} \mathrm{MA}_{0.25} \mathrm{SnI}_{3}$ & $\begin{array}{c}\text { ITO/PEDOT:PSS/PSVK } / \mathrm{C}_{60} / \\
\mathrm{BCP} / \mathrm{Al}\end{array}$ & 1.31 & 0.49 & 23.70 & 55.30 & 6.39 & $\begin{array}{c}\text { Diethyl ether antisolvent } \\
\text { dripping plus } \mathrm{SnF}_{2}\end{array}$ & $2018^{111}$ \\
\hline $\mathrm{Cs}_{x} \mathrm{FA}_{1-x} \mathrm{SnI}_{3}$ & $\begin{array}{l}\text { ITO/PEDOT: } \mathrm{PSS} / \mathrm{PVSK} / \mathrm{C}_{60}{ }^{\prime} \\
\mathrm{BCP} / \mathrm{Ag}\end{array}$ & - & 0.44 & 20.70 & 66.70 & 6.08 & Cs doping & $2018^{62}$ \\
\hline $\mathrm{FASnI}_{3}$ & $\begin{array}{l}\text { ITO/PEDOT: PSS/PVSK/ } \\
\text { PCBM/PEI/Al }\end{array}$ & - & 0.54 & 17.03 & 66.00 & 6.03 & $\begin{array}{c}\mathrm{Pb}(\mathrm{SCN})_{2} \text { additive and } \\
\text { vacuum-assisted annealing }\end{array}$ & $2018^{140}$ \\
\hline $\mathrm{FASnI}_{3}$ & $\begin{array}{c}\text { ITO/PEDOT:PSS/PSVK/C } 60 / \\
\text { BCP/Ag }\end{array}$ & 1.43 & 0.44 & 18.00 & 69.40 & 5.50 & $\begin{array}{l}\text { n-Butylammonium iodide } \\
\text { additive }\end{array}$ & $2018^{129}$ \\
\hline $\mathrm{FASnI}_{3}$ & $\begin{array}{c}\text { ITO/PEDOT:PSS/PVSK/ } \\
\text { PCBM/BCP/Ag } \\
\end{array}$ & - & 0.46 & 17.64 & 67.00 & 5.40 & $\begin{array}{l}\text { Hydrazinium chloride additive } \\
\text { and } \mathrm{SnF}_{2}\end{array}$ & $2018^{164}$ \\
\hline $\mathrm{MASnCI}_{3}$ & $\mathrm{FTO} / \mathrm{c}-\mathrm{TiO}_{2} / \mathrm{PVSK} / \mathrm{CuSCN} / \mathrm{Ag}$ & 1.30 & 0.58 & 12.89 & 55.00 & 3.41 & Annealing temperature & $2018^{74}$ \\
\hline $\mathrm{FA}_{0.75} \mathrm{MA}_{0.25} \mathrm{SnI}_{3}$ & $\begin{array}{l}\text { ITO/PEDOT:PSS/PVSK/ } \\
\mathrm{PCBM} / \mathrm{C}_{60} / \mathrm{BCP} / \mathrm{Ag} / \mathrm{Au}\end{array}$ & 1.40 & 0.46 & 17.61 & 41.00 & 3.31 & MA/FA balance & $2018^{67}$ \\
\hline $\mathrm{MA}_{0.5} \mathrm{FA}_{0.5} \mathrm{~Pb}_{0.5} \mathrm{Sn}_{0.5} \mathrm{I}_{3}$ & $\begin{array}{c}\text { ITO/PEDOT:PSS/PVSK/ } \\
\text { PCBM/bis- }{ }_{60} / \mathrm{Ag} \\
\end{array}$ & 1.24 & 0.78 & 25.69 & 70.00 & 14.01 & Ascorbic acid additive & $2017^{160}$ \\
\hline $\mathrm{FA}_{0.75} \mathrm{MA}_{0.25} \mathrm{SnI}_{3}$ & $\begin{array}{c}\text { ITO/PEDOT:PSS/PVSK/ } \\
\mathrm{PCBM} / \mathrm{C}_{60} / \mathrm{BCP} / \\
\mathrm{Ag}\end{array}$ & 1.33 & 0.61 & 21.20 & 62.7 & 8.12 & $\begin{array}{l}\text { Relation between MA and FA } \\
\text { cation }\end{array}$ & $2017^{57}$ \\
\hline$\{\mathrm{en}\} \mathrm{FASnI}_{3}$ & $\begin{array}{c}\mathrm{FTO} / \mathrm{c}-\mathrm{TiO}_{2} / \mathrm{m}-\mathrm{TiO}_{2} / \mathrm{PVSK} / \\
\mathrm{TPE} / \mathrm{Au}\end{array}$ & - & 0.46 & 22.54 & 69.70 & 7.23 & $\begin{array}{l}\text { Tetrakis-triphenylamine hole } \\
\text { transport material }\end{array}$ & $2017^{85}$ \\
\hline$\{\mathrm{en}\} \mathrm{FASnI}_{3}$ & $\begin{array}{c}\mathrm{FTO} / \mathrm{c}-\mathrm{TiO}_{2} / \mathrm{m}^{-\mathrm{TiO}_{2}} / \mathrm{PVSK} / \\
\mathrm{PTAA} / \mathrm{Au}\end{array}$ & 1.50 & 0.48 & 22.54 & 65.96 & 7.14 & $\begin{array}{l}\text { Ethylenediammonium } \\
\text { incorporation }\end{array}$ & $2017^{61}$ \\
\hline
\end{tabular}

PEA=phenylethylamonium, ITO=indium tin oxide, PEDOT:PSS=poly(3,4-ethylenedioxythiophene):polystyrene sulfonate, PVSK=perovskite, $\mathrm{C}_{60}=$ puckminsterfullerene, $\mathrm{BCP}=$ bathocuproine, $\mathrm{c}-\mathrm{TiO}_{2}=$ compact $\mathrm{TiO}_{2}, \mathrm{~m}-\mathrm{TiO}_{2}=$ mesoporous $\mathrm{TiO}_{2} \mathrm{P} 3 \mathrm{HT}=$ poly $\left(3\right.$-hexylthiophene, $\mathrm{PC}{ }_{61} \mathrm{BM}=[6,6]-\mathrm{Phenyl}$ $\mathrm{C}_{61}^{60}$ butyric acid methyl ester, $\mathrm{BPhen}=$ bathophenanthroline, $\mathrm{EA}=$ ethylammonium, $\mathrm{EDA}=$ ethylenediamine, $\mathrm{PCBM}=[6,6]-\mathrm{Phenyl} \mathrm{C}_{61}$ butyric acid methyl ester, $\mathrm{PC}_{60} \mathrm{BM}=[6,6]$-Phenyl $\mathrm{C}_{61}$ butyric acid methyl ester, PTAA=poly(triaryl amine), \{en $\}=$ =thylenediammonium, BDT-4D=tetra-4,4'-dimethoxy triphenylamine-substituted benzodithiophene, m-MTDATA =4, 4', 4"-tris(N,N-phenyl-3-methylamino) triphenylamine, PTN-Br= poly[tetraphenylethene 3,3'-(((2,2-diphenylethene-1,1-diyl)bis(4,1-phenylene))bis(oxy))-bis(N,N-dimethylpropan-1-amine)tetraphenylethene, FTO=Fluorine doped tin oxide, $\mathrm{PEI}=$ Polyethylenimine, TPE $=$ tetrakis-triphenylamine, $\mathrm{CPTA}=\mathrm{C}_{60}$ Pyrrolidine tris-acid, TPD=Poly(N,N'-bis-4-butylphenyl-N,N'-bisphenyl)benzidine, TBAI= Tetrabutylammonium iodide, TPFB=tetrakis(pentafluorophenyl)borate, tBP=tertbutylpyridine and TFSI=bis(trifluoromethanesulfonyl)imide. 
Table 3. Continued...

\begin{tabular}{|c|c|c|c|c|c|c|c|c|}
\hline Perovskite & Device architecture & $\begin{array}{l}\text { Bandgap } \\
(\mathrm{eV})\end{array}$ & $\begin{array}{l}\text { Voc } \\
(\mathrm{V})\end{array}$ & $\begin{array}{c}\text { Jsc (mA. } \\
\left.\mathrm{cm}^{-2}\right)\end{array}$ & $\mathrm{FF}(\%)$ & $\begin{array}{l}\text { PCE } \\
(\%)\end{array}$ & Main Approach & Yearef \\
\hline $\mathrm{FASnI}_{3}$ & $\begin{array}{c}\text { ITO/PEDOT:PSS)/PVSK/C } 60: 1 \\
\text { wt } \% / \mathrm{TBAI} / \mathrm{Ag}\end{array}$ & 1.40 & 0.47 & 22.45 & 67.80 & 7.09 & $\begin{array}{l}\text { Trimethylamine complex, } \\
\mathrm{SnF}_{2} \text { additive, sequential } \\
\text { deposition and inverted } \\
\text { architecture }\end{array}$ & $2017^{136}$ \\
\hline$\{\mathrm{en}\} \mathrm{MASnI}_{3}$ & $\begin{array}{c}\mathrm{FTO} / \mathrm{c}-\mathrm{TiO}_{2} / \mathrm{m}^{-\mathrm{TiO}_{2}} / \mathrm{PVSK} / \\
\mathrm{PTAA} / \mathrm{Au}\end{array}$ & 1.40 & 0.43 & 24.28 & 63.72 & 6.63 & $\begin{array}{l}\text { Ethylenediammonium } \\
\text { incorporation }\end{array}$ & $2017^{60}$ \\
\hline $\mathrm{FASnI}_{3}$ & $\begin{array}{c}\text { ITO/PEDOT:PSS/PVSK/ } \\
\text { PCBM/C }{ }_{60} / \mathrm{BCP} / \mathrm{Ag}\end{array}$ & 1.36 & 0.48 & 21.3 & 64.60 & 6.60 & FAcation & $2017^{57}$ \\
\hline$(\mathrm{PEA})_{2}(\mathrm{FA})_{8} \mathrm{Sn}_{9} \mathrm{I}_{28}$ & $\mathrm{ITO} / \mathrm{NiO}_{\mathrm{x}} / \mathrm{PVSK} / \mathrm{PCBM} / \mathrm{Al}$ & - & 0.59 & 14.44 & 69.00 & 5.94 & $\begin{array}{l}\text { Phenylethylammonium } \\
\text { doping to form 2D layers }\end{array}$ & $2017^{181}$ \\
\hline $\mathrm{CsSnI}_{3}$ & $\begin{array}{l}\mathrm{FTO} / \mathrm{c}-\mathrm{TiO}_{2} / \mathrm{m}^{-\mathrm{TiO}_{2}} / \mathrm{PVSK} / \\
\text { PTAA doped with TPFB/Au }\end{array}$ & - & 0.38 & 25.71 & 49.05 & 4.81 & $\begin{array}{c}\mathrm{CsI} / \mathrm{SnI}_{2} \text { ratio, reducing } \\
\text { atmosphere and excess } \mathrm{SnI}_{2}\end{array}$ & $2017^{152}$ \\
\hline $\mathrm{FASnI}_{3}$ & $\mathrm{ITO} / \mathrm{SnO}_{2} / \mathrm{C}_{60} / \mathrm{PVSK} /$ Spiro $/ \mathrm{Ag}$ & 1.40 & 0.31 & 21.65 & 64.70 & 4.34 & $\begin{array}{l}\text { Trimethylamine complex, } \\
\mathrm{SnF}_{2} \text { additive and sequential } \\
\text { deposition }\end{array}$ & $2017^{136}$ \\
\hline $\mathrm{MASnI}_{3}$ & $\begin{array}{c}\text { ITO/PEDOT:PSS/PVSK/ } \\
\text { PCBM/C } 60 \text { BCP/Ag }\end{array}$ & 1.26 & 0.46 & 21.4 & 42.70 & 4.29 & MA cation & $2017^{57}$ \\
\hline $\mathrm{MASnI}_{3}$ & $\begin{array}{c}\mathrm{FTO} / \mathrm{c}-\mathrm{TiO}_{2} / \mathrm{m}-\mathrm{TiO}_{2} / \mathrm{PVSK} / / \\
\mathrm{PTAA} / \mathrm{Au}\end{array}$ & 1.30 & 0.37 & 19.92 & 51.73 & 3.89 & $\begin{array}{l}\text { Reducing hydrazine } \\
\text { atmosphere }\end{array}$ & $2017^{161}$ \\
\hline$\{\mathrm{en}\} \mathrm{CsSnI}_{3}$ & $\begin{array}{c}\mathrm{FTO} / \mathrm{c}-\mathrm{TiO}_{2} / \mathrm{m}^{-\mathrm{TiO}_{2}} / \mathrm{PVSK} / \\
\mathrm{PTAA} / \mathrm{Au}\end{array}$ & - & 0.28 & 25.07 & 53.82 & 3.79 & $\begin{array}{l}\text { Ethylenediammonium } \\
\text { incorporation }\end{array}$ & $2017^{60}$ \\
\hline $\mathrm{MASnIBr}_{2}$ & 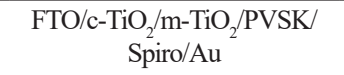 & - & 0.45 & 13.77 & 59.58 & 3.70 & $\mathrm{SnF}_{2}$ additive & $2017^{119}$ \\
\hline $\mathrm{MASnBr}_{0.5} \mathrm{I}_{2.5}$ & $\begin{array}{c}\mathrm{FTO} / \mathrm{c}-\mathrm{TiO}_{2} / \mathrm{m}^{-\mathrm{TiO}_{2}} / \mathrm{PVSK} / \\
\text { Spiro/Au }\end{array}$ & 1.40 & 0.18 & 15.44 & 38.00 & 1.05 & $\begin{array}{l}\text { Br doping and } \mathrm{MeOH} / \\
\text { Dioxane solution }\end{array}$ & $2017^{116}$ \\
\hline $\mathrm{FA}_{0.75} \mathrm{Cs}_{0.25} \mathrm{Sn}_{0.5} \mathrm{~Pb}_{0.5} \mathrm{I}_{3}$ & $\begin{array}{c}\text { ITO/PEDOT:PSS/PVSK/C } 60 / \\
\text { BCP/Ag }\end{array}$ & 1.20 & 0.74 & 26.70 & 71.00 & 14.10 & Sn doping and Cs doping & $2016^{173}$ \\
\hline $\mathrm{MASn}_{0.5} \mathrm{~Pb}_{0.5} \mathrm{I}_{3}$ & $\begin{array}{c}\text { ITO/PEDOT:PSS/PVSK/C } 60 / \\
\text { BCP/Ag }\end{array}$ & 1.18 & 0.75 & 26.30 & 68.80 & 13.60 & $\begin{array}{l}\mathrm{Sn} / \mathrm{Pb} \text { mixture and } \mathrm{Pb} \text { two step } \\
\text { method }\end{array}$ & $2016^{172}$ \\
\hline $\mathrm{CsSnI}_{3}$ & $\mathrm{ITO} / \mathrm{TiO}_{2} / \mathrm{PVSK} / \mathrm{Spiro} / \mathrm{Au}$ & - & 0.86 & 23.21 & 65.00 & 12.96 & Quantum rods & $2016^{189}$ \\
\hline $\mathrm{FASnI}_{3}$ & $\begin{array}{c}\text { ITO/PEDOT:PSS/PVSK/C } 60 \\
\text { BCP/Ag }\end{array}$ & 1.40 & 0.47 & 22.07 & 60.67 & 6.22 & $\begin{array}{c}\text { Inverted cell architecture, } \\
\mathrm{SnF}_{2} \text { additive and solvent } \\
\text { engineering }\end{array}$ & $2016^{49}$ \\
\hline $\mathrm{FASnI}_{3}$ & $\begin{array}{c}\mathrm{FTO} / \mathrm{c}-\mathrm{TiO}_{2} / \mathrm{m}-\mathrm{TiO}_{2} / \mathrm{ZnS}-/ \\
\text { PVSK/PTAA/Au }\end{array}$ & 1.40 & 0.38 & 23.09 & 60.01 & 5.27 & $\begin{array}{c}\mathrm{TiO}_{2}-\mathrm{ZnS} \text { electron transport } \\
\text { material }\end{array}$ & $2016^{96}$ \\
\hline $\mathrm{FASnI}_{3}$ & $\begin{array}{c}\mathrm{FTO} / \mathrm{c}-\mathrm{TiO}_{2} / \mathrm{m}_{2}-\mathrm{TiO}_{2} / \mathrm{PVSK} / \\
\text { Spiro/Au }\end{array}$ & 1.40 & 0.32 & 23.70 & 63.00 & 4.80 & $\mathrm{SnF}_{2}$-pyrazine complex & $2016^{109}$ \\
\hline $\mathrm{CsSnI}_{3}$ & ITO/PVSK/PC ${ }_{61} \mathrm{BM} / \mathrm{BCP} / \mathrm{Al}$ & - & 0.50 & 9.89 & 68.00 & 3.56 & $\begin{array}{c}\mathrm{SnCl}_{2} \text { additive and no electron } \\
\text { transport layer }\end{array}$ & $2016^{153}$ \\
\hline $\mathrm{CsSnI}_{3}$ & $\mathrm{ITO} / \mathrm{NiO}_{\mathrm{x}} / \mathrm{PVSK} / \mathrm{PCBM} / \mathrm{Al}$ & 1.30 & 0.52 & 10.21 & 62.50 & 3.31 & $\begin{array}{c}\text { NiOx hole transport material } \\
\text { and controlled grain } \\
\text { coarsening }\end{array}$ & $2016^{146}$ \\
\hline $\mathrm{MASnI}_{3}$ & $\begin{array}{c}\mathrm{FTO} / \mathrm{c}-\mathrm{TiO} / \mathrm{m}-\mathrm{TiO}_{2} / \mathrm{PVSK} / \\
\mathrm{PTAA} / \mathrm{Au}\end{array}$ & 1.26 & 0.27 & 17.80 & 39.00 & 1.86 & $\begin{array}{l}\text { Temperature controlled } \\
\text { reaction of } \mathrm{SnI}_{2} \text { film with MAI } \\
\text { gas and use of 2,6-lutidine } \\
\text { instead of tBP. }\end{array}$ & $2016^{48}$ \\
\hline $\mathrm{MASnI}_{3}$ & $\begin{array}{c}\text { ITO/PEDOT:PSS/Poly-TPD/ } \\
\text { PVSK/C } 60 \text { BCP/Ag }\end{array}$ & 1.30 & 0.38 & 12.10 & 36.60 & 1.70 & Co-evaporation of precursors & $2016^{99}$ \\
\hline $\mathrm{CsSnI}_{3}$ & $\mathrm{FTO} / \mathrm{c}-\mathrm{TiO}_{2} / \mathrm{PVSK} / \mathrm{Spiro} / \mathrm{Au}$ & 1.30 & 0.48 & 8.11 & 19.80 & 0.77 & Undoped Spiro-OMeTAD & $2016^{146}$ \\
\hline
\end{tabular}

PEA=phenylethylamonium, ITO=indium tin oxide, PEDOT:PSS=poly(3,4-ethylenedioxythiophene):polystyrene sulfonate, PVSK=perovskite, $\mathrm{C}_{60}=$ puckminsterfullerene, $\mathrm{BCP}=$ bathocuproine, $\mathrm{c}-\mathrm{TiO}_{2}=$ compact $\mathrm{TiO}_{2}, \mathrm{~m}-\mathrm{TiO}_{2}=$ mesoporous $\mathrm{TiO}_{2} \mathrm{P} 3 \mathrm{HT}=$ poly $\left(3\right.$-hexylthiophene, $\mathrm{PC} \mathrm{C}_{61} \mathrm{BM}=[6,6]-\mathrm{Phenyl}$ $\mathrm{C}_{61}$ butyric acid methyl ester, $\mathrm{BPhen}=$ bathophenanthroline, $\mathrm{EA}=$ ethylammonium, $\mathrm{EDA}=$ ethylenediamine, $\mathrm{PCBM}=[6,6]-\mathrm{Phenyl} \mathrm{C}_{61}$ butyric acid methyl ester, $\mathrm{PC}_{60} \mathrm{BM}=[6,6]$-Phenyl $\mathrm{C}_{61}$ butyric acid methyl ester, PTAA=poly(triaryl amine), \{en $\}=$ ethylenediammonium, BDT-4D=tetra-4,4'-dimethoxy triphenylamine-substituted benzodithiophene, m-MTDATA $=4,4^{\prime}, 4^{\prime \prime}$-tris(N,N-phenyl-3-methylamino) triphenylamine, $\mathrm{PTN}-\mathrm{Br}=$ poly[tetraphenylethene 3,3'-(((2,2-diphenylethene-1,1-diyl)bis(4,1-phenylene))bis(oxy))-bis(N,N-dimethylpropan-1-amine)tetraphenylethene, FTO=Fluorine doped tin oxide, $\mathrm{PEI}=$ Polyethylenimine, TPE $=$ tetrakis-triphenylamine, $\mathrm{CPTA}=\mathrm{C}_{60}$ Pyrrolidine tris-acid, TPD=Poly $\left(\mathrm{N}, \mathrm{N}^{\prime}\right.$-bis-4-butylphenyl-N,N'-bisphenyl)benzidine, $\mathrm{TBAI}=$ Tetrabutylammonium iodide, $\mathrm{TPFB}=$ tetrakis(pentafluorophenyl)borate, $\mathrm{tBP}=$ tertbutylpyridine and TFSI=bis(trifluoromethanesulfonyl)imide 
Table 3. Continued...

\begin{tabular}{|c|c|c|c|c|c|c|c|c|}
\hline Perovskite & Device architecture & $\begin{array}{c}\text { Bandgap } \\
(\mathrm{eV})\end{array}$ & $\begin{array}{l}\text { Voc } \\
(\mathrm{V})\end{array}$ & $\begin{array}{c}\mathrm{Jsc}(\mathrm{mA} . \\
\left.\mathrm{cm}^{-2}\right)\end{array}$ & $\mathrm{FF}(\%)$ & $\begin{array}{l}\mathrm{PCE} \\
(\%)\end{array}$ & Main Approach & Yearef \\
\hline $\mathrm{MASnI}_{3}$ & $\mathrm{FTO} / \mathrm{c}-\mathrm{TiO}_{2} / \mathrm{PVSK} / \mathrm{PTAA} / \mathrm{Au}$ & 1.30 & 0.23 & 3.32 & 40.70 & 0.31 & One step method and $\mathrm{SnF}_{2}$ & $2016^{86}$ \\
\hline $\mathrm{MASnI}_{3}$ & $\mathrm{FTO} / \mathrm{c}-\mathrm{TiO}_{2} / \mathrm{m}^{-\mathrm{TiO}_{2}} / \mathrm{PVSK} / \mathrm{Au}$ & 1.30 & 0.32 & 21.40 & 46.00 & 3.15 & $\begin{array}{c}\mathrm{DMSO}_{\text {and }} \mathrm{SnF}_{2} \text {-mediated } \\
\text { crystallization and no Spiro- } \\
\text { OMeTAD }\end{array}$ & $2015^{110}$ \\
\hline $\mathrm{FASnI}_{3}$ & $\begin{array}{c}\mathrm{FTO} / \mathrm{c}-\mathrm{TiO}_{2} / \mathrm{m}^{-\mathrm{TiO}_{2}} / \mathrm{PVSK} / \\
\text { Spiro/Au }\end{array}$ & 1.41 & 0.24 & 24.45 & 36.00 & 2.10 & $\begin{array}{c}\text { Stable A cation choice,tin } \\
\text { compensator }\left(20 \% \mathrm{SnF}_{2}\right) \text { and } \\
500 \mathrm{~nm} \mathrm{TiO}_{2}\end{array}$ & $2015^{47}$ \\
\hline $\mathrm{CsSnI}_{2.9} \mathrm{Br}_{0.1}$ & $\begin{array}{c}\mathrm{FTO} / \mathrm{c}-\mathrm{TiO}_{2} / \mathrm{m}^{-\mathrm{TiO}_{2}} / \mathrm{PVSK} / \\
\text { Spiro/Au }\end{array}$ & - & 0.22 & 24.16 & 33.00 & 1.76 & $\begin{array}{l}\text { Br doping and use of } \mathrm{SnF}_{2} \\
\text { additive }\end{array}$ & $2015^{187}$ \\
\hline $\mathrm{MASnBr}_{3}$ & $\mathrm{FTO} / \mathrm{c}-\mathrm{TiO}_{2} / \mathrm{PVSK} / \mathrm{P} 3 \mathrm{HT} / \mathrm{Au}$ & 2.20 & 0.50 & 4.27 & 49.10 & 1.12 & $\begin{array}{l}\text { Sequential evaporation, } \mathrm{P} 3 \mathrm{HT} \\
\text { electron transport material and } \\
\text { annealing at } 1500^{\circ} \mathrm{C} \text {. }\end{array}$ & $2015^{87}$ \\
\hline $\mathrm{MASn}_{0.15} \mathrm{~Pb}_{0.85} \mathrm{X}$ & $\begin{array}{l}\text { ITO/PEDOT:PSS/PVSK/ } \\
\text { PCBM/C } 60 \text {-bis/Ag }\end{array}$ & - & 0.76 & 19.10 & 66.00 & 10.10 & $\mathrm{Sn} / \mathrm{Pb}$ mixture & $2014^{170}$ \\
\hline $\mathrm{MASn}_{0.5} \mathrm{~Pb}_{0.5} \mathrm{I}_{3}$ & 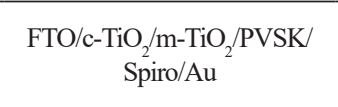 & 1.17 & 0.58 & 20.64 & 60.32 & 7.20 & $\begin{array}{l}\text { Mixed metal cations, bandgap } \\
\text { engineering and } \mathrm{HI} / \mathrm{H}_{3} \mathrm{PO}_{4} \\
\text { solvent }\end{array}$ & $2014^{83}$ \\
\hline $\mathrm{MASnI}_{3}$ & 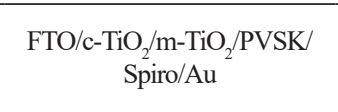 & 1.23 & 0.88 & 16.80 & 42.00 & 6.40 & $\begin{array}{c}400 \mathrm{~nm} \mathrm{~m}-\mathrm{TiO}_{2} \text {, device } \\
\text { encapsulation and replacement } \\
\text { of Li-TFSI with H-TFSI }\end{array}$ & $2014^{18}$ \\
\hline $\mathrm{MASnIBr}_{2}$ & 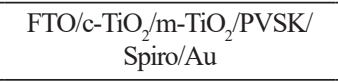 & 1.75 & 0.82 & 12.30 & 57.00 & 5.73 & Br doping & $2014^{19}$ \\
\hline $\mathrm{MASnI}_{3}$ & $\begin{array}{c}\mathrm{FTO} / \mathrm{c}-\mathrm{TiO}_{2} / \mathrm{m}^{-\mathrm{TiO}_{2}} / \mathrm{PVSK} / \\
\text { Spiro/Au }\end{array}$ & 1.30 & 0.72 & 15.18 & 50.07 & 5.44 & $\begin{array}{c}\text { 2,6-lutidine andHI/ } / \mathrm{H}_{3} \mathrm{PO}_{4} \\
\text { solvent }\end{array}$ & $2014^{83}$ \\
\hline $\mathrm{MASnI}_{3}$ & 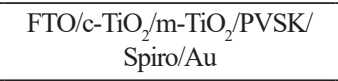 & 1.30 & 0.68 & 16.30 & 48.00 & 5.23 & $\begin{array}{c}\text { Solid state perovskite and } 350 \\
\text { nm thick } \mathrm{TiO}_{2} \text { film }\end{array}$ & $2014^{19}$ \\
\hline $\mathrm{MASn}_{0.5} \mathrm{~Pb}_{0.5} \mathrm{I}_{3}$ & $\begin{array}{c}\mathrm{FTO} / \mathrm{c}-\mathrm{TiO}_{2} / \mathrm{m}^{-\mathrm{TiO}_{2}} / \mathrm{PVSK} / \\
\mathrm{P} 3 \mathrm{HT} / \mathrm{Au} / \mathrm{Ag}\end{array}$ & 1.18 & 0.42 & 20.04 & 50.00 & 4.18 & $\begin{array}{c}\text { Hydrazine atmosphere, } \mathrm{Pb} / \mathrm{Sn} \\
\text { ratio and } \mathrm{P} 3 \mathrm{HT}\end{array}$ & $2014^{151}$ \\
\hline $\mathrm{CsSnI}_{3}$ & $\begin{array}{c}\mathrm{FTO} / \mathrm{c}-\mathrm{TiO}_{2} / \mathrm{m}^{-} \mathrm{TiO}_{2} / \mathrm{PVSK} / \\
\mathrm{m}-\mathrm{MTDATA} / \mathrm{Au}\end{array}$ & 1.30 & 0.24 & 22.70 & 37.00 & 2.02 & $\begin{array}{c}\mathrm{SnF}_{2} \text { additive and 4, 4', } \\
\text { 4"-tris(N,N-phenyl-3- } \\
\text { methylamino) triphenylamine }\end{array}$ & $2014^{154}$ \\
\hline
\end{tabular}

PEA=phenylethylamonium, ITO=indium tin oxide, PEDOT:PSS=poly(3,4-ethylenedioxythiophene):polystyrene sulfonate, PVSK=perovskite,

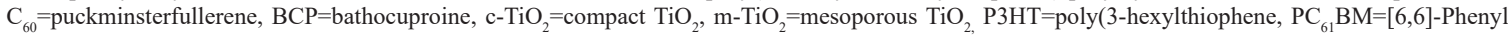
$\mathrm{C}_{61}$ butyric acid methyl ester, BPhen=bathophenanthroline, EA=ethylammonium, EDA=ethylenediamine, $\mathrm{PCBM}=[6,6]-\mathrm{Phenyl} \mathrm{C}_{61}$ butyric acid methyl ester, $\mathrm{PC}_{60} \mathrm{BM}=[6,6]$-Phenyl $\mathrm{C}_{61}$ butyric acid methyl ester, PTAA=poly(triaryl amine), $\{$ en $\}=$ ethylenediammonium, BDT-4D=tetra-4,4'-dimethoxy triphenylamine-substituted benzodithiophene, m-MTDATA $=4,4^{\prime}, 4^{\prime \prime}$-tris(N,N-phenyl-3-methylamino) triphenylamine, PTN-Br= poly $[$ tetraphenylethene 3,3'-(((2,2-diphenylethene-1,1-diyl)bis(4,1-phenylene))bis(oxy))-bis(N,N-dimethylpropan-1-amine)tetraphenylethene, FTO=Fluorine doped tin oxide, PEI= Polyethylenimine, TPE $=$ tetrakis-triphenylamine, $\mathrm{CPTA}=\mathrm{C}_{60}$ Pyrrolidine tris-acid, TPD=Poly(N,N'-bis-4-butylphenyl-N,N'-bisphenyl)benzidine, TBAI= Tetrabutylammonium iodide, $\mathrm{TPFB}=$ tetrakis(pentafluorophenyl)borate, $\mathrm{tBP}=$ tertbutylpyridine and $\mathrm{TFSI}=$ bis(trifluoromethanesulfonyl)imide.

\section{Research Gaps}

From the review, some research gaps were identified. For 1D and $0 \mathrm{D}$ nanostructures, more studies can explore their application in solar cells as complete solar absorbers, dopants ${ }^{193}$, composites and heterostructures. Questions regarding defect tolerance, stability, recombination, carrier transport and optoelectronic properties of 1D and 0D tin perovskites in solar cells are open. Capped quantum dots can be explored in conditions where moisture or oxidation is a challenge, especially for applications such as solar cells, electrochemical applications, water splitting, solar fuels etc. There is limited information about plasmonic tin perovskite solar cells and their possible applications, challenges and mechanisms.

In the area of synthesis, solvothermal and hydrothermal synthesis of perovskites are hardly used. The factors controlling these methods and the properties of such perovskites are limited. Can these methods produce perovskites with lower defect density for direct use or dissolution for films? Electrochemical deposition of perovskite films can be a means of producing perovskite films for alternative applications. There is still the need for air stable options for perovskite synthesis.

B site doping of perovskites can be further explored as regards stability. Can other $\mathrm{BX}_{2}$ additives besides tin be useful for stability? Can these additives form beneficial capping against oxidation without reducing efficiency and optoelectronic properties? What is the effect of halide compensation on stability?

\section{Applications Beyond Solar Cells}

Tin perovskites can find application in many sectors besides solar cells. 2D and 3D tin perovskites can be coupled with other semiconductors for water splitting. Initial test with Phenylehtyammonium $\left(\mathrm{PEA}_{2} \mathrm{SnBr}_{4}\right)$ and dimethylammonium ( $\mathrm{DMASnBr}_{3}$ )-based tin perovskite with $\mathrm{g}-\mathrm{C}_{3} \mathrm{~N}_{4}$ presented hydrogen evolution rates of $925 \mu$ moles $\mathrm{g}^{-1} \cdot \mathrm{h}^{-1}$ and $190 \mu \mathrm{mole}^{194}$ in saccharides aqueous 
solution. $\mathrm{PEA}_{2} \mathrm{SnBr}_{4} / \mathrm{g}-\mathrm{C}_{3} \mathrm{~N}_{4}$ produced $1600 \mu \mathrm{mol} \mathrm{g}{ }^{-1} \cdot \mathrm{h}^{-1}$ in triethanolamine aqueous solution ${ }^{195}$.

The optical properties of 1D and OD perovskites should be explored. The area of sensors is emergent in tin perovskites. $\mathrm{NO}_{2}$ gas was successfully detected by $\mathrm{Ag} / \mathrm{MASnI}_{3} / \mathrm{SnO}_{2}$ architecture with a low detection limit of $55 \mathrm{ppb}^{196}$. FASnI $3 / \mathrm{SnO}_{2} / \mathrm{Pt}$ detected formaldehyde gas with a low detection limit of $65 \mathrm{ppb}^{197}$.

$\mathrm{MASnI}_{3}, \mathrm{FASnI}_{3}$ and $\mathrm{MASnBr}_{3}$ have been used as piezoelectric generators for self-powered and wearable technologies ${ }^{198-200}$. $\mathrm{CsSnX}_{3}$ and $\mathrm{MASnI}_{3}$ due to their infra-red absorption have potential applications in light-emitting diodes ${ }^{201,202}$. Photocatalytic degradation of substances mediated by perovskites can be explored.

\section{Summary}

The review highlights tin perovskites as promising lead-free alternatives. However, they face challenges in terms of stability, efficiency, poor film morphology and reproducibility, which hinder commercialization prospects. On the other hand, intense research and the application of computational methods are underway to improve these properties. Furthermore, novel degradation mechanisms of tin perovskites provide insights into the process and opens up possibilities to tackle the problem.

So far, the level of $\mathrm{Sn}$ (II) in the perovskite phase can be sustained by controlling oxidation via tin compensators, reducing agents and additives. Although a variety of them have been presented, there is room for more alternatives. Doping and bandgap tuning with $\mathrm{A}, \mathrm{B}$ and $\mathrm{X}$ ions, do not only modify optical properties but also confer stability. The perovskite structure can accommodate different ions as dopants, thus this avenue with metal cations can be explored more. In relation to film morphology, the reaction kinetics of tin perovskites can be engineered for the consistent production of full coverage, pinhole-free and large grained films. In fact, morphology and oxidation management play a major role in reproducibility, thus they go hand-in-hand.

The solar cell design is another factor that contributes to high efficiency. The positions of the valence band maximum and conduction band minimum of tin perovskites demand the judicious selection of non-conventional electron and hole transport materials with minimal offsets for improved efficiency.

In general, the recent developments in tin perovskites open up opportunities for advancement in the field. There is the need for protocols and standardized methods for the assessment of oxidation. This will allow easy comparison of results and reproducibility. The properties of tin perovskite can be employed in other applications such as light emitting diodes, photodetectors, radiation detectors and sensors among others.

\section{Acknowledgments}

The authors are grateful to the Ministry of Science, Technology, and Innovation (SisNANO Program - National System of Laboratories in Nanotechnology); the National Council for Scientific and Technological Development (CNPq, Brazil China Virtual Center in Nanotechnology Project and grant \#141704/2015-2), CAPES-Embrapa Program, Sao Paulo Research Foundation (FAPESP\#18/01258-5), and Embrapa Rede AgroNano for their financial support. This study was financed in part by the Coordenação de Aperfeiçoamento de Pessoal de Nível Superior - Brasil (CAPES) - Finance Code 001. Caue Ribeiro also acknowledges Alexander von Humboldt Foundation by Experienced Research Fellowship (CAPES/ Humboldt Agreement - Process 88881.145566/2017-1) and Return Grant.

\section{References}

1. Bye G, Ceccaroli B. Solar grade silicon: technology status and industrial trends. Sol Energy Mater Sol Cells. 2014;130:634-46. http://dx.doi.org/10.1016/j.solmat.2014.06.019.

2. Dong Z, Lin Y. Ultra-thin wafer technology and applications: a review. Mater Sci Semicond Process. 2020;105:104681. http:// dx.doi.org/10.1016/j.mssp.2019.104681.

3. Mingsukang MA, Buraidah MH, Arof AK. Third-generationsensitized solar cells. In: Das N, editor. Nanostructured solar cells. Rijeka: IntechOpen; 2017. Chapter 2. http://dx.doi. org/10.5772/65290.

4. Herz LM. Charge-carrier mobilities in metal halide perovskites: fundamental mechanisms and limits. ACS Energy Lett. 2017;2(7):1539-48. http://dx.doi.org/10.1021/acsenergylett.7b00276.

5. Umari P, Mosconi E, De Angelis F. Relativistic GW calculations on $\mathrm{CH}_{3} \mathrm{NH}_{3} \mathrm{PbI}_{3}$ and $\mathrm{CH}_{3} \mathrm{NH}_{3} \mathrm{SnI}_{3}$ perovskites for solar cell applications. Sci Rep. 2015;4(1):4467. http://dx.doi.org/10.1038/ srep04467. PMid:24667758.

6. Kojima A, Teshima K, Shirai Y, Miyasaka T. Organometal halide perovskites as visible-light sensitizers for photovoltaic cells. J Am Chem Soc. 2009;131(17):6050-1. http://dx.doi. org/10.1021/ja809598r. PMid:19366264.

7. Im J-H, Lee C-R, Lee J-W, Park S-W, Park N-G. 6.5\% efficient perovskite quantum-dot-sensitized solar cell. Nanoscale. 2011;3(10):4088-93. http://dx.doi.org/10.1039/c1nr10867k. PMid:21897986.

8. Kim H-S, Lee C-R, Im JH, Lee KB, Moehl T, Marchioro A, et al. Lead iodide perovskite sensitized all-solid-state submicron thin film mesoscopic solar cell with efficiency exceeding $9 \%$. Sci Rep. 2012;2(1):591. http://dx.doi.org/10.1038/srep00591. PMid:22912919.

9. Sha WEI, Ren X, Chen L, Choy WCH. The efficiency limit of $\mathrm{CH}_{3} \mathrm{NH}_{3} \mathrm{PbI}_{3}$ perovskite solar cells. Appl Phys Lett. 2015;106(22):221104. http://dx.doi.org/10.1063/1.4922150.

10. Pazos-Outón LM, Xiao TP, Yablonovitch E. Fundamental efficiency limit of lead iodide perovskite solar cells. J Phys Chem Lett. 2018;9(7):1703-11. http://dx.doi.org/10.1021/acs. jpclett.7b03054. PMid:29537271.

11. Jeong J, Kim M, Seo J, Lu H, Ahlawat P, Mishra A, et al. Pseudo-halide anion engineering for $\alpha-\mathrm{FAPbI}_{3}$ perovskite solar cells. Nature. 2021;592(7854):381-5. http://dx.doi.org/10.1038/ s41586-021-03406-5. PMid:33820983.

12. National Renewable Energy Laboratory. Best research-cell efficiency chart [Internet]. 2021 [cited 2021 June 10]. Available from: https://www.nrel.gov/pv/assets/pdfs/cell-pv-eff-emergingpvrev210726.pdf

13. Benedict O. A responsible compromise? [Internet]. 2019 [cited 2019 Nov 20]. Available from: https://www.pv-magazine. com/2019/11/16/the-weekend-read-a-responsible-compromise/

14. Hsu H-Y, Ji L, Du M, Zhao J, Yu ET, Bard AJ. Optimization of lead-free organic-inorganic tin(II) halide perovskite semiconductors by scanning electrochemical microscopy. Electrochim Acta. 2016;220:205-10. http://dx.doi.org/10.1016/j. electacta.2016.10.049.

15. Sun P-P, Li Q-S, Yang L-N, Li Z-S. Theoretical insights into a potential lead-free hybrid perovskite: substituting $\mathrm{Pb}^{2+}$ with 
$\mathrm{Ge}^{2+}$. Nanoscale. 2016;8(3):1503-12. http://dx.doi.org/10.1039/ C5NR05337D. PMid:26673960.

16. Benabdallah I, Boujnah M, El Kenz A, Benyoussef A, Abatal M, Bassam A. Lead-free perovskite based bismuth for solar cells absorbers. J Alloys Compd. 2019;773:796-801. http:// dx.doi.org/10.1016/j.jallcom.2018.09.332.

17. Lin T-W, Su C, Lin CC. Phase transition and energy transfer of lead-free $\mathrm{Cs}_{2} \mathrm{SnCl}_{6}$ perovskite nanocrystals by controlling the precursors and doping manganese ions. J Inf Disp. 2019;20(4):209-16. http://dx.doi.org/10.1080/15980316.201 9.1655493 .

18. Noel NK, Stranks SD, Abate A, Wehrenfennig C, Guarnera S, Haghighirad A-A, et al. Lead-free organic-inorganic tin halide perovskites for photovoltaic applications. Energy Environ Sci. 2014;7(9):3061-8. http://dx.doi.org/10.1039/C4EE01076K.

19. Hao F, Stoumpos CC, Cao DH, Chang RPH, Kanatzidis MG. Lead-free solid-state organic-inorganic halide perovskite solar cells. Nat Photonics. 2014;8(6):489-94. http://dx.doi.org/10.1038/ nphoton.2014.82.

20. Jiang X, Li H, Zhou Q, Wei Q, Wei M, Jiang L, et al. One-step synthesis of $\mathrm{SnI}_{2} \cdot(\mathrm{DMSO})_{\mathrm{x}}$ adducts for high-performance tin perovskite solar cells. J Am Chem Soc. 2021;143(29):10970-6. http://dx.doi.org/10.1021/jacs.1c03032. PMid:34196528.

21. Kieslich G, Sun S, Cheetham AK. An extended tolerance factor approach for organic-inorganic perovskites. Chem Sci. 2015;6(6):3430-3. http://dx.doi.org/10.1039/C5SC00961H. PMid:28706705.

22. Jiang L, Wu T, Sun L, Li Y-J, Li A-L, Lu R-F, et al. Firstprinciples screening of lead-free methylammonium metal iodine perovskites for photovoltaic application. J Phys Chem C. 2017;121(44):24359-64. http://dx.doi.org/10.1021/acs. jpcc.7b04685.

23. Svane KL, Forse AC, Grey CP, Kieslich G, Cheetham AK, Walsh A, et al. How strong is the hydrogen bond in hybrid perovskites? J Phys Chem Lett. 2017;8(24):6154-9. http:// dx.doi.org/10.1021/acs.jpclett.7b03106. PMid:29216715.

24. Varadwaj PR, Varadwaj A, Marques HM, Yamashita K. Significance of hydrogen bonding and other noncovalent interactions in determining octahedral tilting in the $\mathrm{CH}_{3} \mathrm{NH}_{3} \mathrm{PbI}_{3}$ hybrid organicinorganic halide perovskite solar cell semiconductor. Sci Rep. 2019;9(1):50. http://dx.doi.org/10.1038/s41598-018-36218-1. PMid:30631082.

25. Walsh A. Principles of chemical bonding and band gap engineering in hybrid organic-inorganic halide perovskites. J Phys Chem C Nanomater Interfaces. 2015;119(11):5755-60. http://dx.doi.org/10.1021/jp512420b. PMid:25838846.

26. Li C, Lu X, Ding W, Feng L, Gao Y, Guo Z. Formability of $\mathrm{ABX}_{3}(\mathrm{X}=\mathrm{F}, \mathrm{Cl}, \mathrm{Br}, \mathrm{I})$ halide perovskites. Acta Crystallogr $\mathrm{B}$. 2008;64(6):702-7. http://dx.doi.org/10.1107/S0108768108032734. PMid:19029699.

27. Goldschmidt VM. Die Gesetze der Krystallochemie. Naturwissenschaften. 1926;14(21):477-85. http://dx.doi. org/10.1007/BF01507527.

28. Travis W, Glover ENK, Bronstein H, Scanlon DO, Palgrave RG. On the application of the tolerance factor to inorganic and hybrid halide perovskites: a revised system. Chem Sci. 2016;7(7):4548-56. http://dx.doi.org/10.1039/C5SC04845A. PMid:30155101.

29. Stoumpos CC, Malliakas CD, Kanatzidis MG. Semiconducting tin and lead iodide perovskites with organic cations: phase transitions, high mobilities, and near-infrared photoluminescent properties. Inorg Chem. 2013;52(15):9019-38. http://dx.doi. org/10.1021/ic401215x. PMid:23834108.

30. De Trizio L, Li H, Casu A, Genovese A, Sathya A, Messina $\mathrm{GC}$, et al. Sn cation valency dependence in cation exchange reactions involving $\mathrm{cu}_{2-\mathrm{x}}$ Se nanocrystals. $\mathrm{J} \mathrm{Am}$ Chem Soc. 2014;136(46):16277-84. http://dx.doi.org/10.1021/ja508161c. PMid:25340627.
31. Whitfield PS, Herron N, Guise WE, Page K, Cheng YQ, Milas I, et al. Structures, phase transitions and tricritical behavior of the hybrid perovskite methyl ammonium lead iodide. Sci Rep. 2016;6(1):35685. http://dx.doi.org/10.1038/srep35685. PMid:27767049.

32. Takahashi Y, Hasegawa $H$, Takahashi Y, Inabe T. Hall mobility in tin iodide perovskite $\mathrm{CH}_{3} \mathrm{NH}_{3} \mathrm{SnI}_{3}$ : evidence for a doped semiconductor. J Solid State Chem. 2013;205:39-43. http:// dx.doi.org/10.1016/j.jssc.2013.07.008.

33. Dimesso L, Das C, Mayer T, Jaegermann W. Investigation of earth-alkaline $(\mathrm{EA}=\mathrm{Mg}, \mathrm{Ca}, \mathrm{Sr})$ containing methylammonium tin iodide perovskite systems. J Mater Sci. 2018;53(1):356-68. http://dx.doi.org/10.1007/s10853-017-1545-0.

34. Lü X, Wang Y, Stoumpos CC, Hu Q, Guo X, Chen H, et al. Enhanced structural stability and photo responsiveness of $\mathrm{CH}_{3} \mathrm{NH}_{3} \mathrm{SnI}_{3}$ perovskite via pressure-induced amorphization and recrystallization. Adv Mater. 2016;28(39):8663-8. http:// dx.doi.org/10.1002/adma.201600771. PMid:27514760.

35. Takahashi Y, Obara R, Lin Z-Z, Takahashi Y, Naito T, Inabe T, et al. Charge-transport in tin-iodide perovskite $\mathrm{CH}_{3} \mathrm{NH}_{3} \mathrm{SnI}_{3}$ : origin of high conductivity. Dalton Trans. 2011;40(20):5563-8. http://dx.doi.org/10.1039/c0dt01601b. PMid:21494720.

36. Li Q, Wan W, Ge Y, Wang B, Li Y, Wang C, et al. Hexagonal $\mathrm{MASnI}_{3}$ exhibiting strong absorption of ultraviolet photons. Appl Phys Lett. 2019;114(10):101906. http://dx.doi. org/10.1063/1.5087649.

37. Ozório MS, Srikanth M, Besse R, Da Silva JLF. The role of the A-cations in the polymorphic stability and optoelectronic properties of lead-free $\mathrm{ASnI}_{3}$ perovskites. Phys Chem Chem Phys. 2021;23(3):2286-97. http://dx.doi.org/10.1039/D0CP06090A. PMid:33443529.

38. Stoumpos CC, Mao L, Malliakas CD, Kanatzidis MG. Structure-band gap relationships in hexagonal polytypes and low-dimensional structures of hybrid tin iodide perovskites. Inorg Chem. 2017;56(1):56-73. http://dx.doi.org/10.1021/acs. inorgchem.6b02764. PMid:27997156.

39. Parrott ES, Milot RL, Stergiopoulos T, Snaith HJ, Johnston MB, Herz LM. Effect of structural phase transition on chargecarrier lifetimes and defects in $\mathrm{CH}_{3} \mathrm{NH}_{3} \mathrm{SnI}_{3}$ perovskite. J Phys Chem Lett. 2016;7(7):1321-6. http://dx.doi.org/10.1021/acs. jpclett.6b00322. PMid:26990282.

40. Sharma VK, Kanchana V, Gupta MK, Mittal R. Ultra-low thermal conductivity of orthorhombic $\mathrm{CH}_{3} \mathrm{NH}_{3} \mathrm{SnI}_{3}$ : A first principles investigation. J Solid State Chem. 2020;290:121541. http://dx.doi.org/10.1016/j.jssc.2020.121541.

41. Chung I, Song J-H, Im J, Androulakis J, Malliakas CD, Li $\mathrm{H}$, et al. $\mathrm{CsSnI}_{3}$ : semiconductor or metal? High electrical conductivity and strong near-infrared photoluminescence from a single material. high hole mobility and phase-transitions. J Am Chem Soc. 2012;134(20):8579-87. http://dx.doi.org/10.1021/ ja301539s. PMid:22578072.

42. Chander N, Chandrasekhar PS, Komarala VK. Solid state plasmonic dye sensitized solar cells based on solution processed perovskite $\mathrm{CsSnI} 3$ as the hole transporter. RSC Advances. 2014;4(98):55658-65. http://dx.doi.org/10.1039/C4RA09719J

43. Chung I, Lee B, He J, Chang RPH, Kanatzidis MG. All-solidstate dye-sensitized solar cells with high efficiency. Nature. 2012;485(7399):486-9. http://dx.doi.org/10.1038/nature11067. PMid:22622574.

44. Qiu X, Cao B, Yuan S, Chen X, Qiu Z, Jiang Y, et al. From unstable $\mathrm{CsSnI}_{3}$ to air-stable $\mathrm{Cs}_{2} \mathrm{SnI}_{6}$ : A lead-free perovskite solar cell light absorber with bandgap of $1.48 \mathrm{eV}$ and high absorption coefficient. Sol Energy Mater Sol Cells. 2017;159:227-34. http://dx.doi.org/10.1016/j.solmat.2016.09.022.

45. Sabetvand R, Ghazi ME, Izadifard M. DFT study of electronic and optical properties of $\mathrm{CH}_{3} \mathrm{NH}_{3} \mathrm{SnI}_{3}$ perovskite. Energy Sources A Recovery Util Environ Effects. 2020;1-13. In press. http:// dx.doi.org/10.1080/15567036.2020.1805047. 
46. Mortan C, Hellmann T, Clemens O, Mayer T, Jaegermann W. Preparation of methylammonium tin iodide $\left(\mathrm{ch}_{3} \mathrm{nh}_{3} \mathrm{sni}_{3}\right)$ perovskite thin films via flash evaporation. Phys Status Solidi. 2019;216(18):1900209. http://dx.doi.org/10.1002/pssa.201900209.

47. Koh TM, Krishnamoorthy T, Yantara N, Shi C, Leong WL, Boix PP, et al. Formamidinium tin-based perovskite with low Eg for photovoltaic applications. J Mater Chem A Mater Energy Sustain. 2015;3(29):14996-5000. http://dx.doi.org/10.1039/ C5TA00190K.

48. Yokoyama T, Cao DH, Stoumpos CC, Song TB, Sato Y, Aramaki $\mathrm{S}$, et al. Overcoming short-circuit in lead-free $\mathrm{CH}_{3} \mathrm{NH}_{3} \mathrm{SnI}_{3}$ perovskite solar cells via kinetically controlled gas-solid reaction film fabrication process. J Phys Chem Lett. 2016;7(5):776-82. http://dx.doi.org/10.1021/acs.jpclett.6b00118. PMid:26877089.

49. Liao W, Zhao D, Yu Y, Grice CR, Wang C, Cimaroli AJ, et al. Lead-free inverted planar formamidinium tin triiodide perovskite solar cells achieving power conversion efficiencies up to $6.22 \%$. Adv Mater. 2016;28(42):9333-40. http://dx.doi.org/10.1002/ adma.201602992. PMid:27571446.

50. Prasanna R, Gold-Parker A, Leijtens T, Conings B, Babayigit A, Boyen $\mathrm{HG}$, et al. Band gap tuning via lattice contraction and octahedral tilting in perovskite materials for photovoltaics. J Am Chem Soc. 2017;139(32):11117-24. http://dx.doi.org/10.1021/ jacs.7b04981. PMid:28704048.

51. Lee J-H, Bristowe NC, Lee JH, Lee S-H, Bristowe PD, Cheetham $\mathrm{AK}$, et al. Resolving the physical origin of octahedral tilting in halide perovskites. Chem Mater. 2016;28(12):4259-66. http:// dx.doi.org/10.1021/acs.chemmater.6b00968.

52. Ferrara C, Patrini M, Pisanu A, Quadrelli P, Milanese C, Tealdi $\mathrm{C}$, et al. Wide band-gap tuning in Sn-based hybrid perovskites through cation replacement: the $\mathrm{FA}_{1-\mathrm{x}} \mathrm{MA}_{\mathrm{x}} \mathrm{SnBr}_{3}$ mixed system. J Mater Chem A Mater Energy Sustain. 2017;5(19):9391-5. http://dx.doi.org/10.1039/C7TA01668A.

53. Ma Z-Q, Pan H, Wong PK. A first-principles study on the structural and electronic properties of sn-based organic-inorganic halide perovskites. J Electron Mater. 2016;45(11):5956-66. http://dx.doi.org/10.1007/s11664-016-4822-9.

54. Singh R, Jun HK, Arof AK. Activated carbon as back contact for HTM-free mixed cation perovskite solar cell. Phase Transit. 2018;91(12):1268-76. http://dx.doi.org/10.1080/01411594.20 18.1527914

55. Dang Y, Zhou Y, Liu X, Ju D, Xia S, Xia H, et al. Formation of hybrid perovskite tin iodide single crystals by top-seeded solution growth. Angew Chem Int Ed Engl. 2016;55(10):344750. http://dx.doi.org/10.1002/anie.201511792. PMid:26889919.

56. Pisanu A, Speltini A, Quadrelli P, Drera G, Sangaletti L, Malavasi L. Enhanced air-stability of Sn-based hybrid perovskites induced by dimethylammonium (DMA): synthesis, characterization, aging and hydrogen photogeneration of the $\mathrm{MA}_{1-\mathrm{x}} \mathrm{DMA}_{\mathrm{x}} \mathrm{SnBr}_{3}$ system. J Mater Chem C Mater Opt Electron Devices. 2019;7(23):70206. http://dx.doi.org/10.1039/C9TC01743G.

57. Zhao Z, Gu F, Li Y, Sun W, Ye S, Rao H, et al. Mixed-organiccation tin iodide for lead-free perovskite solar cells with an efficiency of 8.12\%. Adv Sci. 2017;4(11):1700204. http:// dx.doi.org/10.1002/advs.201700204. PMid:29201617.

58. Zheng C, Rubel O. Aziridinium lead iodide: a stable, lowband-gap hybrid halide perovskite for photovoltaics. J Phys Chem Lett. 2018;9(4):874-80. http://dx.doi.org/10.1021/acs. jpclett.7b03114. PMid:29390607.

59. Teng Q, Shi T, Liao C, Zhao Y-J. First-principles study of aziridinium tin iodide perovskites for photovoltaics. J Mater Chem C Mater Opt Electron Devices. 2021;9(3):982-90. http:// dx.doi.org/10.1039/D0TC03902K.

60. Ke W, Stoumpos CC, Spanopoulos I, Mao L, Chen M, Wasielewski MR, et al. Efficient lead-free solar cells based on hollow $\{\mathrm{en}\}$ MASnI ${ }_{3}$ perovskites. J Am Chem Soc. 2017;139(41):14800-6. http://dx.doi.org/10.1021/jacs.7b09018. PMid:28953381.
61. Ke W, Stoumpos CC, Zhu M, Mao L, Spanopoulos I, Liu J, et al. Enhanced photovoltaic performance and stability with a new type of hollow 3D perovskite $\{\mathrm{en}\} \mathrm{FASnI}_{3}$. Sci Adv. 2017;3(8):e1701293. http://dx.doi.org/10.1126/sciadv.1701293. PMid:28875173.

62. Gao W, Ran C, Li J, Dong H, Jiao B, Zhang L, et al. Robust stability of efficient lead-free formamidinium tin iodide perovskite solar cells realized by structural regulation. J Phys Chem Lett. 2018;9(24):6999-7006. http://dx.doi.org/10.1021/ acs.jpclett.8b03194. PMid:30499301.

63. Nawale VV, Sheikh T, Nag A. Dual excitonic emission in hybrid 2D layered tin iodide perovskites. J Phys Chem C. 2020;124(38):21129-36. http://dx.doi.org/10.1021/acs. jpcc.0c05301.

64. Lanzetta L, Marin-Beloqui JM, Sanchez-Molina I, Ding D, Haque SA. Two-dimensional organic tin halide perovskites with tunable visible emission and their use in light-emitting devices. ACS Energy Lett. 2017;2(7):1662-8. http://dx.doi. org/10.1021/acsenergylett.7b00414.

65. Cao DH, Stoumpos CC, Yokoyama T, Logsdon JL, Song T-B, Farha OK, et al. Thin films and solar cells based on semiconducting two-dimensional Ruddlesden-Popper $\left(\mathrm{CH}_{3}\left(\mathrm{CH}_{2}\right)_{3} \mathrm{NH}_{3}\right)_{2}\left(\mathrm{CH}_{3} \mathrm{NH}_{3}\right)$ ${ }_{\mathrm{n}-1} \mathrm{Sn}_{\mathrm{n}} \mathrm{I}_{3 \mathrm{n}+1}$ perovskites. ACS Energy Lett. 2017;2(5):982-90. http://dx.doi.org/10.1021/acsenergylett.7b00202.

66. Yuan J, Li B, Hao C. Study on cobalt doped tin based perovskite material with enhanced air stability. Mater Sci Semicond Process. 2017;57:95-8. http://dx.doi.org/10.1016/j.mssp.2016.09.029.

67. Ito N, Kamarudin MA, Hirotani D, Zhang Y, Shen Q, Ogomi $\mathrm{Y}$, et al. Mixed Sn-Ge perovskite for enhanced perovskite solar cell performance in air. J Phys Chem Lett. 2018;9(7):1682-8. http://dx.doi.org/10.1021/acs.jpclett.8b00275. PMid:29536736.

68. Hasegawa H, Kobayashi K, Takahashi Y, Harada J, Inabe T. Effective band gap tuning by foreign metal doping in hybrid tin iodide perovskites. J Mater Chem C Mater Opt Electron Devices. 2017;5(16):4048-52. http://dx.doi.org/10.1039/C7TC00446J.

69. Dawson M, Ribeiro C, Morelli MR. $\mathrm{MnCl}_{2}$ doping increases phase stability of tin halide perovskites. Mater Sci Semicond Process. 2021;132:105908. http://dx.doi.org/10.1016/j. mssp.2021.105908.

70. Kobayashi K, Hasegawa H, Takahashi Y, Harada J, Inabe T. Electronic properties of tin iodide hybrid perovskites: effect of indium doping. Mater Chem Front. 2018;2(7):1291-5. http:// dx.doi.org/10.1039/C7QM00587C.

71. Castelli IE, García-Lastra JM, Thygesen KS, Jacobsen KW. Bandgap calculations and trends of organometal halide perovskites. APL Mater. 2014;2(8):81514. http://dx.doi.org/10.1063/1.4893495.

72. Kumar S, Ansari MZ, Khare N. Transparent $\mathrm{CH}_{3} \mathrm{NH}_{3} \mathrm{SnCl}_{3} / \mathrm{Al}-\mathrm{ZnO}$ p-n heterojunction diode. AIP Conf Proc. 2016;1731(1):120025. http://dx.doi.org/10.1063/1.4948097.

73. Gopinathan N, Basha SS, Banu IBS, Mamat MH, Sirajudeen MMS. Solvents driven structural, morphological, optical and dielectric properties of lead free perovskite $\mathrm{CH}_{3} \mathrm{NH}_{3} \mathrm{SnCl}_{3}$ for optoelectronic applications: experimental and DFT study. Mater Res Express. 2020;6(12):125921. http://dx.doi.org/10.1088/20531591/ab6a47.

74. Moyez SA, Roy S. Thermal engineering of lead-free nanostructured $\mathrm{CH}_{3} \mathrm{NH}_{3} \mathrm{SnCl}_{3}$ perovskite material for thin-film solar cell. $\mathrm{J}$ Nanopart Res. 2017;20(1):5. http://dx.doi.org/10.1007/s11051017-4108-z.

75. Rameez M, Lin EY-R, Raghunath P, Narra S, Song D, Lin $\mathrm{MC}$, et al. Development of hybrid pseudohalide tin perovskites for highly stable carbon-electrode solar cells. ACS Appl Mater Interfaces. 2020;12(19):21739-47. http://dx.doi.org/10.1021/ acsami.0c03704. PMid:32295339.

76. Baranowski M, Plochocka P. Excitons in metal-halide perovskites. Adv Energy Mater. 2020;10(6):1903659. http:// dx.doi.org/10.1002/aenm.201903659. 
77. Miyata A, Mitioglu A, Plochocka P, Portugall O, Wang JT-W, Stranks SD, et al. Direct measurement of the exciton binding energy and effective masses for charge carriers in organicinorganic tri-halide perovskites. Nat Phys. 2015;11(7):582-7. http://dx.doi.org/10.1038/nphys3357.

78. Yang Z, Surrente A, Galkowski K, Bruyant N, Maude DK, Haghighirad AA, et al. Unraveling the exciton binding energy and the dielectric constant in single-crystal methylammonium lead triiodide perovskite. J Phys Chem Lett. 2017;8(8):1851-5. http://dx.doi.org/10.1021/acs.jpclett.7b00524. PMid:28393517.

79. Galkowski K, Surrente A, Baranowski M, Zhao B, Yang Z, Sadhanala A, et al. Excitonic properties of low-band-gap lead-tin halide perovskites. ACS Energy Lett. 2019;4(3):615-21. http:// dx.doi.org/10.1021/acsenergylett.8b02243.

80. Manser JS, Christians JA, Kamat PV. Intriguing optoelectronic properties of metal halide perovskites. Chem Rev. 2016;116(21):12956-3008. http://dx.doi.org/10.1021/acs. chemrev.6b00136. PMid:27327168.

81. Shi Z, Jayatissa AH. Perovskites-based solar cells: a review of recent progress, materials and processing methods. Mater. 2018;11(5):729. http://dx.doi.org/10.3390/ma11050729. PMid:29734667.

82. Song Z, Watthage SC, Phillips AB, Heben MJ. Pathways toward high-performance perovskite solar cells: review of recent advances in organo-metal halide perovskites for photovoltaic applications. J Photonics Energy. 2016;6(2):1-23. http://dx.doi. org/10.1117/1.JPE.6.022001.

83. Hao F, Stoumpos CC, Chang RPH, Kanatzidis MG. Anomalous band gap behavior in mixed $\mathrm{sn}$ and $\mathrm{pb}$ perovskites enables broadening of absorption spectrum in solar cells. J Am Chem Soc. 2014;136(22):8094-9. http://dx.doi.org/10.1021/ja5033259. PMid:24823301.

84. Yokoyama T, Song T-B, Cao DH, Stoumpos CC, Aramaki S, Kanatzidis MG. The origin of lower hole carrier concentration in methylammonium tin halide films grown by a vapor-assisted solution process. ACS Energy Lett. 2017;2(1):22-8. http:// dx.doi.org/10.1021/acsenergylett.6b00513.

85. Ke W, Priyanka P, Vegiraju S, Stoumpos CC, Spanopoulos I, Soe CMM, et al. Dopant-free tetrakis-triphenylamine hole transporting material for efficient tin-based perovskite solar cells. J Am Chem Soc. 2018;140(1):388-93. http://dx.doi. org/10.1021/jacs.7b10898. PMid:29211458.

86. Ma L, Hao F, Stoumpos CC, Phelan BT, Wasielewski MR, Kanatzidis MG. Carrier diffusion lengths of over $500 \mathrm{~nm}$ in lead-free perovskite $\mathrm{CH}_{3} \mathrm{NH}_{3} \mathrm{SnI}_{3}$ Films. J Am Chem Soc. 2016;138(44):14750-5. http://dx.doi.org/10.1021/jacs.6b09257. PMid:27750426.

87. Jung M-C, Raga SR, Qi Y. Properties and solar cell applications of $\mathrm{Pb}$-free perovskite films formed by vapor deposition. RSC Advances. 2016;6(4):2819-25. http://dx.doi.org/10.1039/ C5RA21291J.

88. Patel PK. Device simulation of highly efficient eco-friendly $\mathrm{CH}_{3} \mathrm{NH}_{3} \mathrm{SnI}_{3}$ perovskite solar cell. Sci Rep. 2021;11(1):3082. http://dx.doi.org/10.1038/s41598-021-82817-w. PMid:33542464.

89. Yin X, Guo Y, Xie H, Que W, Kong LB. Nickel oxide as efficient hole transport materials for perovskite solar cells. Sol RRL. 2019;3(5):1900001. http://dx.doi.org/10.1002/solr.201900001.

90. Vegiraju S, Ke W, Priyanka P, Ni J-S, Wu Y-C, Spanopoulos I, et al. Benzodithiophene hole-transporting materials for efficient tin-based perovskite solar cells. Adv Funct Mater. 2019;29(45):1905393. http://dx.doi.org/10.1002/adfm.201905393.

91. Yokoyama T, Nishitani Y, Miyamoto Y, Kusumoto S, Uchida $\mathrm{R}$, Matsui $\mathrm{T}$, et al. Improving the open-circuit voltage of Snbased perovskite solar cells by band alignment at the electron transport layer/perovskite layer interface. ACS Appl Mater Interfaces. 2020;12(24):27131-9. http://dx.doi.org/10.1021/ acsami.0c04676. PMid:32427458.
92. Gagandeep, Singh M, Kumar R, Singh V. Graphene as charge transport layers in lead free perovskite solar cell. Mater Res Express. 2019;6(11):115611. http://dx.doi.org/10.1088/20531591/ab4b02.

93. Yang Z, Zhong M, Liang Y, Yang L, Liu X, Li Q, et al. $\mathrm{SnO}_{2}-\mathrm{C} 60$ pyrrolidine tris-acid (CPTA) as the electron transport layer for highly efficient and stable planar Sn-based perovskite solar cells. Adv Funct Mater. 2019;29(42):1903621. http://dx.doi. org/10.1002/adfm.201903621.

94. Huang D, Goh T, Kong J, Zheng Y, Zhao S, Xu Z, et al. Perovskite solar cells with a DMSO-treated PEDOT:PSS hole transport layer exhibit higher photovoltaic performance and enhanced durability. Nanoscale. 2017;9(12):4236-43. http:// dx.doi.org/10.1039/C6NR08375G. PMid:28291270.

95. Al Mamun A, Ava TT, Zhang K, Baumgart H, Namkoong G. New PCBM/carbon based electron transport layer for perovskite solar cells. Phys Chem Chem Phys. 2017;19(27):17960-6. http:// dx.doi.org/10.1039/C7CP02523H. PMid:28664965.

96. Ke W, Stoumpos CC, Logsdon JL, Wasielewski MR, Yan Y, Fang $\mathrm{G}$, et al. $\mathrm{TiO}_{2}-\mathrm{ZnS}$ cascade electron transport layer for efficient formamidinium tin iodide perovskite solar cells. J Am Chem Soc. 2016;138(45):14998-5003. http://dx.doi.org/10.1021/ jacs.6b08790. PMid:27776416.

97. Liu C, Tu J, Hu X, Huang Z, Meng X, Yang J, et al. Enhanced hole transportation for inverted tin-based perovskite solar cells with high performance and stability. Adv Funct Mater. 2019;29(18):1808059. http://dx.doi.org/10.1002/adfm.201808059.

98. Ran C, Xi J, Gao W, Yuan F, Lei T, Jiao B, et al. Bilateral interface engineering toward efficient $2 \mathrm{D}-3 \mathrm{D}$ bulk heterojunction tin halide lead-free perovskite solar cells. ACS Energy Lett. 2018;3(3):71321. http://dx.doi.org/10.1021/acsenergylett.8b00085.

99. Yu Y, Zhao D, Grice CR, Meng W, Wang C, Liao W, et al. Thermally evaporated methylammonium tin triiodide thin films for lead-free perovskite solar cell fabrication. RSC Advances. 2016;6(93):90248-54. http://dx.doi.org/10.1039/C6RA19476A.

100.Jiang X, Wang F, Wei Q, Li H, Shang Y, Zhou W, et al. Ultra-high open-circuit voltage of tin perovskite solar cells via an electron transporting layer design. Nat Commun. 2020;11(1):1245. http:// dx.doi.org/10.1038/s41467-020-15078-2. PMid:32144245.

101.Bakr ZH, Wali Q, Fakharuddin A, Schmidt-Mende L, Brown $\mathrm{TM}$, Jose R. Advances in hole transport materials engineering for stable and efficient perovskite solar cells. Nano Energy. 2017;34:271-305. http://dx.doi.org/10.1016/j.nanoen.2017.02.025.

102.Zentrum für Sonnenenergie- und Wasserstoff-Forschung Baden-Württemberg. Perovskite solar cells [Internet]. 2019 [cited 2019 Nov 17]. Available from: https://www.zsw-bw.de/ forschung/photovoltaik/themen/perowskitsolarzellen.html

103. Yang M, Zeng Y, Li Z, Kim DH, Jiang CS, van de Lagemaat $\mathrm{J}$, et al. Do grain boundaries dominate non-radiative recombination in $\mathrm{CH}_{3} \mathrm{NH}_{3} \mathrm{PbI}_{3}$ perovskite thin films? Phys Chem Chem Phys. 2017;19(7):5043-50. http://dx.doi.org/10.1039/C6CP08770A. PMid:28168255.

104.Luo D, Su R, Zhang W, Gong Q, Zhu R. Minimizing non-radiative recombination losses in perovskite solar cells. Nat Rev Mater. 2020;5(1):44-60. http://dx.doi.org/10.1038/s41578-019-0151-y.

105.Manjunath V, Krishna R, Maniarasu S, Ramasamy E, Shanmugasundaram S, Veerappan G. Perovskite solar cell architectures. In: Thomas S, Thankappan A, editors. Perovskite photovoltaics: basic to advanced concepts and implementation. London: Academic Press; 2018. Chapter 4; p. 89-121. http:// dx.doi.org/10.1016/B978-0-12-812915-9.00004-6.

106.Heo JH, Im SH. Highly reproducible, efficient hysteresis-less $\mathrm{CH}_{3} \mathrm{NH}_{3} \mathrm{PbI}_{3-\mathrm{x}} \mathrm{Cl}_{\mathrm{x}}$ planar hybrid solar cells without requiring heat-treatment. Nanoscale. 2015;8(5):2554-60. http://dx.doi. org/10.1039/C5NR08458J. PMid:26781644.

107.Starr DE, Sadoughi G, Handick E, Wilks RG, Alsmeier JH, Köhler L, et al. Direct observation of an inhomogeneous chlorine distribution in $\mathrm{CH}_{3} \mathrm{NH}_{3} \mathrm{PbI}_{3-\mathrm{x}} \mathrm{Cl}_{\mathrm{x}}$ layers: surface depletion and 
interface enrichment. Energy Environ Sci. 2015;8(5):1609-15. http://dx.doi.org/10.1039/C5EE00403A.

108. Wang P, Li F, Jiang K-J, Zhang Y, Fan H, Zhang Y, et al. Ion exchange/insertion reactions for fabrication of efficient methylammonium tin iodide perovskite solar cells. Adv Sci. 2020;7(9):1903047. http://dx.doi.org/10.1002/advs.201903047. PMid:32382478.

109.Lee SJ, Shin SS, Kim YC, Kim D, Ahn TK, Noh JH, et al. Fabrication of efficient formamidinium tin iodide perovskite solar cells through $\mathrm{SnF}_{2}$-pyrazine complex. J Am Chem Soc. 2016;138(12):3974-7. http://dx.doi.org/10.1021/jacs.6b00142. PMid:26960020.

110. Hao F, Stoumpos CC, Guo P, Zhou N, Marks TJ, Chang $\mathrm{RP}$, et al. Solvent-mediated crystallization of $\mathrm{CH}_{3} \mathrm{NH}_{3} \mathrm{SnI}_{3}$ films for heterojunction depleted perovskite solar cells. J Am Chem Soc. 2015;137(35):11445-52. http://dx.doi.org/10.1021/ jacs.5b06658. PMid:26313318.

111.Liu X, Yan K, Tan D, Liang X, Zhang H, Huang W. Solvent engineering improves efficiency of lead-free tin-based hybrid perovskite solar cells beyond 9\%. ACS Energy Lett. 2018;3(11):27017. http://dx.doi.org/10.1021/acsenergylett.8b01588.

112. Vidyasagar CC, Muñoz Flores BM, Jiménez Pérez VM. Recent advances in synthesis and properties of hybrid halide perovskites for photovoltaics. Nano-Micro Lett. 2018;10(4):68. http:// dx.doi.org/10.1007/s40820-018-0221-5. PMid:30393716.

113.Zuo C, Ding L. Drop-casting to make efficient perovskite solar cells under high humidity. Angew Chem Int Ed Engl. 2021;60(20):11242-6. http://dx.doi.org/10.1002/anie.202101868. PMid:33683785.

114. Cheng J, Liu F, Tang Z, Li Y. Scalable blade coating: a technique accelerating the commercialization of perovskite-based photovoltaics. Energy Technol. 2021;9(8):2100204. http:// dx.doi.org/10.1002/ente.202100204.

115. Angmo D, DeLuca G, Scully AD, Chesman ASR, Seeber A, Zuo C, et al. A lab-to-fab study toward roll-to-roll fabrication of reproducible perovskite solar cells under ambient room conditions. Cell Reports Phys Sci. 2021;2(1):100293. http:// dx.doi.org/10.1016/j.xcrp.2020.100293.

116. Greul E, Docampo P, Bein T. Synthesis of hybrid tin halide perovskite solar cells with less hazardous solvents: methanol and 1,4-dioxane. Z Anorg Allg Chem. 2017;643(21):1704-11 http://dx.doi.org/10.1002/zaac.201700297.

117.Xiao M, Huang F, Huang W, Dkhissi Y, Zhu Y, Etheridge $\mathrm{J}$, et al. A fast deposition-crystallization procedure for highly efficient lead iodide perovskite thin-film solar cells. Angew Chem. 2014;126(37):10056-61. http://dx.doi.org/10.1002/ ange.201405334. PMid:25047967.

118.Xiao M, Zhao L, Geng M, Li Y, Dong B, Xu Z, et al. Selection of an anti-solvent for efficient and stable cesium-containing triple cation planar perovskite solar cells. Nanoscale. 2018;10(25):121418. http://dx.doi.org/10.1039/C8NR03580F. PMid:29920570.

119.Xiao M, Gu S, Zhu P, Tang M, Zhu W, Lin R, et al. Tin-based perovskite with improved coverage and crystallinity through tin-fluoride-assisted heterogeneous nucleation. Adv Opt Mater. 2018;6(1):1700615. http://dx.doi.org/10.1002/adom.201700615.

120.Fujihara T, Terakawa S, Matsushima T, Qin C, Yahiro M, Adachi C. Fabrication of high coverage $\mathrm{MASnI}_{3}$ perovskite films for stable, planar heterojunction solar cells. J Mater Chem C Mater Opt Electron Devices. 2017;5(5):1121-7. http://dx.doi. org/10.1039/C6TC05069G.

121.Liu J, Ozaki M, Yakumaru S, Handa T, Nishikubo R, Kanemitsu Y, et al. Lead-free solar cells based on tin halide perovskite films with high coverage and improved aggregation. Angew Chem Int Ed. 2018;57(40):13221-5. http://dx.doi.org/10.1002/ anie.201808385. PMid:30110137.

122.Li X-L, Gao L-L, Chu Q-Q, Li Y, Ding B, Yang G-J. Green solution-processed tin-based perovskite films for lead-free planar photovoltaic devices. ACS Appl Mater Interfaces.
2019;11(3):3053-60. http://dx.doi.org/10.1021/acsami.8b19143. PMid:30585479.

123.Li P, Dong H, Xu J, Chen J, Jiao B, Hou X, et al. Ligand orientationinduced lattice robustness for highly efficient and stable tin-based perovskite solar cells. ACS Energy Lett. 2020;5(7):2327-34. http://dx.doi.org/10.1021/acsenergylett.0c00960.

124.Meng X, Lin J, Liu X, He X, Wang Y, Noda T, et al. Highly stable and efficient fasni ${ }_{3}$-based perovskite solar cells by introducing hydrogen bonding. Adv Mater. 2019;31(42):1903721. http:// dx.doi.org/10.1002/adma.201903721. PMid:31495977.

125.Chang B, Li B, Pan L, Li H, Wang L, Fu L, et al. Polyethylene glycol polymer scaffold induced intermolecular interactions for crystallization regulation and defect passivation in FASnI3 films. ACS Appl Energy Mater. 2021;4(4):3622-32. http:// dx.doi.org/10.1021/acsaem.1c00009.

126.Liu G, Liu C, Lin Z, Yang J, Huang Z, Tan L, et al. Regulated crystallization of efficient and stable tin-based perovskite solar cells via a self-sealing polymer. ACS Appl Mater Interfaces. 2020;12(12):14049-56. http://dx.doi.org/10.1021/acsami.0c01311. PMid:32129060

127.Meng X, Wang Y, Lin J, Liu X, He X, Barbaud J, et al. Surfacecontrolled oriented growth of fasni ${ }_{3}$ crystals for efficient lead-free perovskite solar cells. Joule. 2020;4(4):902-12. http://dx.doi. org/10.1016/j.joule.2020.03.007.

128.Liu X, Wu T, Chen J-Y, Meng X, He X, Noda T, et al. Templated growth of $\mathrm{FASnI}_{3}$ crystals for efficient tin perovskite solar cells. Energy Environ Sci. 2020;13(9):2896-902. http://dx.doi. org/10.1039/D0EE01845G

129.Jokar E, Chien C-H, Fathi A, Rameez M, Chang Y-H, Diau EW-G. Slow surface passivation and crystal relaxation with additives to improve device performance and durability for tin-based perovskite solar cells. Energy Environ Sci. 2018;11(9):235362. http://dx.doi.org/10.1039/C8EE00956B.

130.Kamarudin MA, Hirotani D, Wang Z, Hamada K, Nishimura K, Shen Q, et al. Suppression of charge carrier recombination in lead-free tin halide perovskite via lewis base post-treatment. J Phys Chem Lett. 2019;10(17):5277-83. http://dx.doi.org/10.1021/ acs.jpclett.9b02024. PMid:31423786.

131.Nishimura K, Kamarudin MA, Hirotani D, Hamada K, Shen Q, Iikubo S, et al. Lead-free tin-halide perovskite solar cells with 13\% efficiency. Nano Energy. 2020;74:104858. http:// dx.doi.org/10.1016/j.nanoen.2020.104858.

132.Jellicoe TC, Richter JM, Glass HFJ, Tabachnyk M, Brady R, Dutton SE, et al. Synthesis and optical properties of lead-free cesium tin halide perovskite nanocrystals. J Am Chem Soc. 2016;138(9):2941-4. http://dx.doi.org/10.1021/jacs.5b13470. PMid:26901659.

133. Wang Y, Tu J, Li T, Tao C, Deng X, Li Z. Convenient preparation of $\mathrm{CsSnI}_{3}$ quantum dots, excellent stability, and the highest performance of lead-free inorganic perovskite solar cells so far. J Mater Chem A Mater Energy Sustain. 2019;7(13):7683-90. http://dx.doi.org/10.1039/C8TA10901J.

134. Huang H, Li Y, Tong Y, Yao EP, Feil MW, Richter AF, et al. Spontaneous crystallization of perovskite nanocrystals in nonpolar organic solvents: a versatile approach for their shape-controlled synthesis. Angew Chem Int Ed. 2019;58(46):16558-62. http:// dx.doi.org/10.1002/anie.201906862. PMid:31433100.

135.Burschka J, Pellet N, Moon S-J, Humphry-Baker R, Gao P, Nazeeruddin MK, et al. Sequential deposition as a route to high-performance perovskite-sensitized solar cells. Nature. 2013;499(7458):316-9. http://dx.doi.org/10.1038/nature12340. PMid:23842493.

136.Zhu Z, Chueh C-C, Li N, Mao C, Jen AK-Y. Realizing efficient lead-free formamidinium tin triiodide perovskite solar cells via a sequential deposition route. Adv Mater. 2018;30(6):1703800. http://dx.doi.org/10.1002/adma.201703800. PMid:29250846.

137. Shahbazi S, Li M-Y, Fathi A, Diau EW-G. Realizing a cosolvent system for stable tin-based perovskite solar cells using a two- 
step deposition approach. ACS Energy Lett. 2020;5(8):2508-11. http://dx.doi.org/10.1021/acsenergylett.0c01190.

138. Weiss M, Horn J, Richter C, Schlettwein D. Preparation and characterization of methylammonium tin iodide layers as photovoltaic absorbers. Phys Status Solidi. 2016;213(4):97581. http://dx.doi.org/10.1002/pssa.201532594.

139. Chowdhury TH, Kayesh ME, Lee J-J, Matsushita Y, Kazaoui S, Islam A. Post-deposition vapor annealing enables fabrication of 1 $\mathrm{cm}^{2}$ lead-free perovskite solar cells. Sol RRL. 2019;3(12):1900245. http://dx.doi.org/10.1002/solr.201900245.

140.Gao F, Li C, Qin L, Zhu L, Huang X, Liu H, et al. Enhanced performance of tin halide perovskite solar cell by addition of lead thiocyanate. RSC Advances. 2018;8(25):14025-30. http:// dx.doi.org/10.1039/C8RA00809D.

141.Wan ZX, Ren SQ, Lai HG, Jiang Y, Wu X, Luo J, et al. Suppression of nonradiative recombination by vacuum-assisted process for efficient lead-free tin perovskite solar cells. Adv Mater Interfaces. 2021;8(9):2100135. http://dx.doi.org/10.1002/ admi.202100135.

142.Arend T, Tönnies M, Reisbeck P, Rieckmann C, Kersting R. Physical vapor deposition of methylammonium tin iodide thin films. Phys Status Solidi. 2017;214(6):1600796. http://dx.doi. org/10.1002/pssa.201600796.

143.Hoffmann-Urlaub S, Zhang Y, Wang Z, Kressdorf B, Meyer T. Fabrication of tin-based halide perovskites by pulsed laser deposition. Appl Phys, A Mater Sci Process. 2020;126(7):553. http://dx.doi.org/10.1007/s00339-020-03699-9.

144.El Ajjouri Y, Locardi F, Gélvez-Rueda MC, Prato M, Sessolo M, Ferretti M, et al. Mechanochemical synthesis of $\mathrm{Sn}(\mathrm{II})$ and $\mathrm{Sn}(\mathrm{IV})$ iodide perovskites and study of their structural, chemical, thermal, optical, and electrical properties. Energy Technol. 2020;8(4):1900788. http://dx.doi.org/10.1002/ente.201900788.

145.López CA, Abia C, Gainza J, Kayser P, Nemes NN, Dura OJ, et al. Structural evolution,optical gap and thermoelectric properties of $\mathrm{CH}_{3} \mathrm{NH}_{3} \mathrm{SnBr}_{3}$ hybrid perovskite prepared by mechanochemistry. Mater Adv. 2021;2(11):3620-8. http:// dx.doi.org/10.1039/D1MA00196E.

146.Wang N, Zhou Y, Ju M-G, Garces HF, Ding T, Pang S, et al. Heterojunction-depleted lead-free perovskite solar cells with coarse-grained B- $\gamma$-CsSnI 3 thin films. Adv Energy Mater. 2016;6(24):1601130. http://dx.doi.org/10.1002/aenm.201601130.

147. Weber D. $\mathrm{CH}_{3} \mathrm{NH}_{3} \mathrm{SnBr}_{x} \mathrm{I}_{3-\mathrm{x}}(\mathrm{x}=0-3)$, ein $\mathrm{Sn}(\mathrm{II})$-system mit kubischer perowskitstruktur/ $\mathrm{CH}_{3} \mathrm{NH}_{3} \mathrm{SnBr}_{\mathrm{x}} \mathrm{I}_{3-\mathrm{x}}(\mathrm{x}=0-3)$, a $\mathrm{Sn}(\mathrm{II})$-system with cubic perovskite structure. $Z$ Naturforsch B. 1978;33(8):862-5. http://dx.doi.org/10.1515/znb-1978-0809.

148. Yamada K, Matsui T, Tsuritani T, Okuda T, Ichiba S. 127I-NQR, 119 Sn Mössbauer effect, and electrical conductivity of $\mathrm{MSnI}_{3}$ (M $=\mathrm{K}, \mathrm{NH}_{4}, \mathrm{Rb}, \mathrm{Cs}$, and $\mathrm{CH}_{3} \mathrm{NH}_{3}$ ). Z Naturforsch A. 1990;45(34):307-12. http://dx.doi.org/10.1515/zna-1990-3-416.

149. Mitzi DB, Feild CA, Harrison WTA, Guloy AM. Conducting tin halides with a layered organic-based perovskite structure. Nature. 1994;369(6480):467-9. http://dx.doi.org/10.1038/369467a0.

150.Mitzi DB, Feild CA, Schlesinger Z, Laibowitz RB. Transport, optical, and magnetic properties of the conducting halide perovskite $\mathrm{CH}_{3} \mathrm{NH}_{3} \mathrm{SnI}_{3}$. J Solid State Chem. 1995;114(1):15963. http://dx.doi.org/10.1006/jssc.1995.1023.

151.Ogomi Y, Morita A, Tsukamoto S, Saitho T, Fujikawa N, Shen Q, et al. $\mathrm{CH}_{3} \mathrm{NH}_{3} \mathrm{Sn}_{\mathrm{x}} \mathrm{Pb}_{1-\mathrm{x}} \mathrm{I}_{3}$ perovskite solar cells covering up to 1060 nm. J Phys Chem Lett. 2014;5(6):1004-11. http://dx.doi. org/10.1021/jz5002117. PMid:26270980.

152. Song T-B, Yokoyama T, Aramaki S, Kanatzidis MG. Performance enhancement of lead-free tin-based perovskite solar cells with reducing atmosphere-assisted dispersible additive. ACS Energy Lett. 2017;2(4):897-903. http://dx.doi.org/10.1021/ acsenergylett. $7 \mathrm{~b} 00171$.

153. Marshall KP, Walker M, Walton RI, Hatton RA. Enhanced stability and efficiency in hole-transport-layer-free $\mathrm{CsSnI}_{3}$ perovskite photovoltaics. Nat Energy. 2016;1(12):16178. http:// dx.doi.org/10.1038/nenergy.2016.178.

154.Kumar MH, Dharani S, Leong WL, Boix PP, Prabhakar RR, Baikie T, et al. Lead-free halide perovskite solar cells with high photocurrents realized through vacancy modulation. Adv Mater. 2014;26(41):7122-7. http://dx.doi.org/10.1002/ adma.201401991. PMid:25212785.

155.Nakamura T, Yakumaru S, Truong MA, Kim K, Liu J, Hu $\mathrm{S}$, et al. $\mathrm{Sn}(\mathrm{IV})$-free tin perovskite films realized by in situ $\mathrm{Sn}(0)$ nanoparticle treatment of the precursor solution. Nat Commun. 2020;11(1):3008. http://dx.doi.org/10.1038/s41467020-16726-3. PMid:32546736.

156.Pascual J, Flatken M, Félix R, Li G, Turren-Cruz S-H, Aldamasy $\mathrm{MH}$, et al. Fluoride chemistry in tin halide perovskites. Angew Chem Int Ed Engl. 2021;60(39):21583-91. http://dx.doi. org/10.1002/anie.202107599.

157.Marshall KP, Walton RI, Hatton RA. Tin perovskite/fullerene planar layer photovoltaics: improving the efficiency and stability of lead-free devices. J Mater Chem A Mater Energy Sustain. 2015;3(21):11631-40. http://dx.doi.org/10.1039/C5TA02950C.

158.Hoshi H, Shigeeda N, Dai T. Improved oxidation stability of tin iodide cubic perovskite treated by 5 -ammonium valeric acid iodide. Mater Lett. 2016;183:391-3. http://dx.doi.org/10.1016/j. matlet.2016.07.048.

159.Gu F, Ye S, Zhao Z, Rao H, Liu Z, Bian Z, et al. Improving performance of lead-free formamidinium tin triiodide perovskite solar cells by tin source purification. Sol RRL. 2018;2(10):1800136. http://dx.doi.org/10.1002/solr.201800136.

160.Xu X, Chueh C-C, Yang Z, Rajagopal A, Xu J, Jo SB, et al. Ascorbic acid as an effective antioxidant additive to enhance the efficiency and stability of $\mathrm{Pb} / \mathrm{Sn}$-based binary perovskite solar cells. Nano Energy. 2017;34:392-8. http://dx.doi.org/10.1016/j. nanoen.2017.02.040.

161.Song T-B, Yokoyama T, Stoumpos CC, Logsdon J, Cao DH, Wasielewski MR, et al. Importance of reducing vapor atmosphere in the fabrication of tin-based perovskite solar cells. J Am Chem Soc. 2017;139(2):836-42. http://dx.doi.org/10.1021/ jacs.6b10734. PMid:27977193.

162.Tsarev S, Boldyreva AG, Luchkin SY, Elshobaki M, Afanasov MI, Stevenson KJ, et al. Hydrazinium-assisted stabilisation of methylammonium tin iodide for lead-free perovskite solar cells. J Mater Chem A Mater Energy Sustain. 2018;6(43):21389-95. http://dx.doi.org/10.1039/C8TA07699E.

163.Li F, Zhang C, Huang J-H, Fan H, Wang H, Wang P, et al. A cation-exchange approach for the fabrication of efficient methylammonium tin iodide perovskite solar cells. Angew Chem Int Ed. 2019;58(20):6688-92. http://dx.doi.org/10.1002/ anie.201902418. PMid:30884017.

164.Kayesh ME, Chowdhury TH, Matsuishi K, Kaneko R, Kazaoui S, Lee J-J, et al. Enhanced photovoltaic performance of FASnI 3 -based perovskite solar cells with hydrazinium chloride coadditive. ACS Energy Lett. 2018;3(7):1584-9. http://dx.doi. org/10.1021/acsenergylett.8b00645.

165. You J, Wang M, Xu C, Yao Y, Zhao X, Liu D, et al. Hydrazine dihydrochloride as a new additive to promote the performance of tin-based mixed organic cation perovskite solar cells. Sustain Energy Fuels. 2021;5(10):2660-7. http://dx.doi.org/10.1039/ D1SE00160D.

166.Li F, Fan H, Zhang J, Huang J-H, Wang P, Gao C, et al. Trihydrazine dihydriodide-assisted fabrication of efficient formamidinium tin iodide perovskite solar cells. Sol RRL. 2019;3(9):1900285. http://dx.doi.org/10.1002/solr.201900285.

167. Wang C, Gu F, Zhao Z, Rao H, Qiu Y, Cai Z, et al. Self-repairing tin-based perovskite solar cells with a breakthrough efficiency over 11\%. Adv Mater. 2020;32(31):1907623. http://dx.doi. org/10.1002/adma.201907623. PMid:32583926.

168. Yang W-F, Cao J-J, Dong C, Li M, Tian Q-S, Wang Z-K, et al. Suppressed oxidation of tin perovskite by Catechin for eco- 
friendly indoor photovoltaics. Appl Phys Lett. 2021;118(2):23501. http://dx.doi.org/10.1063/5.0032951.

169. Tosado GA, Zheng E, Yu Q. Tuning cesium-guanidinium in formamidinium tin triiodide perovskites with an ethylenediammonium additive for efficient and stable lead-free perovskite solar cells. Mater Adv. 2020;1(9):3507-17. http://dx.doi.org/10.1039/ D0MA00520G

170.Zuo F, Williams ST, Liang P-W, Chueh C-C, Liao C-Y, Jen AK$\mathrm{Y}$. Binary-metal perovskites toward high-performance planarheterojunction hybrid solar cells. Adv Mater. 2014;26(37):6454-60. http://dx.doi.org/10.1002/adma.201401641. PMid:25123496.

171.Leijtens T, Prasanna R, Gold-Parker A, Toney MF, McGehee MD Mechanism of tin oxidation and stabilization by lead substitution in tin halide perovskites. ACS Energy Lett. 2017;2(9):2159-65. http://dx.doi.org/10.1021/acsenergylett.7b00636.

172.Li Y, Sun W, Yan W, Ye S, Rao H, Peng H, et al. 50\% Sn-based planar perovskite solar cell with power conversion efficiency up to $13.6 \%$. Adv Energy Mater. 2016;6(24):1601353. http:// dx.doi.org/10.1002/aenm.201601353.

173.Eperon GE, Leijtens T, Bush KA, Prasanna R, Green T, Wang JT-W, et al. Perovskite-perovskite tandem photovoltaics with optimized band gaps. Science. 2016;354(6314):861-5. http:// dx.doi.org/10.1126/science.aaf9717.

174.Wang F, Ma J, Xie F, Li L, Chen J, Fan J, et al. Organic cation-dependent degradation mechanism of organotin halide perovskites. Adv Funct Mater. 2016;26(20):3417-23. http:// dx.doi.org/10.1002/adfm.201505127.

175.Funabiki F, Toda Y, Hosono H. Optical and electrical properties of perovskite variant $\left(\mathrm{CH}_{3} \mathrm{NH}_{3}\right)_{2} \mathrm{SnI}_{6}$. J Phys Chem C. 2018;122(20):10749-54. http://dx.doi.org/10.1021/acs. jpcc. $8 \mathrm{~b} 01820$.

176.Lanzetta L, Webb T, Zibouche N, Liang X, Ding D, Min G, et al. Degradation mechanism of hybrid tin-based perovskite solar cells and the critical role of tin (IV) iodide. Nat Commun. 2021;12(1):2853. http://dx.doi.org/10.1038/s41467-021-22864-z. PMid:33990560.

177.Bandara RMI, Jayawardena KDGI, Adeyemo SO, Hinder SJ, Smith JA, Thirimanne HM, et al. Tin(IV) dopant removal through anti-solvent engineering enabling tin based perovskite solar cells with high charge carrier mobilities. J Mater Chem C Mater Opt Electron Devices. 2019;7(27):8389-97. http:// dx.doi.org/10.1039/C9TC02003A.

178.Xie G, Xu L, Sun L, Xiong Y, Wu P, Hu B. Insight into the reaction mechanism of water, oxygen and nitrogen molecules on a tin iodine perovskite surface. J Mater Chem A Mater Energy Sustain. 2019;7(10):5779-93. http://dx.doi.org/10.1039/ C8TA11705E

179.Lee YM, Park J, Yu BD, Hong S, Jung M-C, Nakamura M. Surface instability of Sn-based hybrid perovskite thin film, $\mathrm{CH}_{3} \mathrm{NH}_{3} \mathrm{SnI}_{3}$ : the origin of its material instability. J Phys Chem Lett. 2018;9(9):2293-7. http://dx.doi.org/10.1021/acs. jpclett.8b00494. PMid:29667412.

180.Xu X, Cao K, Zhu W, Gu W, Ma B, Qin M, et al. Improved crystallization and stability of mixed-cation tin iodide for lead-free perovskite solar cells. ACS Appl Energy Mater. 2020;3(6):5415-26. http://dx.doi.org/10.1021/acsaem.0c00407.

181.Liao Y, Liu H, Zhou W, Yang D, Shang Y, Shi Z, et al. Highly oriented low-dimensional tin halide perovskites with enhanced stability and photovoltaic performance. J Am Chem Soc. 2017;139(19):6693-9. http://dx.doi.org/10.1021/jacs.7b01815. PMid:28438016.

182.Hu Z, Zeng Y, Li X, Meng L. Enhancing the stability of perovskites by constructing heterojunctions of graphene/ MASnI ${ }_{3}$. Phys Chem Chem Phys. 2020;22(6):3724-33. http:// dx.doi.org/10.1039/C9CP06464H. PMid:32003766.

183. Chen M, Dong Q, Eickemeyer FT, Liu Y, Dai Z, Carl AD, et al. High-performance lead-free solar cells based on tin-halide perovskite thin films functionalized by a divalent organic cation. ACS Energy Lett. 2020;5(7):2223-30. http://dx.doi. org/10.1021/acsenergylett.0c00888.

184.Kachmar A, Berdiyorov G, Madjet ME-A. Effect of water on the structural, optical, and hot-carrier cooling properties of the perovskite material MASnI ${ }_{3}$. J Phys Chem C. 2019;123(7):405663. http://dx.doi.org/10.1021/acs.jpcc.8b11651.

185.Ito S, Tanaka S, Manabe K, Nishino H. Effects of surface blocking layer of $\mathrm{Sb}_{2} \mathrm{~S}_{3}$ on nanocrystalline $\mathrm{TiO}_{2}$ for $\mathrm{CH}_{3} \mathrm{NH}_{3} \mathrm{PbI}_{3}$ perovskite solar cells. J Phys Chem C. 2014;118(30):169957000. http://dx.doi.org/10.1021/jp500449z.

186.Akbulatov AF, Tsarev SA, Elshobaki M, Luchkin SY, Zhidkov IS, Kurmaev EZ, et al. Comparative intrinsic thermal and photochemical stability of $\mathrm{Sn}$ (II) complex halides as nextgeneration materials for lead-free perovskite solar cells. J Phys Chem C. 2019;123(44):26862-9. http://dx.doi.org/10.1021/acs. jpcc. 9 b09200.

187.Sabba D, Mulmudi HK, Prabhakar RR, Krishnamoorthy T, Baikie T, Boix PP, et al. Impact of anionic $\mathrm{Br}^{-}$substitution on open circuit voltage in lead free perovskite $\left(\mathrm{CsSnI}_{3-\mathrm{Br}} \mathrm{Br}_{\mathrm{x}}\right)$. J Phys Chem C. 2015;119(4):1763-7. http://dx.doi.org/10.1021/ jp5126624.

188.Liu X, Wang Y, Wu T, He X, Meng X, Barbaud J, et al. Efficient and stable tin perovskite solar cells enabled by amorphouspolycrystalline structure. Nat Commun. 2020;11(1):2678. http:// dx.doi.org/10.1038/s41467-020-16561-6. PMid:32472006.

189. Chen L-J, Lee C-R, Chuang Y-J, Wu Z-H, Chen C. Synthesis and optical properties of lead-free cesium tin halide perovskite quantum rods with high-performance solar cell application. $\mathrm{J}$ Phys Chem Lett. 2016;7(24):5028-35. http://dx.doi.org/10.1021/ acs.jpclett.6b02344. PMid:27973874.

190. Ye T, Wang X, Wang K, Ma S, Yang D, Hou Y, et al. Localized electron density engineering for stabilized B- $\gamma \mathrm{CsSnI}_{3}$-based perovskite solar cells with efficiencies $>10 \%$. ACS Energy Lett. 2021;6(4):1480-9. http://dx.doi.org/10.1021/acsenergylett.1c00342.

191. Ye T, Wang K, Hou Y, Yang D, Smith N, Magill B, et al. Ambient-air-stable lead-free cssni ${ }_{3}$ solar cells with greater than 7.5\% efficiency. J Am Chem Soc. 2021;143(11):4319-28. http://dx.doi.org/10.1021/jacs.0c13069. PMid:33705120.

192.Jokar E, Chien C-H, Tsai C-M, Fathi A, Diau EW-G. Robust tinbased perovskite solar cells with hybrid organic cations to attain efficiency approaching 10\%. Adv Mater. 2019;31(2):1804835. http://dx.doi.org/10.1002/adma.201804835. PMid:30411826.

193. Mahmoudi T, Rho W-Y, Kohan M, Im YH, Mathur S, Hahn Y-B. Im YH, Mathur S, Hahn Y-B. Suppression of $\mathrm{Sn}^{2+} / \mathrm{Sn}^{4+}$ oxidation in tin-based perovskite solar cells with graphene-tin quantum dots composites in active layer. Nano Energy. 2021;90:106495. http://dx.doi.org/10.1016/j.nanoen.2021.106495.

194. Speltini A, Romani L, Dondi D, Malavasi L, Profumo A. Carbon nitride-perovskite composites: evaluation and optimization of photocatalytic hydrogen evolution in saccharides aqueous solution. Catal. 2020;10(11):1259. http://dx.doi.org/10.3390/ catal10111259.

195.Romani L, Bala A, Kumar V, Speltini A, Milella A, Fracassi $\mathrm{F}$, et al. $\mathrm{PEA}_{2} \mathrm{SnBr}_{4}$ : a water-stable lead-free two-dimensional perovskite and demonstration of its use as a co-catalyst in hydrogen photogeneration and organic-dye degradation. J Mater Chem C Mater Opt Electron Devices. 2020;8(27):9189-94. http://dx.doi.org/10.1039/D0TC02525A

196.Chen Y, Zhang X, Liu Z, Zeng Z, Zhao H, Wang X, et al. Light enhanced room temperature resistive $\mathrm{NO} 2$ sensor based on a gold-loaded organic-inorganic hybrid perovskite incorporating tin dioxide. Mikrochim Acta. 2019;186(1):47. http://dx.doi. org/10.1007/s00604-018-3155-1. PMid:30610459.

197.Zhang X, Sun Y, Fan Y, Liu Z, Zeng Z, Zhao H, et al. Effects of organotin halide perovskite and $\mathrm{Pt}$ nanoparticles in $\mathrm{SnO}_{2}-$ based sensing materials on the detection of formaldehyde. $\mathrm{J}$ Mater Sci Mater Electron. 2019;30(23):20624-37. http://dx.doi. org/10.1007/s10854-019-02428-0. 
198.Ippili S, Jella V, Eom J-H, Kim J, Hong S, Choi J-S, et al. An eco-friendly flexible piezoelectric energy harvester that delivers high output performance is based on lead-free $\mathrm{MASnI}_{3}$ films and MASnI 3 -PVDF composite films. Nano Energy. 2019;57:911-23. http://dx.doi.org/10.1016/j.nanoen.2019.01.005.

199.Ippili S, Jella V, Kim J, Hong S, Yoon S-G. Unveiling predominant air-stable organotin bromide perovskite toward mechanical energy harvesting. ACS Appl Mater Interfaces. 2020;12(14):16469-80. http://dx.doi.org/10.1021/acsami.0c01331. PMid:32174105.

200.Pandey R, Sb G, Grover S, Singh SK, Kadam A, Ogale $\mathrm{S}$, et al. Microscopic origin of piezoelectricity in lead-free halide perovskite: application in nanogenerator design. ACS Energy Lett. 2019;4(5):1004-11. http://dx.doi.org/10.1021/ acsenergylett.9b00323.

201.Lai ML, Tay TYS, Sadhanala A, Dutton SE, Li G, Friend $\mathrm{RH}$, et al. Tunable near-infrared luminescence in tin halide perovskite devices. J Phys Chem Lett. 2016;7(14):2653-8. http://dx.doi.org/10.1021/acs.jpclett.6b01047. PMid:27336412. 202.Xing G, Kumar MH, Chong WK, Liu X, Cai Y, Ding H, et al. Solution-processed tin-based perovskite for near-infrared lasing. Adv Mater. 2016;28(37):8191-6. http://dx.doi.org/10.1002/ adma.201601418. PMid:27417520. 